\title{
Lapurdum
}

Euskal ikerketen aldizkaria | Revue d'études basques |

Revista de estudios vascos | Basque studies review

Numéro spécial 2 | 2015

Othoi çato etchera

\section{Le Dauphin : euskarazko gutunak (1757)}

\section{Manuel Padilla-Moyano et Charles Videgain}

\section{OpenEdition \\ Journals}

Édition électronique

URL : https://journals.openedition.org/lapurdum/2561

DOI : 10.4000/lapurdum.2561

ISSN : 1965-0655

Éditeur

IKER

Édition imprimée

Date de publication : 1 octobre 2015

Pagination : $95-160$

ISBN : 978-2-9553413-1-5

ISSN : $1273-3830$

\section{Référence électronique}

Manuel Padilla-Moyano eta Charles Videgain, «Le Dauphin : euskarazko gutunak (1757)», Lapurdum [Linean], Numéro spécial 2 | 2015, Sarean emana---an 01 septembre 2016, kontsultatu 02 avril 2023. URL: http://journals.openedition.org/lapurdum/2561 ; DOI: https://doi.org/10.4000/lapurdum.2561

\section{(c)}

Creative Commons - Attribution-NonCommercial-NoDerivatives 4.0 International - CC BY-NC-ND 4.0

https://creativecommons.org/licenses/by-nc-nd/4.0/ 


\section{Le Dauphin: euskarazko gutunak (1757)}

Manuel PADILLA MOYANO ${ }^{1} \&$ Xarles VIDEGAIN ${ }^{2}$

\section{1}

Data: $1757 / 2 / 2$

Non idatzia: Urruña

Igorlea: Martin de Arrunde

Hartzailea: Martin de Arrunde

Lotura: aita-semeak

Helmuga: Louisbourg

\section{A bertsioa}

$<01.1$ r $>114$

Lapresente letre / rendu martin / arrunde aLouisbourge / ALouis Bourge

$<01.1 v>$ Urrugne le 2 febrier 1756

/ Martin [de] arrunde escribacen darosquicut / Bilero ossasuna dugu jeancoari Esquer / Eta dessiracen ginduque Curia hala balix $\rho^{5}$ Eta Cerbeit egin duculaaditudugu Eta / unqigobernacaite Eta erecibitunuben / Caspi libera martinen ganic deussic ecin / jrrisca desaqueguque unciguciiacarcen / tuste Eregeren cerbicutic Ethorinincen $/{ }^{10}$ Eta Corsurat noa hogoieta sei pecetaquo / fragata Berribatian Eta helduden / urtian Cato Echerat eta Cerequin Ecdiru / Guciiac jrisca Eta halic obeciiena Eginen / Ducu eta Cerbicarry martin de arrunde

lv:1 1756 urteaz tronpatu da: 1757 irakurri behar da.

\section{B bertsioa}

$<01.1$ r $>114$

La presente letre rendu Martin Arrunde a Louisbourge. A Louisbourge.

<01.1v> Urrugne, le 2 febrier 1757.

Martin de Arrunde, eskribatzen darozkitzut bi lerro. Osasuna dugu Jenkoari esker, eta desiratzen ginduke zuria hala balitz. Eta zerbeit egin duzula aditu dugu, eta unki goberna zaite; eta errezibitu nuben zazpi libera Martinenganik. Deusik ezin irriska dezakeguke: unzi guzijak artzen tuzte. Erregeren zerbitzutik ethorri nintzen eta korsurat noa hogoi eta sei pezetako fragata berri batian eta heldu den urtian zato etxerat eta zerekin; ez diru guzijak irriska, eta halik obekijena eginen duzu. Eta zerbitzari Martin de Arrunde. 
Data: $1757 / 2 / 4$

Non idatzia: Hendaia

Igorlea: Marie d'Etcheverry [Don Qoche idazlariak egina]

Hartzailea: Pierre Daguerre

Lotura: ama-semeak

Helmuga: Louisbourg

A bertsioa

\section{$<02.1 r>65$}

A Monsieur / Monsieur Pierre Daguere / A

Louisburque.

$<02.2$ r $>$ Ahenday 4e de fevrier 1757

/ Ene seme maitija

/ Escrivacendisut Bilerro hauq surymarquaceratemateco / Estatu miserable Baitan qaucicenais Erresivitudut sure ${ }^{5}$ Lettra Ere han iqussydut sure Berrijaq Baignan / Esnaibessala martineq eta huncija galdudute Berris Ere / horraçu Desiradu arrequinservait icendusu mariqatan ${ }_{\mathrm{ia}} /$ assareda sure contra Estyossula Lettrabat Eguinlau / hurtehuntan alababat badusu iduridubena perfeq $/{ }^{10}$ Etorryqoda horat Baquija Eguitendenian Jduriquicen / Du Emendiq harat orroitu saren Baigno obequy / orroituçu sarella guissona hor laster aberestenomendira / Suceresa?adusugaihona ( $†$ ) horsure Lettra Ematen / Dossuna arren conseluvaq hunguy artasu sure annaya $/{ }^{15}$ Bessela Esagusasu deusit Egorceco dusunian horren / ganat adresasu adisquide handibatdugu Etacontu / horre hunguy Eguignedu ganes pellobaitaco ganda / Corsurat sure gorrancijaq Emandijosagu banuque / sury servait gastijaceco icenda Berceoquasionebat ${ }^{20}$ ganesen Berririq Estugu deusit jaquiten Badusu / gastijasasu apachappanaq gorrancy harengalsardy / gorrijaq nontusu ganachume assareda surecontra / Merrisidu sureganiq gusama Ere Bai

${ }^{24}$ Marie d Eceverry

[marjinean idatzia] / haucuquouaq gorrancy Donqocheq Eguigndu Lettrahau
B bertsioa

$<02.1$ r $>65$

A Monsieur Monsieur Pierre Daguerre. A Louisburque.

$<02.2$ r > A Henday, 4e de fevrier, 1757.

Ene seme maitija,

Eskribatzen dizut bi lerro hauk zuri markatzerat emateko estatu miserable batian kausitzen naiz. Errezibitu dut zure letra ere; han ikusi dut zure berrijak, baiñan ez nai bezala. Martinek eta hunzija galdu dute berriz ere, horra zu, desira du arekin zerbait izanen duzu. Marikatania asarre da zure kontra, eztiozula letra bat egin lau hurte huntan. Alaba bat baduzu iduri dubena perfek; etorriko da horrat bakija egiten denian, idurikitzen du. Emendik harat oroitu zaren baiño obeki oroitu zu zarela gizona. Hor laster aberesten omen dira; zuk ere sa?a duzu gai hona $(\dagger)$. Hor zure letra ematen dozunaren konselubak hungi artzazu, zure anaia bezela ezaguzazu; deusit egortzeko duzunian horrenganat adrezazu, adiskide handi bat dugu eta kontu horre hungi eguiñe du. Ganes Pellobaitako gan da korsurat; zure gorantzijak eman dijotzagu. Banuke zuri zerbait gaztijatzeko; izanen da bertze okasione bat. Ganesen berririk eztugu, deusit jakiten baduzu gaztijazazu. Apa Xapanak goranzi, haren galzardi gorrijak non tuzu? Gana Xume asarre da zure kontra, merisi du zureganik; gusama ere bai.

Marie d'Etcheverry.

Hauzukuak gorantzi. Don Qochek egiñ du letra hau

2r:4 Baitan : batian irakurri behar. 7 icendusu : izanen duzu ulertzen dugu; cf. icenda Berceoquasionebat (19. lerro). 14 artasu : (h)artzazu ulertu behar da. 
Data: $1757 / 2 / 12$

Non idatzia: Hendaia

Igorlea: Gacina de Biscarrondo

Hartzailea: Patchiqu de Biscarrondo

Lotura: anai-arrebak

Helmuga: Louisbourg

\section{A bertsioa}

$<03.1 r>71$

A Monsieure / Monsieure / patchiqu de bis- / carondo / A Lisbourc

\section{$<03$. lr.bis $>$}

A Monsieure / Monsieure / patchiqu de bis-/ carondo / A Lisbourc

\section{$<03.2$ r $>$ endan eguina oxalen amabiian}

/ Ene anayamaitja escribatcen dosquicut belero / famila gucien partes vngui gare jainqoary / esquer amaso dugu etxituba eta cure emaste$I^{5}$ a ere esxituba espacatuda bainan orai vn-/ guida aura ere vnguida cuben beri hainits / estucube gastigatcen nolacaiten eta es / deus hainits egortcen letrabat solamen-/ te estucu eguiten esguri eta es emas- $/{ }^{10}$ teari penatuba gare hainits beriric / gabes otoisten cait cuhurjcatias etacu-/ re beriac gastiatcias miguel etche-/ veriari goraintci aitac eta famila / guciac eta osabas beri onac ditugu eta $/ 15$ cubec ere aitudugu cerbait baducula / hobe atxeguindut otoisten caitut letra hu-/ nen barnian egortcendut anajary eta / nola es homen baitcaite erealequin eren-/ datuqo diocu otoisten caitut erepusta egui- $\rho^{20}$ tias lehen bicico comoitatian

[marjinean idatzia] / guelditcen nais cure cerbit cary gacina de / biscarondo

\section{B bertsioa}

$<03.1 \mathrm{r}>71$

A Monsieure Monsieure Patchiqu de Biscarrondo. A Lisbourc.

$<03.1$ r.bis $>$

A Monsieure Monsieure Patchiqu de Biscarrondo. A Lisbourc.

$<03.2$ r $>$ Endan egina, otsalen amabijan.

Ene anaia maitia, eskribatzen dozkitzut be lerro famila guzien partez. Ungi gare Jainkoari esker. Amaso dugu etsituba eta zure emaztea ere etsituba espakatu da, bainan orai ungi da. Aurra ere ungi da. Zuben berri hainitz eztuzube gaztigatzen, nola zaiten, eta ez deus hainitz egortzen; letra bat solamente eztuzu egiten, ez guri eta ez emazteari. Penatubak gare hainitz berririk gabez. Otoizten zaitut zuhur izatiaz eta zure berriak gaztiatziaz. Miguel Etcheverriari goraintzi. Aitak eta famila guziak eta osabaz berri onak ditugu, eta zubek ere. Aitu dugu zerbait baduzula; hobe, atsegin dut. Otoizten zaitut: letra hunen barnian egortzen dut anaiari eta, nola ez homen baitzaite, Errealekin errendatuko diozu. Otoizten zaitut errepusta egitiaz lehenbiziko komoitatian.

Gelditzen naiz zure zerbitzari, Gacina de Biscarrondo.

2r:10 penatuba : penatubac irakurri behar da. Menturaz ondoko belarrak eragotzi du $k$-ren agerpena: penatuba(c) gare. 11 cait : uste dugu çaitut irakurri behar dela; gero bi aldiz ageriko da çaitut. 
Data: $1757 / 2 / 12$

Non idatzia: Hendaia

Igorlea: Gacina de Biscarrondo

Hartzailea: Martin Josepe de Biscarrondo

Lotura: anai-arrebak

Helmuga: Louisbourg

\section{A bertsioa}

$<04.1 r>$ [71bis]

A Monsieur / Monsieur / Martin josepe de / biscarondo / A Lisbourc

$<04.2$ r $>$ endajan eguina oxalaren amabican

/ eneanaja maitia escribatcen darasquitcut / bilero auc curi gureberies satifacione em-/ ateqo ossasuna gdugu bainan amaso $/ 5$ etxituba dugu aitudugu cerbait baducube- $/$ la atxeguindugu saraqo guicon gastebat / anguelec arturic gure etchia jodu cure / conpaniatic cuhurqui gobernacaite eta / ossabas ere berri onac ditugu amaso bear$/ 10$ retand cerbait fagore eguiocu aurten / etorcaite niolere posible bada goraintcy / aispac ere otoisten caitut erepusta / eguitias

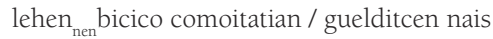
cure cerbitcary $/{ }^{15}$ erespetuhandibatequin gaci-/ na biscarondo

\section{B bertsioa}

$<04.1 r>$ [71bis]

A Monsieur Monsieur Martin Josepe de Biscarrondo. A Lisbourc.

$<04.2$ r $>$ Endaian egina, otsalaren amabikan.

Ene anaia maitia, eskribatzen darazkitzut bi lerro auk zuri gure berriez satifazione emateko. Osasuna dugu, bainan amaso etsituba dugu. Aitu dugu zerbait baduzubela; atsegin dugu. Sarako gizon gazte bat angelek arturik gure etxia jo du, zure konpaniatik. Zuhurki goberna zaite. Eta osabaz ere berri onak ditugu. Amaso bearretan da, zerbait fagore egiozu. Aurten etor zaite, niolere posible bada. Goraintzi aizpak ere. Otoizten zaitut errepusta egitiaz lehenbiziko komoitatian. Gelditzen naiz zure zerbitzari, errespetu handi batekin, Gacina Biscarrondo.

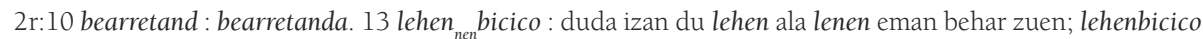
irakur bedi. 
Data: $1757 / 2 / 14$

Non idatzia: Sara

Igorlea: Catalin Lalanne

Hartzailea: Esteben Gourdo

Lotura: senar-emazteak

Helmuga: Louisbourg

\section{A bertsioa}

$<05.1$ r $>120$

La presente soit / rendue a Esteben / Gourdo. marinier / A Loüisbourq

$<05.2$ r $>$ Ene espos maitea

/ Letra hau esquiribatcen darotçut / çuri erraiteco errecebitu nuela / çure lettra 120 liberaco / $/ 5$ letra sanjarequin cenitaz / pagatua içan bainaiz. / bercealde erranaracitut / çuc marcatcen cinarozquidan / meçac.

$/{ }^{10}$ eztut berceriq çuri marcatceco, / choilquy ossassuna dudala / Desiratcendut nere bihotz / guciaz çuc ere hala Bacinu. / çure semea unguida bere $/ 15$ errespetuez seguratcen çaitu / ortholopitzco andrea jincoac / deithu du bereganat hilhunen / hirurean sanblaz egunean $<05.2 \mathrm{v}>$ andre gaztea.

/ harburuco familiaq mila / gorainci darotçu bai eta ere / çure arrebec eta coinatec $/ 5$ guciec ossassuna dute / finean guerla hunen beldurrez / deussen çuri igorcera ecin / ausartatu naiz. / guelditcen naiz ene espos $/{ }^{10}$ maitea çure ikhusteco / esperançarequin çure cerbitçary / humila eta obedienta

/ Catalin Lalanne

/ saran oxailaren /15 14an 1757 harburun / egoiten naiz bethy

2r:5 cenitaz : ceintaz irakur.

\section{B bertsioa}

$<05.1$ r $>120$

La presente soit rendue a Esteben Gourdo, marinier a Loüisbourq.

$<05.2$ r $>$ Ene espos maitea,

Letra hau eskiribatzen darotzut zuri erraiteko errezebitu nuela zure letra 120 liberako letra sanjarekin, zeintaz pagatua izan bainaiz. Bertze alde, erranarazi tut zuk markatzen zinarozkidan mezak.

Eztut bertzerik zuri markatzeko, xoilki osasuna dudala; desiratzen dut nere bihotz guziaz zuk ere hala bazinu. Zure semea ungi da; bere errespetuez seguratzen zaitu. Ortholopitzko andrea Jinkoak deithu du bereganat hil hunen hirurean, San Blaz egunean; <05.2v> andre gaztea.

Harburuko familiak mila goraintzi darotzu, bai eta ere zure arrebek eta koinatek; guziek osasuna dute. Finean, gerla hunen beldurrez deusen zuri igortzera ezin ausartatu naiz. Gelditzen naiz, ene espos maitea, zure ikhusteko esperantzarekin. Zure zerbitzari humila eta obedienta,

Catalin Lalanne.

Saran, otsailaren 14an, 1757. Harburun egoiten naiz bethi. 
Data: $1757 / 2 / 20$

Non idatzia: ?

Igorlea: Maria de Molleres [Etchegarayco Haurra Maria idazlari]

Hartzailea: Bitor \& Bernat de Farandiret

Lotura: adiskideak

Helmuga: Louisbourg

A bertsioa

$<06.1$ r $>69$

presenteco lettra hau errendatuco / caio laures tirun mariacoeneco / semeari chanpartierari chebecat / eta harc errendatuco du bitor $/^{5}$ de Farandiret edo bernat de / Farandiret anaia bata edo / bercea ganat

$<06.2$ r $>$ Bitor de Farandiret eta Beinat de Farandiret / eneadisquide maite maitiac harcen dut libertate / cuei bi lerroren eschribaceco jaquin deçaçuen / amoreac gatic cuen aita eta amaren b eta $/ 5$ arebaren ahaide eta adisquide gucien berriac / gorainçi darotcue gastigacen ossasuna on bat / dutela desiraçen luquetela cuec hala bacind / ute errecibitu dute cuec eguin letra ungui / placer hartu baitute cuen berrien adicias $/ 10$ aita eta ama hamar urtes gastatu dire cuen / berrien adicias orai desiracen tute luquete / ceboc cuen berriequin icustias marchoaren / lehenbicico jgandian eguin behartu bors urte / hemendic partitu cinetela gerostic esquara $/{ }^{15}$ hala satifatu nola aurten jaincoac gracia / handiac eguiten darosquicue eta estarotcue / batere gutiago eguinen baldin ematen badi / ocue satifacionea cuen aitari eta amari cue ${ }^{\mathrm{n}}$ / jcustecoa ecen hurren dire hagorandu cuec ${ }^{20}$ beguis jcusi nahis munduco ontasun guciac / baino nahiago luquete cuec beguis jcusi guer ${ }^{\circ}$ / hilen badire ere hain ungui cuen arebac / cuen jcusteco desira baluque non uste balu / munduco tresoric handienac guciac uts bai $/ 25$ lecaque cuen jcusteco non bordele becain / hurbil balis esbailuque batere herabe urr / axa cuen jcusteco hambat demboras jbiri / dire cuen berriac jaquin nahis hirur urtes / eguin tuste bors letra eta behin ere cuenic ${ }^{\beta 0}$ ecin jcan bainan aurten comprenitu $\mathrm{dut}^{\mathrm{e}}$ / eguin tucuela cuec ere letrac arebac
B bertsioa

$<06.1 r>69$

Presenteko letra hau errendatuko zaio Laures Tirun Mariakoeneko semeari, xanpartierari xebekat ( $†$ ), eta hark errendatuko du Bitor de Farandiret edo Bernat de Farandiret, anaia bata edo bertzeaganat.

$<06.2$ r $>$ Bitor de Farandiret eta Beinat de Farandiret, ene adiskide maite-maitiak, hartzen dut libertate zuei bi lerroren eskribatzeko, jakin dezazuen amoreak gatik zuen aita eta amaren, bai eta arrebaren, ahaide eta adiskide guzien berriak. Goraintzi darotzue, gaztigatzen osasuna on bat dutela, desiratzen luketela zuek hala bazindute. Errezibitu dute zuek egin letra, ungi plazer hartu baitute zuen berrien aditziaz. Aita eta ama hamar urtez gastatu dire zuen berrien aditziaz; orai desiratzen lukete zebok zuen berriekin ikustiaz. Martxoaren lehenbiziko igandian egin behar tu bortz urte hemendik partitu zinetela. Geroztik ezkara hala satifatu, nola aurten Jainkoak grazia handiak egiten darozkitzue, eta eztarotzue batere gutiago eginen baldin ematen badiozue satifazionea zuen aitari eta amari zuen ikustekoa, ezen hurren dire hagorandu zuek begiz ikusi nahiz: munduko ontasun guziak baino nahiago lukete zuek begiz ikusi, gero hilen badire ere. Hain ungi zuen arrebak zuen ikusteko desira baluke, non uste balu munduko tresorik handienak, guziak utz bailezake zuen ikusteko, non Bordele bezain hurbil balitz ez bailuke batere herabe urratsa zuen ikusteko. Hanbat denboraz ibiri dire zuen berriak jakin nahiz; hirur urtez egin tuzte bortz letra, eta behin ere zuenik ezin izan, bainan aurten konprenitu dute egin tuzuela zuek ere letrak. Arrebak 
$<06.3 r>$ goraici osaba eta jceba guciec gorainci cusina / guciec gorainci etchegaraico familia guciac / gorainci erotaco falia guciac gorainci ague / reco familia guciac gorainci camietaco $/^{5}$ familia guciac gorainci andregaia escondu / da hausteico cadetequin seme handi bate / quin daude cuen arebac eguin du hequien / esconca cuenac ere eguina dago baldin dispo / sacen bacarete bitor ene anaia maitia compre $/{ }^{10}$ niaraci jcatu daut marinel batec hor ha / bitacen carela bainan guciarequin ere / behinere estut sinesi cergatic espaicaoscat / capable cu guri damu horren eguiteco / beinat ene bihos maitia dio cure arrebac $/{ }^{15}$ baduela hirur urte cure emaste gaia / bilatua duela bethi dagoela hagorandua cu / jcusi nahis bethi galdeguiten dioscala $\mathrm{cu}^{\mathrm{re}} /$ berriac eta bethi aguincen caituela baldin / fraide eguin gogo espaducu esconca trataça $/ 20$ le handi bat da hura bainan berreric estu / eguiten hargatic cuec eguiteco dauca hura / apa landaburucoac mariac machume estebe / necoc gachina chume castienecoc gaachic / guci guciec gorainci $/ 25$ bitor eta beinat ene / adisquide eta hauco maite maitiac gororaici / darotcuet particularsqui nic letraren / eguiliac gucien gainetic maria de molleres / etchegaraico hauramariac eguina $/{ }^{\beta 0}$ oxailaren 20 an eguina 1757 / lapiceco andregaiac gorainci mila mila

$<06.3 v>$ orai compreni cacue guc cuec cein maite / caitustegun candela bat ere erre guin / duen hunen eguitian berciac / liberticionian eta gu hunen / eguiten
$<06.3 r>$ goraintzi, osaba eta izeba guziek goraintzi, kusina guziek goraintzi, Etchegaraiko familia guziak goraintzi, Errotako familia guziak goraintzi, Agerreko familia guziak goraintzi, Kamietako familia guziak goraintzi; andregaia ezkondu da Hausteiko Kadetekin, seme handi batekin daude. Zuen arrebak egin du hekien ezkontza; zuenak ere egina dago, baldin disposatzen bazarete. Bitor, ene anaia maitia, konpreniarazi izatu daut marinel batek hor habitatzen zarela, bainan guziarekin ere behin ere eztut sinetsi, zergatik ezpaitzaozkat kapable zu guri damu horren egiteko. Beinat, ene bihotz maitia, dio zure arrebak baduela hirur urte zure emaztegaia bilatua duela, bethi dagoela hagorandua zu ikusi nahiz, bethi galdegiten diozkala zure berriak eta bethi agintzen zaituela, baldin fraide egin gogo ezpaduzu. Ezkontza tratazale handi bat da hura, bainan berrerik eztu egiten, hargatik zuek egiteko dauka hura. Apa Landaburukoak, Mariak, Maxume Estebenekok, Gaxina Xume Kastienekok, Gaaxik... Guzi-guziek gorainzi. Bitor eta Beinat, ene adiskide eta hauzo maitemaitiak, goraintzi darotzuet partikularzki nik, letraren egiliak, guzien gainetik, Maria de Molleres. Etxegaraiko Haurra Mariak egina. Otsailaren 20an egina, 1757. Lapitzeko andregaiak goraintzi mila-mila.

$<06.3 v>$ Orai konpreni zazue guk zuek zein maite zaituztegun: kandela bat ere erre ginduen hunen egitian, bertziak libertizionian eta gu hunen egiten.

3r:3 falia : familia irakurri behar da. 26 gororaici : gorain $(t) c i$. 
Data: 1757/2/26

Non idatzia: Sara

Igorlea: Miguel Harismendy

Hartzailea: Bernard Harismendy

Lotura: aita-semeak

Helmuga: Louisbourg

A bertsioa

$<07.1 \mathrm{r}>59 a$

La Presente Lettre / soit rendüe a Bernard / harismendy habitant de / Loüisbourg. / A Loüisbourg.

$<07.2$ r $>$ Saran eguina oxailaren $26^{\text {an }} 1757$

/ Ene seme maitea

/ Badaquiçu bi urthe huntan ezdarotaçula ez bici çaren ez / eta ere çure berriric batere eman; apparancias ahanxi $/ 5$ çaitçu aita nauçula; aditu dut fortuna handi bat / eguin duçula hor esconçeas, jainco jaunac lagun eta / guida çaitçala, eta eguin deçaçula gratia cure baithan / ongui onguy sarthuric çure faltac ongui essaguturic / niri eta çure ama gachoari eta familia guciari eman $/^{10}$ darocussun nahigabe handia erreparatçeco, nic dessiratçen / darosquiçudan gaixac aise jassanen tutçu. Errecibitu / nituen çuc egorri cinerosquidan $250^{\text {ac }}$ eta alchatcera / eman niotçan M. Haranchipiry, eta guero ondoan nere / behar handian erretiratu nituen handic eta emplegatu $/ 15$ nere denboran uste dut aita qualitatean cenbait axeguin / chumes lagundu eta favoratu caitudala; bisquitartean / egorri tutçun sossen galdea eguin dioçu eguin behar / etçinionari erran nahi dut M. Harançhipiri, niri egorri / çinerosquidan eta niri galdeguin behar cinerosquidan ${ }^{20}$ eta ez hari, eznuen pretenitçen sos hequin galdea / eguin behar çinerotala, hor eguin duçun saltsa, hor

$<07.2 v>$ çhuçhen saçu, nitas nitas beçanbatean estut pagatuco / çure anaya primoa escondu ha goanareneco alabarequin, / berce familia guciac ere ossassuna du. dessiratcen / darotçut ossassuna perfet bat eta guelditçen nais çuc $/^{5}$ ni ahanxi arren çure aita ona
B bertsioa

$<07.1$ r $>59 a$

La presente lettre soit rendüe a Bernard Harismendy, habitant de Loüisbourg. A Loüisbourg.

$<07.2$ r > Saran egina, otsailaren 26an, 1757.

Ene seme maitea,

Badakizu bi urthe huntan ez darotazula ez bizi zaren ez eta ere zure berririk batere eman; apharantziaz ahantzi zaitzu aita nauzula. Aditu dut fortuna handi bat egin duzula hor ezkontzeas. Jainko jaunak lagun eta gida zaitzala, eta egin dezazula grazia, zure baithan ongi-ongi sarthurik, zure faltak ongi ezaguturik, niri eta zure ama gaxoari eta familia guziari eman darokuzun nahigabe handia erreparatzeko. Nik desiratzen darozkitzudan gaitzak aise jasanen tutzu. Errezibitu nituen zuk egorri zinerozkidan 250ak, eta altxatzera eman niotzan M. Haranchipiri, eta gero ondoan nere behar handian erretiratu nituen handik, eta enplegatu nere denboran. Uste dut aita kalitatean zenbait atsegin xumez lagundu eta faboratu zaitudala. Bizkitartean, egorri tutzun sosen galdea egin diozu egin behar etzinionari, erran nahi dut M Haranchipiri. Niri egorri zinerozkidan eta niri galdegin behar zinerozkidan eta ez hari, ez nuen pretenitzen sos hekin galdea egin behar zinerotala. Hor egin duzun saltsa hor

$<07.2 v>$ xuxen zazu, nitaz bezanbatean eztut pagatuko. Zure anaia primoa ezkondu da Goanareneko alabarekin; bertze familia guziak ere osasuna du. Desiratzen darotzut osasuna perfet bat, eta gelditzen naiz, zuk ni ahantzi arren, zure aita ona. 
/ Miguel Harismendy

/ marcatu baitçinarotan collacareneco semeari prestatu ciniotçala / hemecorcy libera, eta galde netçola, eta erretira netçola / hartu dut particularrean guiçon gaste hura, eta dio / 10 egundaino ezdioçula deussic eman; bioc hori elquarganatçen / çaretenean churituco duçue;

/ Monsieur haranchipic milla gorainci darotçula / jaincoari othoix eguinen diola çutas eta orhoit / çaitecila heriotçeas eta çure arimaren salbamenduas

2v:2 escondu ha : escondu da irakur bedi.
Miguel Harismendy.

Markatu baitzinarotan Kolakareneko semeari prestatu ziniotzala hemezortzi libera, eta galde netzola, eta erretira netzola. Hartu dut partikularrean gizon gazte hura, eta dio egundaino ez diozula deusik eman; biok hori elkarganatzen zaretenean xurituko duzue.

Monsieur Haranchipik mila goraintzi darotzula, Jainkoari othoitz eginen diola zutaz, eta orhoit zaitezila heriotzeaz eta zure arimaren salbamenduaz. 
Data: $1757 / 2 / 26$

Non idatzia: Azkaine

Igorlea: Maria de Bortairay

Hartzailea: Joannis Hiribarren

Lotura: kusiak

Helmuga: Louisbourg

\begin{abstract}
A bertsioa
$<08.1$ r $>119$

La Presante / soit rendu á / joannis hiribarren apresens / A Louisbourg

$<08.2$ r $>$ Ene adisquide maitea

/ Escribatcen dausquitçut bi lerro hauc çury / aditcerat emateco ene eta cure ezposaren ossasunaren / berry ceiñetan ossasuna baitugu çure haurrequin $/ 5$ batean dessiratcen nuque edo guinduque çurea hala / icatea, badaquiçu lau atorra nolla eman / nausquitçun eta sembat hetaz progoitchatu çaren / uste nuen oray baiño lehen satisfactua içanen / nintcella ceiñetan hamar escutu montatcen $/{ }^{10}$ baitute, nere nessesitateac huntarat obligatcen / nau, beras othoisten caitut lehenbicico c[omoditatean] / egotzaz egortceaz erran den hamar liuera escutuac hec, eta othoisten / caitut çure fammillarat erretira caitecin ecen çure emaste / gaichoa çure arribada noiz icañen duen gdago cerbait$/ 15$ equin, salutatcen caitu cure andreac haide eta aquide / guiciec eta ni guelditcen naiz çure cussina maria de / bortairay servitçary ascain ${ }^{\text {en }}$ oxaillaren 26an 1757an
\end{abstract}

\section{B bertsioa}

$<08.1$ r $>119$

La presante soit rendu á Joannis Hiribarren, a presens a Louisbourg.

$<08.2 r>$ Ene adiskide maitea,

Eskribatzen dauzkitzut bi lerro hauk zuri aditzerat emateko ene eta zure esposaren osasunaren berri, zeiñetan osasuna baitugu zure haurrekin batean. Desiratzen nuke, edo ginduke, zurea hala izatea. Badakizu lau atorra nola eman nauzkitzun, eta zenbat hetaz progoitxatu zaren. Uste nuen orai baiño lehen satisfaktua izanen nintzela, zeiñetan hamar ezkutu montatzen baitute. Nere nezesitateak huntarat obligatzen nau; beraz, othoizten zaitut lehenbiziko komoditatean egortzeaz erran den hamar ezkutuak, eta othoizten zaitut zure famillarat erretira zaitezin, ezen zure emazte gaixoa zure arribada noiz izañen duen dago zerbaitekin. Salutatzen zaitu zure andreak, haide eta adiskide giziek, eta ni gelditzen naiz zure kusina, Maria de Bortairay, zerbitzari. Azkainen, otsaillaren 26an, 1757an.

2r:12 liuera ${ }^{\text {escutuac }}$ hec : lehenbiziko idatzaldian hamar liuera hec, baina gainidatziarekin hamar escutuac irakurri behar da. 15 aquide : adisquide irakur bedi. 16 guiciec : guciec irakur. 
9

Data: 1757/2/28

Non idatzia: Hendaia

Igorlea: Gaçina Diyarz

Hartzailea: Joannes Hiraburu

Lotura: senar-emazteak

Helmuga: Louisbourg

\section{A bertsioa}

$<09.1$ r $>43$

Monsieur / Monsieur Joannes hirabouru / charpantie marein / a Louis bourc

/ fait a hendaye

$<09.2$ r $>$ Hendayan Eguigna otxaillaren

28-1757

\section{/ Ene Senar maitea}

/ Causitçen gare ossassuna parfait Batian / familla gucija non Desiratçen nuque ${ }^{5}$ Çuria Ere hala jçaitea Eta Contignuatxia / halaber nere Bihotz gouçijaz / jçatudut Çuc Egorri dautaçun Léttra / chanjia non marquatçen baititu Berogoy / Louis Çeignetan adreçatuba Baita $\mathrm{M}^{\mathrm{r}} / 10$ Manesco miarritz qouaren ganat Beras / jçatu nais jaun haren Baitan nola / Egorri dautaçun Eta Errepusta Emandarot / nola Estuben Chanje Egortçaille horren / ganic deus funsic Erreçibitu vntxijac / $/ 15$ galdu direla Batçubec Eta Bertçiac / Es aguery non diren Esdarot sinatu / ortaric hartuco ditutçu Çure précossijon[eac] / Ene Espos maitea Eguignen duçu haha[lic]

$<09.2 v>$ hobequijena Eçen jduritçen Çait pagatçeco / Borondateric jçatu Balu sinatuco çubela / afin salutaçen çaituste çure Burassuec / Eta anaya arrebac Eta coignatec Eta Bertçe $I^{5}$ ahaide Eta adisquide guçijec halaber / milla goraintçy ossassuna on bat dessiratçen / dautçutela Ene Espos maitea / guelditçen nais Çure / cerbitçary Çure / ${ }^{10}$ jqousteco dessira handy / Batequin

\section{/ Gaçina Diyarz}

\section{B bertsioa}

$<09.1$ r $>43$

Monsieur Monsieur Joannes Hiraburu, charpantie marein a Louisbourc.

Fait a Hendaye.

$<09.2$ r> Hendaian egiña, otsaillaren 28-1757.

Ene senar maitea,

Kausitzen gare osasuna parfeit batian familla guzija, non desiratzen nuke zuria ere hala izaitea, eta kontiñuatzia, halaber, nere bihotz guzijaz. Izatu dut zuk egorri dautazun letra xanjia, non markatzen baititu berrogoi luis, zeiñetan adrezatuba baita $\mathrm{M}^{\mathrm{r}}$ Manesko Miarritzkuarenganat. Beraz, izatu naiz jaun haren baitan, nola egorri dautazun, eta errepusta eman darot nola eztuben xanje egortzaille horrenganik deus funtsik errezibitu, untzijak galdu direla, batzubek eta bertziak ez ageri non diren. Ez darot sinatu, ortarik hartuko ditutzu zure prekozijoneak. Ene espos maitea, egiñen duzu hahalik

$<09.2 v>$ hobekijena, ezen iduritzen zait pagatzeko borondaterik izatu balu sinatuko zubela. Afin, salutatzen zaituzte zure burasuek eta anaia arrebak eta koiñatek, eta bertze ahaide eta adiskide guzijek, halaber milla goraintzi, osasuna on bat desiratzen dautzutela. Ene espos maitea, gelditzen naiz zure zerbitzari, zure ikusteko desira handi batekin.

/ Gaçina Diyarz. 
Data: $1757 / 3 / 1$

Non idatzia: Sara

Igorlea: Martin Borda

Hartzailea: Andreco Borda

Lotura: aita-semeak

Helmuga: Labrador

\author{
A bertsioa \\ $<10.1$ r $>67$ \\ A Monsieur / Monsieur andreco de Borda / \\ Marinier demeurant a Larbardor. / a terneuve \\ Maitre de Grave / Larbardor \\ $<10.1 v>$ Saran eguina mar[choar]en lehenean \\ $1757^{\text {an }}$
}

/ Ene seme maitea hartcen dut libertate Curi Bi / lerroren escribatceco etaÇuri gure familiaco Berri / onen gastigatceco ossasuna dugu jaincoari Esquer $/ \bar{s}$ eta desiratcen guinouque denbora Berean Çuc / Ere hala Bacindu Çuc jgorri letra chanya / Bat Baicen estugu erreçivitu esdausquigou lannesec / sinatu nahi nola Bouryessari jgorriada arretcholara / hadicaaco gastigouarenBeha gaude esdaquigou Cer $/{ }^{10}$ gastigou jçanendugun eta horco letra çhanyas balia / Çaite possible Bada jgortcen darotçugou Betri maingouarequin / athorraBat Bertceric ecin aussarta gaitesque jgortcerat hunat / passatcera eguicu ahal Badaguiçu anaya guanes Cortsuan dabila / hirugarren Campainan guanada eta aita Bera ere Bigarrenean $/{ }^{15}$ doha Cortsurat joite handiBaten Beldurrean Berrogoi / untçi donibanetic eta Bayonnatic badoha Corsurat / orai artainocoan urus dabilla hemengo yendea untçi Bat / Baicen estu hartu anguelessac hartu Corsulariric eta / hartan Baciren Saratic Çortci guicon Çure adisquide $/ 20$ guciec guaraintci etaparticularqui amasso çaharrac / Cure Cerbitçari Martin /22 Borda

\section{B bertsioa}

$<10.1$ r $>67$

A Monsieur Monsieur Andreco de Borda Marinier demeurant a Larbardor, a Terneuve, maitre de Grave. Larbardor.

$<10.1$ v $>$ Saran egina, martxoaren lehenean, 1757 an.

Ene seme maitea, hartzen dut libertate zuri bi lerroren eskribatzeko eta zuri gure familiako berri onen gaztigatzeko. Osasuna dugu Jainkoari esker, eta desiratzen ginuke denbora berean zuk ere hala bazindu. Zuk igorri letra xanja bat baizen eztugu errezibitu; ez dauzkigu Lannesek sinatu nahi. Nola burjesari igorria da Arretxolara, handikako gaztiguaren beha gaude. Ez dakigu zer gaztigu izanen dugun, eta horko letra xanjaz balia zaite, posible bada. Igortzen darotzugu Betri Mainguarekin athorra bat, bertzerik ezin ausarta gaitezke igortzerat; hunat pasatzera egizu ahal badagizu. Anaia Guanes kortsuan dabila, hirugarren kanpainan guana da; eta aita bera ere bigarrenean doha kortsurat, joite handi baten beldurrean. Berrogoi untzi Donibanetik eta Baionatik badoha kortsurat. Orai artainokoan urus dabila hemengo jendea, untzi bat baizen eztu angelesak hartu kortsularirik, eta hartan baziren Saratik zortzi gizon. Zure adiskide guziek goraintzi, eta partikularki amaso zaharrak.

Zure zerbitzari, Martin Borda.

lv:9 hadicaaco : handicaco (aierua). 18 aditz nagusia bi aldiz da emana. Bata zein bestea dira posible baina ez biak aldi berean. Bigarrena proposatzen dugu: untçi bat baicen estu anguelessac hartu corsulariric. 20 guaraintci: goraintzi irakur. <gu> g balio duen digrafoa lekukotzen ahal da tradizioan, eta gutuneria honetan ere. 


\section{1}

Data: 1757/3/1

Non idatzia: Sempere

Igorlea: Maria Dihitx

Hartzailea: Haurra Maria Hiriart

Lotura: ama-alabak

Helmuga: Louisbourg

\section{A bertsioa}

$<11.1$ r $>19$

A Mademoiselle / Mademoiselle hiriart /

Basquesse / A Louis Bourg

<11.2r>A St pée le premier mars 1757

/ Ene alaba maitea

/ jçatu dugu ohore iqusteco çuq monsieur / Diharci Vicarioari jsquiribatu jçatu dioçun $/$ L Letra ceinetan marquatcen baitcinioen / seigarren aldia cindubela eta datatuba baitcen / goanden abendoaren hamaseian, bai eta guerorrec / ere errecibitu dugu cure letra hainits placer / hartu dugu çure ossasunas eta cure berri onen $/{ }^{10}$ jaquiteas guq ere bada presentean ossasuna / dugu famila guciac jaincoari esquerrac / gure orhoitçapençat jgorcen darotçut çapata / parebat martin pillisen semearequin eta / Desiratcen nuque hemedic joan cinen sentimendu 115 beretan causitcen bacine othoisten çaitut çure / fideltasuna guardatceas eta hortic nihorat ere / esairatceas ecen bertcetan ere bada cerbait escasia

$<11.2 v>$ eta badaqisu cembat samur tasun duben / amabatec bere umen aldera desiratcen nuque / hainits çure jqustea baldin jaincac eguiten badu / gracia baquearen eguiteco eta badaquiçu orobat ₹ ume batec badubela obligacionea buraso baten / obeditceco, beras hortaracots othoits eguiten / darotçut neure ahal gucias guerla hunec / dirabeino hor egoteas eta guero baquea eguiten den / pontutic etçherat erretiratceas horra cer othoits $/{ }^{10}$ Dudan çuri eguiteco eta desiratcen nuque / entçuna banins ene othoisean / guelditcen naicelaric cure ama maitea / eta fidella bihots samurres / bethea

${ }^{15}$ Maria Dihitx

\section{B bertsioa}

$<11.1 r>19$
A Mademoiselle Mademoiselle Hiriart,
basquesse. A Louisbourg.

<11.2r>A St. Pée, le premier mars 1757.

Ene alaba maitea,

Izatu dugu ohore ikusteko zuk Monsieur Diharci, bikarioari, iskiribatu izatu diozun letra, zeinetan markatzen baitzinioen seigarren aldia zindubela eta datatuba baitzen goan den abendoaren hamaseian, bai eta gerorrek ere errezibitu dugu zure letra. Hainitz plazer hartu dugu zure osasunaz eta zure berri onen jakiteaz. Guk ere, bada, presentean osasuna dugu famila guziak Jainkoari eskerrak. Gure orhoitzapentzat igortzen darotzut zapata pare bat Martin Pillisen semearekin, eta desiratzen nuke hemendik joan zinen sentimendu beretan kausitzen bazine. Othoizten zaitut zure fideltasuna guardatzeaz eta hortik nihorat ere ez airatzeaz, ezen bertzetan ere bada zerbait eskasia.

$<11.2 v>$ Eta badakizu zenbat samurtasun duben ama batek bere umen aldera: desiratzen nuke hainitz zure ikustea, baldin Jainkoak egiten badu grazia bakearen egiteko. Eta badakizu, orobat, ume batek badubela obligazionea buraso baten obeditzeko. Beraz, hortarakotz othoitz egiten darotzut, neure ahal guziaz, gerla hunek dirabeino hor egoteaz, eta gero, bakea egiten den pontutik etxerat erretiratzeaz. Horra zer othoitz dudan zuri egiteko, eta desiratzen nuke entzuna banintz ene othoitzean, gelditzen naizelarik zure ama maitea eta fidela, bihotz samurrez bethea.

Maria Dihitz.

2r:14 hemedic : hemendic irakur bedi. 2v:3 jaincac : kopia hutsa den 12. gutunean ere horrela datza. Jaincoac proposatzen dugu. 


\section{2 [11.aren kopia]}

Data: $1757 / 3 / 1$

Non idatzia: Sempere

Igorlea: Maria Dihitx

Hartzailea: Haurra Maria Hiriart

Lotura: ama-alabak

Helmuga: Louisbourg

\section{A bertsioa}

$<12.1 \mathrm{r}>75$

La presente soit / Rendüe a haurramaria / hiriart Basquesse / demurant presentement / Louis Bourg / A Louis bourg

$<12.2$ r $>$ à St pée le $1^{\text {re }}$ mars 1757

/ Ene alaba maitea

/ jçatu dugu ohore jqusteco çuq monsieur / diharci vicarioari jsquiribatujçatu dioçun $\rho^{5}$ Letrea ceinetan marquatcen baitcinioen / seigarren aldia cindubela eta datatuba / baitcen goanden abendoaren hamaseian / bai eta guerorrec ere errecibitu dugu cure / letra hainits placer hartu dugu çure ossasun $/{ }^{10}$ ossasunas eta cure berri onen jaquiteas guq / ere bada presentean ossasuna dugu famila gucia / jaincoari esquerrac gure orhoitçapençat jgorcen / darotçut çapata parebat martin pillisen / semearequin eta desiratcen nuque hemed $/{ }^{15}$ hemendic joan cinen sentimendu beretan / causitcen bacine othoisten caitut cure / fideltasuna guardatceas etahortic nihoratere / es airatceas ecen bertcetan ere bada cerbait / escasia

$<12.2 v>$ eta badaquisu Cembat Samurtasun duben / amabatec bere umen aldera desiratcen nuqu / nuque hainits cure jqustea baldin jaincac / eguitenbadu gracia baquearen eguiteco $/ 5$ eta badaquiçu orobat ume batec badubel / obligacionea buraso baten obeditceco, beras / hortaracots othoits eguiten darotçut neure / ahal gucias guerla hunec dirabeino / horegoteas eta guero baquea eguiten den $/{ }^{10}$ pontutic etçherat erretiratceas / horra cer othois dudan çuri eguiteco eta / desiratcen nuque entçuna banins ene / othoiscean guelditcen naicelaric
B bertsioa

$<12.1$ r $>75$

La presente soit rendüe a Haurra Maria Hiriart, basquesse, demurant presentement Louisbourg. A Louisbourg.

$<12.2$ r $>$ À St. Pée, le $1^{\text {re }}$ mars 1757.

Ene alaba maitea,

Izatu dugu ohore ikusteko zuk Monsieur Diharci, bikarioari, iskiribatu izatu diozun letra, zeinetan markatzen baitzinioen seigarren aldia zindubela eta datatuba baitzen goan den abendoaren hamaseian, bai eta gerorrek ere errezibitu dugu zure letra. Hainitz plazer hartu dugu zure osasunaz eta zure berri onen jakiteaz. Guk ere, bada, presentean osasuna dugu famila guziak Jainkoari eskerrak. Gure orhoitzapentzat igortzen darotzut zapata pare bat Martin Pillisen semearekin. Eta desiratzen nuke hemendik joan zinen sentimendu beretan kausitzen bazine. Othoizten zaitut zure fideltasuna guardatzeaz eta hortik nihorat ere ez airatzeaz, ezen bertzetan ere bada zerbait eskasia.

$<12.2 \mathrm{v}>$ Eta badakizu zenbat samurtasun duben ama batek bere umen aldera: desiratzen nuke hainitz zure ikustea, baldin Jainkoak egiten badu grazia bakearen egiteko. Eta badakizu orobat ume batek badubela obligazionea buraso baten obeditzezo. Beraz, hortarakotz othoitz egiten darotzut, neure ahal guziaz, gerla hunek dirabeino hor egoteaz, eta gero, bakea egiten den pontutik, etxerat erretiratzeaz. Horra zer othoitz dudan zuri egiteko, eta desiratzen nuke entzuna banintz ene othoitzean, gelditzen naizelarik zure ama maitea eta 
cure / ama maitea / eta fidella bihots samurres 15 bethea

/ maria d'ihitx

2v:3 jaincac : jaincoac irakurri behar da. Cf. jaincac 11, 2v:3. fidela, bihotz samurrez bethea Maria d'Ihitz.

\section{3}

Data: $1757 / 3 / 2$

Non idatzia: Getaria

Igorlea: Joanna de Salla

Hartzailea: Jean Caztillou

Lotura: auzoak

Helmuga: Louisbourg

\section{A bertsioa}

$<13.1 r>84$

A Monsieur / Monsieur jean Caztilou / $\mathrm{m}^{\mathrm{e}} \mathrm{de}$ grabe pour monsieur Laborde / a Luisbourg

$<13.2$ r> A Guettary le 2 mars 1757

/ Ene hauco majtea / Prezentequo coury adicerá emaitequo Neure ossasunaren / Beria eta denbora verean coure

famillarená ossasuná $/ 5$ Dougou jaincoary esquer deciracen guindouque coubena / ala jcaitea Neure semea joannis gomendacen daucout / otoy coure qonpania oná Eguiteás hauco onen / adisquidetacouna hunetaquo hourtetan da senálle / coure Esparancan gueldicen Naiz Esparanca dout $/{ }^{10}$ coure partetiq esdiocula faltatuquo halaber ene / semea piarressy goraincy milla coure famillaq / saloutacen saitou eta piarres hacharrenequoq / Beré Biox gucias eta Naiz cure servicary joanná / Desallá

\section{B bertsioa}

$<13.1 r>84$

A Monsieur Monsieur Jean Caztilou, maitre de grabe pour Monsieur Laborde. A Luisbourg.

<13.2r>A Guettary le 2 mars 1757.

Ene hauzo maitea, Presenteko zuri aditzera emaiteko neure osasunaren berria, eta denbora berean zure famillarena. Osasuna dugu Jainkoari esker; desiratzen ginduke zubena ala izaitea. Neure semea Joanis gomendatzen dautzut otoi zure konpania ona egiteaz. Hauzo onen adiskidetasuna hunetako hurtetan da senalle; zure esparantzan gelditzen naiz. Esparantza dut zure partetik ez diozula faltatuko halaber ene semea Piarresi. Goraintzi milla. Zure famillak salutatzen zaitu, eta Piarres Hacharrenekok bere biotz guziaz. Eta naiz zure zerbitzari, Joanna de Salla. 


\section{4}

Data: $1757 / 3 / 2$

Non idatzia: Sara

Igorlea: Martin Durruitz

Hartzailea: Domingo Durruitz

Lotura: aita-semeak

Helmuga: Louisbourg

\begin{abstract}
A bertsioa
$<14.1 \mathrm{r}>88$

A Monsieur / Monsieur domingo / Durruitts sarafais / dolhabide

/ A Luisbrorc

$<14.2$ r> Escribatua marçhoaren 2 saran 1757

/ Ene seme maitea / Escribatçen darozquiçut bilero Çuri / nere berien marcatçeco osasunadut $/^{5}$ neure famillia.guçiarequin jaincoari / Esquer.Eta.denbora berean desiratçen / nuque Çurea hala balitz Eta Çuc / Egoriac Ereçibitutugu hirur letra / Eta Çuc Egoriac berçe gauçac ere Ere-/ ${ }^{10}$ çibitugu Eta Cure Erecuntra / gaiçhtoez damuhandibathartu / dugu eta badaquigu damu hartu / Çarela guc Çuri Letraric Ez Eguiteaz / bainan Ezpaiquinaquien Loisborcquen $/{ }^{15}$ ala Chebequen Çinen Eta Letra ezquina-/ quijen norat jgor Eta piares Eregu-/ eren Çerbitçuanda urthe bat bada / goana dela Eta martin gazte cor-/ xurata goan Eta presan heldudela $/ 20$ anguellesec harturic plemuanda $<14.2 \mathrm{v}>$ hemen udaldia pasatuduberedirua / Emanguidion Eta halere bere ofiçioan / hasigabe corxurat goançen eta çhiquia / ere corxurat goancen duela hogoi / $/ 5$ Egun Baijonatic Etçen beriric agueri / oraino Eta jçeba jxaso garatecoa / hilçen badu urthebat abançu / Eta jgorcen darozquiçut urdai / azpibat Eta luchainca.cenbeit $/{ }^{10}$ eta andoilla bat biranda.Etçheberi-/ co betirequin Çure çerbitcari / gueldiçennais cure aita / maitea martin Durruittz
\end{abstract}

\section{B bertsioa}

$<14.1$ r $>88$

A Monsieur Monsieur Domingo Durruitz, Sara, fais d'Olhabide.

A Luisbrorc.

<14.2r> Eskribatua martxoaren 2, Saran, 1757.

Ene seme maitea, Eskribatzen darozkitzut bi lerro zuri nere berrien markatzeko. Osasuna dut neure famillia guziarekin Jainkoari esker, eta denbora berean desiratzen nuke zurea hala balitz. Eta zuk egorriak errezibitu tugu hirur letra, eta zuk egorriak bertze gauzak ere errezibitugu. Eta zure errekuntra gaixtoez damu handi bat hartu dugu. Eta badakigu damu hartua zarela guk zuri letrarik ez egiteaz, bainan ezpaikinakien Loisborcqen ala Quebec-en zinen eta letra ezkinakijen norat igor..

Eta Piarres Erregeren zerbitzuan da, urthe bat bada goana dela. Eta Martin gazte kortsutara goan eta presan heldu dela, angelesek harturik Plemuan da. $<14.2 v>$ Hemen udaldia pasatu du. Bere dirua eman gindion eta halere bere ofizioan hasi gabe kortsurat goan zen. Eta xikia ere kortsurat goan zen duela hogoi egun. Baijonatik etzen berririk ageri oraino. Eta izeba Itsasogaratekoa hil zen badu urthe bat abantzu. Eta igortzen darozkitzut urdaiazpi bat eta lukhainka zenbeit, eta andoilla bat, biranda, Etçheberriko Betirekin.

Zure zerbitzari gelditzen naiz. Zure aita maitea, Martin Durruitz.

Ir sarafais : gaude Sara, fils irakurri behar ote den. 2r:19 corxurata : posiblea da cortsutara zein cortsurat interpretatzea; lehena hautatzen dugu. 2v:2 Emanguidion : eman guindion irakur bedi. 


\section{5}

Data: $1757 / 3 / 3$

Non idatzia: Getaria

Igorlea: Joanna de Castillou

Hartzailea: Jean Castillou

Lotura: aita-alabak

Helmuga: Louisbourg

\section{A bertsioa}

$<15.1 \mathrm{r}>61$

Monsieur / Monsieur / Jean qastillou / Metre de Grabe / pour monsieur Laborde / a Louis bourg

$<15.2$ r> Getharian egina marchoaren 31757

/ Ene / aita maitia hartcendut libertade Curi bi leroren / Esqribatceqo Eta denbora berian Curi Ene osasunaren $/ 5$ beria aditcerat Emateqo Cinetan ona baita Etadesiratcen / bainuque Curia hala jcaitia cure qonpania guciareqin batian / sallutatcen caitut Ene bihotc gucias eta halaber / sallutacen caituste aispa nanaq Ceinetan miariscenbaita / nesqato Eta domincheq eta qailantaq eta goanahauraq $/{ }^{10}$ Eta dominiqaq mila gorainci Eta areba chabadineq / Eta hiribarongo ania arebeq eta baroineneqo familaq / mila gorainci hachareneqo familaq mila gorainci / goanatipitoa chabadineneqoaq Eta bere alabaq mila / gorainci Eta othoi gomendatcen darotcula haren $/ 15$ semia joanis cure prudencias Esenpluonbatenematias / bere burasoaren aldera miseria gucien erdian horeq / sofritcen ditubeneq Ematen dautedatela Enepenagucia / mila gorainciamaq Eta arebaq Eta gaineraqo cure / hauco ahaide adisqide gucieq mila gorainci ${ }^{20}$ Ene aita maitia bihotces Curi Erateqo hemengo dolore / Eta miseria gucieqbaino gehiago afligitcenaute / Cuhor gerlatriste huneqin jcanaq EtaCu jqusinahia / Cureberia Escinjaqines hiltcerat goasguciaq

$<15.2 v>$ Ene aita maitia Egicu bethi quraie Ceruqo aitaq bethi / jcaren du gure artha Eta Cure doloreguciaq ofregi / diotcotcu jnqoari ahaliq hobeqiena Cure horqo / dolorieq
B bertsioa

$<15.1 r>61$

Monsieur Monsieur Jean Qastillou, metre de grabe pour Monsieur Laborde. A Louisbourg.

$<15.2$ r> Getharian egina, martxoaren 3, 1757.

Ene aita maitia, hartzen dut libertade zuri bi lerroren eskribatzeko eta denbora berian zuri ene osasunaren berria aditzerat emateko, zinetan ona baita, eta desiratzen bainuke zuria hala izaitia, zure konpania guziarekin batian. Salutatzen zaitut ene bihotz guziaz, eta halaber salutatzen zaituzte aizpa Nanak, zeinetan Miarritzen baita neskato. Eta Dominxek eta Kailantak eta Goana Haurrak eta Dominikak mila goraintzi. Eta arreba Xabadinek eta Hiribarrongo ania-arrebek eta Baroineneko familak mila goraintzi. Haxarreneko familak mila goraintzi; Goana Tipitoa Xabadinenekoak eta bere alabak mila goraintzi, eta othoi gomendatzen darotzula haren semia Joanis zure prudentziaz esenplu on baten ematiaz. Bere burasoaren aldera, miseria guzien erdian, horrek sofritzen ditubenek ematen dautedatela ene pena guzia. Mila goraintzi amak eta arrebak, eta gainerako zure auzo, ahaide, adiskide guziek mila goraintzi. Ene aita maitia, bihotzez zuri errateko hemengo dolore eta miseria guziek baino gehiago aflijitzen naute zuhor gerla triste hunekin izanak eta zu ikusi nahiak; zure berriak ezin jakinez hiltzerat goaz guziak.

$<15.2 \mathrm{v}>$ Ene aita maitia, egizu bethi kuraie; zeruko Aitak bethi izaren du gure artha; eta zure dolore guziak ofreji diotzotzu Jinkoari ahalik hobekiena. Zure horko 
Ematen dute Ene bihotcian penariqhandiena ${ }^{5}$ agerida ginqoaq horla placer dubela qonplibedi / bada bethi jaunaren borondatia goanden urthian / Egori darosquitcut corciletra Eta Estaqit jcatu / othe ducun batere hiriartenas landan gastiatu / narotcun supreni escintescen nola mahitcheneqo $/{ }^{10}$ semia Esposatuden butuneneqo alabarequin dioelariq / Escarotcula Eman hitciq Eta trufatu cindubela / Eta senqriqeneqo premuba Ere esposatuda / danielen arebareqin hauq marqatcen darosqitcut / Es nahis curi hutsiq Eta damuriq Egin batere / 15 horietas Esdolora batere Ceren jnqoaq premetitcen / baiqitu horiec gucia qomeni estiren gaucetan / Estut presentian deus berceriq Curi cer gastia / baiciq Ere naisela gelditcen Cure Cerbitcari / Cure ume naisen becalaqo miserablia orai Eta ${ }^{20}$ bethi bihos Eta borondate ones Eta Escin pagatube $_{\mathrm{s}}$ / bethia joanna de qastillou doloriek ematen dute ene bihotzian penarik handiena. Ageri da Jinkoak horla plazer dubela; konpli bedi, bada, bethi Jaunaren borondatia. Goan den urthian egorri darozkitzut zortzi letra, eta eztakit izatu othe duzun batere. Hiriartenaz landan, gaztiatu narotzun supreni etzintezen nola Mahixeneko semia esposatu den Butuneneko alabarekin, dioelarik eztarotzula eman hitzik, eta trufatu zindubela. Eta Senkrikeneko premuba ere esposatu da Danielen arrebarekin. Hauk markatzen darozkitzut, ez nahiz zuri hutsik eta damurik egin batere. Horietaz ez dolora batere, zeren Jinkoak premetitzen baikitu horiek guziak komeni eztiren gauzetan. Eztut presentian deus bertzerik zuri zer gaztia, baizik ere naizela gelditzen zure zerbitzari. Zure ume naizen bezalako miserablia, orai eta bethi, bihotz eta borondate onez eta ezin pagatubez bethia, Joanna de Qastillou.

2v:11 Escarotcula : irakur bedi estarotçula. Herskarien arteko batetortzea gertatu da hemen, nahiz fenomenoaren testuingurua hitz bukaera den; cf. baiqitu 'baititu' ondoko oharrean. 16. baiqitu : uler bedi baititu. gucia : guciac irakur; menturaz herskaria ez da grafiatu ondoko hitzaren hastapeneko qoren eraginaz. 
16

Data: $1757 / 3 / 7$

Non idatzia: Senpere

Igorlea: Joanes de Matet

Hartzailea: Joannes de Matet

Lotura: aita-semeak

Helmuga: Louisbourg

\author{
A bertsioa \\ $<16.1$ r $>107$ \\ Lapresente soit / rendüe a joannes / dematet / A \\ Louis Bourg
}

$<16.2$ r > A St pée le 7 mars 1757

/ Ene semea

/ Ohore dugu curi presenteco letra hunen / jgorceco eta dembora berean gure berrien marcatce ${ }^{c} I^{5}$ osasuna dugu familla guciac jaincoari esquer eta / Desiratcen daroçugu curi ere osasun bera guc dugun / beçala baldin jaincoari conbeni baçaio eta / desiratcen guinduque cure jqustea cure anaiac / othoisten çaitu çuben arteco duçubenjrabacia $/{ }^{10}$ edo ontasuna lechu on eta escu segur batetan / hor usteas badaquiçula cer jrrisqulitequen orai / eta den anguelesarençat eta cerorri nihola ere / posible bada jrrisca çaiteçilla alderdi huntarat / pasatcerat aguian jaincoac eguinen darotçulla $/ 15$ pasatceco gracia salboric eta bera corsuban / dabila baionnatic adiu ene semea / cure serbitçari guelditcen gare gure bihots gucias / ni aita eta ama eta bai haurride guciac eta ahaide / eta adisquide guciac

${ }^{20}$ joannes de matet

\section{B bertsioa}

$<16.1$ r $>107$

La presente soit rendüe a Joannes de Matet. A Louisbourg.

<16.2r> A St. Pée, le 7 mars 1757.

Ene semea,

Ohore dugu zuri presenteko letra hunen igortzeko eta denbora berean gure berrien markatzeko. Osasuna dugu familla guziak Jainkoari esker, eta desiratzen darotzugu zuri ere osasun bera guk dugun bezala, baldin Jainkoari konbeni bazaio, eta desiratzen ginduke zure ikustea. Zure anaiak othoizten zaitu zuben arteko duzuben irabazia edo ontasuna lekhu on eta esku segur batetan hor uzteaz, badakizula zer irrisku liteken orai, eta den, angelesarentzat; eta zerorri, nihola ere posible bada, irriska zaitezila alderdi huntarat pasatzerat, agian Jainkoak eginen darotzula pasatzeko grazia salborik; eta bera korsuban dabila Baionatik. Adiu ene semea, zure zerbitzari gelditzen gare gure bihotz guziaz, ni aita, eta ama, eta bai haurride guziak eta ahaide eta adiskide guziak.

Joannes de Matet. 


\section{7}

Data: $1757 / 3 / 9$

Non idatzia: ?

Igorlea: ?

Hartzailea: Bernat Aroqi

Lotura: auzoak?

Helmuga: Louisbourg

\begin{abstract}
A bertsioa
$<17.1$ r $>94$

perssenteqo letra hau Eren / Datuco caigo

bernat aro / qiry a lurjs burcq / Lurjsburcq

$<17.1$ v $>$ Marsoaen 9 egina 1757

/ Bernat dearoqi harcendut libertate hemen cerba ${ }_{\text {pa }}$ / sacen den cury adiaracteqo horticq ethoricicaiqunber- / j tiristia gucq guti ustecaberi ethory ciçaiqun cure $/ 5$ jceba goan martin coennecqoc gastigacendaucu / Estaqigu cehetassunnjc gehigago baldin cuq hunat / deusjq escirbattu edo gastigatu badauqucuere estugudeusic / aditu allabainan cucen eta justu den becala curebaita[n] / dugu Esparanca ene seme defuntu cena cure conpaini $/{ }^{10}$ gan eedo cure sumicjgonnecogo cenacs gerosticq otoict- / Encaitut cure cussina goanes defuntucenaen jcate / Edo mojgana horgelditudenas contu edo arta jduqicia $_{\mathrm{s}}$ / Etahortic ahalic lasterena hunat hedaceas
\end{abstract}

/Esteben Ecgoraincj $/ 15$ halalaber bernat gaucabera gactigacendaucu curjbelx / cenaen Emastiac otoi curebaitan dubere Esparanca Eta / Eta orobat cusina goanes defuntu cenaencat becalaharen / callupamasturbaencatere horduben moigan edoontasunas / contu Eta arta bera jçatias eta Lehen ba Lehen hunat ${ }^{20}$ hedaceas cure crbicary

\section{B bertsioa}

$<17.1$ r $>94$

Persenteko letra hau errendatuko zaijo Bernat Aroqiri, a Lurisburcq. Lurisburcq.

$<17.1 v>$ Marsoaen 9 egina, 1757.

Bernat de Aroqi, hartzen dut libertate hemen zer pasatzen den zuri adiarazteko. Hortik ethorri zitzaikun berri tiristia guk guti ustekaberik ethorri zitzaikun. Zure izeba Goan Martinkoenekok gaztigatzen dauku. Eztakigu zehetasunik gehijago, baldin zuk hunat deusik eskirbatu edo gaztigatu badaukuzu ere eztugu deusik aditu. Alabainan, zuzen eta justu den bezala, zure baitan dugu esparantza ene seme defuntu zena zure konpainijan edo zure sumizijonekogo zenaz geroztik. Otoizten zaitut zure kusina Goanes defuntu zenaen izate edo moijana hor gelditu denaz kontu edo arta idukitziaz, eta hortik ahalik lasterrena hunat hedatzeaz.

Estebenek goraintzi. Halaber, Bernat, gauza bera gaztigatzen dautzu Zuribeltz zenaen emaztiak, otoi zure baitan du bere esparantza, eta orobat kusina Goanes defuntu zenaentzat bezala haren kalupa masturubaentzat ere hor duben moijan edo ontasunaz kontu eta arta bera izatiaz, eta lehenbalehen hunat hedatzeaz. Zure zerbitzari.

Ir caigo : egile honek <g> grafemaz zerbitzatzen da /j/ irristariaren balioa adierazteko. Gutunean zehar zaigo, moigan, konpainigan, gehigago, sumizigoneko.

Gainerateko testuetan halako epentesiak maizenik $<j>,<i>$ grafiekin adierazten dira. 1v: 10 eedo : horrela. 15 halalaber : horrela. 18 callupamasturbaencatere : 'kalupa masturbaentzat ere'. 


\section{8}

Data: $1757 / 3 / 10$

Non idatzia: Getaria

Igorlea: Maria de Lamarq

Hartzailea: Bernat de Lupoy

Lotura: ama-semeak

Helmuga: Louisbourg

\section{A bertsioa}

$<18.1$ r $>124$

Lapresente lettre soite / reandeue a Bernat / de Lupoy çhentiqa / a Louisbourg de Louis[bourg]

<18.2r> fait aguethary, cé 10 Marz 1757

/ Enne seme maitea gastiaxen dauxut / milla gorainxy Estut Erreçibitu çure / ganiq aurten Es Letrariq Es çolament $/ 5$ gorainxibat jçatu ditut $2 \mathrm{tt}$ ahex / Bordaganiq chanpeletaqo Eta Egorxen / dausquixut çhanpelaq çançingorrieneqo / jaunarequin

/ gueldixen nais cure ama allargun / ${ }^{10}$ gaçhoa çure çerbitçary mariade / Lamarq

\section{B bertsioa}

$<18.1$ r $>124$

La presente lettre soite reandeue a Bernat de Lupoy Chentiqa, a Louisbourg. De Louisbourg.

<18.2r> Fait a Guethary, cé 10 Marz 1757.

Ene seme maitea, gaztiatzen dautzut milla goraintzi. Eztut errezibitu zureganik aurten ez letrarik ez solament goraintzi bat. Izatu ditut 2 libera Ahetz Bordaganik xanpeletako, eta egortzen dauzkitzut xanpelak Zanzingorrieneko jaunarekin.

Gelditzen naiz zure ama alargun gaxoa, zure zerbitzari, Maria de Lamarq. 
Data: $1757 / 3 / 12$

Non idatzia: Sara

Igorlea: Joannes d'Etcheverry

Hartzailea: Joannes d'Etcheverry

Lotura: aita-semeak

Helmuga: Louisbourg

\begin{abstract}
A bertsioa
$<19.1$ r $>24$

Monsieur / Monsieur Joannes D Etcheverry / Marinier demeurant a Louisbourq / pour Mieux dire fils de la maison / de Maiteguenia de Sare a present / a Louisbourq / Louisbourq
\end{abstract}

$<19.2$ r $>$ Sare le $12^{\mathrm{m}}$ Mars 1757

/ Eneseme Maitea Errecibitudut çure letra abenduaren / hogoi eta borcian Eguina ceinac Marcatu baitarotçu / çure ossassuna ona, guissaberian ossassuna onbatean $/^{5}$ caussitcen baicare gubere Jaincoaresquer, Errecibitu dugu / çure lettra chanja $919^{\text {tt }}$ liberaco bat ceina placer han / dia hartu baitut arribatu denean hainberce arriscuren / ondoan, baldin harcen baduçu deliberacioneriq etcherat / Ethorceco francian barna harçaçu mando gaztebat $/{ }^{10}$ lau urtetaco çure eta çure bagaijen echarceco eta ustedut / despendioac atheraco tutçun, amac milla goraincy eta / cure haurridec eta çure ahaidec eta adisquidec eta / hauço guciec, finean guelditcen naiz çure aita eguiazcua / eta fidella bicinaiceino

/15 Joannes d'Etcheverry

\section{B bertsioa}

$<19.1$ r $>24$

Monsieur Monsieur Joannes d'Etcheverry, marinier demeurant a Louisbourq, pour mieux dire fils de la maison de Maiteguenia de Sare, a present a Louisbourq. Louisbourq.

$<19.2$ r> Sare, le $12^{\text {ème }}$ mars 1757.

Ene seme maitea, errezibitu dut zure letra abenduaren hogoi eta bortzian egina, zeinak markatu baitarotzu zure osasuna ona. Gisa berian, osasuna on batean kausitzen baikare gu bere Jainkoar'esker. Errezibitu dugu zure letra xanja, 919 liberako bat zeina plazer handia hartu baitut arribatu denean, hainbertze arriskuren ondoan. Baldin hartzen baduzu deliberazionerik etxerat ethortzeko, Frantzian barna hartzazu mando gazte bat lau urtetako, zure eta zure bagajien ekhartzeko, eta uste dut despendioak atherako tutzun. Amak milla goraintzi, eta zure haurridek eta zure ahaidek eta adiskidek eta hauzo guziek. Finean, gelditzen naiz zure aita egiazkua eta fidela bizi naizeino.

Joannes d'Etcheverry. 
Data: $1757 / 3 / 13$

Non idatzia: Donibane Lohizune

Igorlea: Mari Darburu

Hartzailea: Marie Harboure

Lotura: ama-alabak

Helmuga: Louisbourg

\author{
A bertsioa \\ $<20.1 r>27$ \\ A Mademoyselle / Mademoyselle Marie

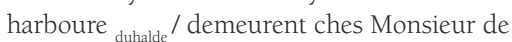 \\ Laborde / Trezorier Du roy / Louizbourq
}

$<20.2$ r $>$ Donibanen eguina marxoanen 13

/ Ene haur maitea estinat faltatu nahi hiri / ene berijac marcatu gabe cenac eraten baitun / estunala aspaldijon gure beriric jcatu hanbat ${ }^{5}$ gastoago gurexat nic eguin dausquinat beti / unsi gusietan letrac eta hic es jsatu estun / beras ene faltaric egori dinat bat lanxecanetu ${ }^{\text {in }}$ / bersea hire cusina defuntubarequin cenac etori / baixen miselequin bajonarat gasoa eta egori $/{ }^{10}$ naunan harequin berajnquin mantalina angelet / acoa ungi fina bere eribana eta siricubarequin / cenac hire matantac churunecoac cuxan sartu / omen baixuben eta berce bi letra patineneco / siburuco premubarequin cenac egun angeletaran $/ 15$ baita gasoa Ene haur maitea badin hilhunen / hogoy eta sejean exetit partitu hinxela egundano / hirur urte egundano estinat jsatu oren laurden / baten erepausuric basaquinat gusijac ene / faltat direla cenac ene becatubac handijac ${ }^{20}$ baitire banan esparanxa dinat jeancoac / misericordia jsanen dubela nitas cergatit / ene uste gusijan ungi harcen tinat eta / adixen tugunaren arabera estela posible / salbaxea hemen non estugun becatuba /25 purgaxen beras esparanxan nijagon / jencoac estausquidala bi pena emanen / ene haur maitea dominica comentuban / esquibas cuxaturic exerat etori sijaetanen / ganxen hirur jlabeteren buruco marascas $\beta 0$ eta ni gaixarequin eta gabearequin anaja / bisentec jcusiric ene sangrin handija / hamabors libera eman sitinan bere / bartetit saflenxat eta orano hanix / behar aita laurenxec aituric ene

\section{B bertsioa}

$<20.1$ r $>27$

A Mademoyselle Mademoyselle Marie Harboure, demeurent ches Monsieur de Laborde, trezorier du Roy. Louizbourq.

$<20.2$ r > Donibanen egina, martxoanen 13

Ene haur maitea, eztinat faltatu nahi hiri ene berrijak markatu gabe, zenak erraten baitun eztunala aspaldijon gure berririk izatu; hanbat gastoago guretzat. Nik egin dauzkinat beti untzi guzietan letrak, eta hik ez izatu. Eztun, beraz, ene faltarik. Egorri dinat bat Lantzekaneturekin, bertzea hire kusina defuntubarekin, zenak etorri baitzen Miselekin Baionarat, gasoa, eta egorri naunan harekin berainkin mantalina Angeletakoa ungi fina, bere erribana eta zirikubarekin, zenak hire matantak Xurunekoak kutxan sartu omen baitzuben; eta bertze bi letra Patineneko Ziburuko premubarekin, zenak egun Angeletarran baita, gasoa. Ene haur maitea, badin hil hunen hogoi eta seiean etxetit partitu hintzela egundano hirur urte. Egundano eztinat izatu oren laurden baten errepausurik. Bazakinat guzijak ene faltat direla, zenak ene bekatubak handijak baitire, banan esparantza dinat Jenkoak miserikordia izanen dubela nitaz, zergatit ene uste guzijan ungi hartzen tinat, eta aditzen tugunaren arabera eztela posible salbatzea hemen, non eztugun bekatuba purgatzen. Beraz, esparantzan nijagon Jenkoak eztauzkidala bi pena emanen. Ene haur maitea, Dominika komentuban ezkibaz kutsaturik etxerat etorri zijaetanen. Gan tzen hirur ilabeteren buruko marraskaz, eta ni gaitzarekin eta gabearekin. Anaia Bisentek ikusirik ene sangrin handija hamabortz libera eman zitinan bere bartetit saflentzat, eta orano hanitz behar. Aita Laurentzek aiturik ene 
$<20.2$ v $>$ dolore handijac exerat etori sixaitanen / bera bere pesunan gaisoa esqueletaric / hela ganincenenean hura nonxare ene / afijutu gasoa harxasu curaje jsanen dut $/^{5}$ nic çure habraren sendaxecoa beharden / gusija emansinan asquenean paruca eta / sapela eta galderdi pare berijac eta begui / suri baitacoec neroni ganic sapata pareberijac / eta bi atora olal pesatit hec pagaxe cotan $/{ }^{10}$ aita laurenxec gastijaxen daun gorainxi / eta jeancoari gomendaxen habela eta / letra bat eguin diosanala falta gabe / anaja bisentet ere bai gorainxi mila mila / eta otoisten haute nitas oroit hadiela $/ 15$ jencoac benedicatuco habela ene haur ma $a^{\text {itea } / ~ e n e ~ h a u r ~}$ maitea badaqun ganis exerat / nola etoricen sarpan borsoseqin eta esquijes / esquebias betea bisajarano presune exiru nan $(\dagger) /$ besala exaquinat bisiric nola egotu $/ 20$ ninxen hura jcusi nubenean gasoa / eta neronj jop besala asdipat gabe / egundano besala aita laurenxec / aituric hurere sendarasi sinan beharden / gusija emanic cenac bijac gosta baitire $/ 25$ larogoy libera pasaturic eta nirijere / socolotat eta masapanac eta biscoxac / gaisoac egorcen sijauquidan denboratit denborara / seculan estinan pagatuco haren borondatea / bisi naisseno banan sendubec asco hortaco eguit$\beta^{30}$ en diten diten salbaxeco eta hura halacoa dun / ene haur maitea ganisona ganxunan / corxura eta angelesec harturic exatu sistenen / espanijarat lisibona eratendioten portu / batera senac gasoa etori baixen ones $\beta^{35}$ berehun lecoatan bere lagunequin / pilala trjste batean exunan hura jcustea $<20.3$ r $>$ baisic berxe miraculuric bulus gorija huren / egundano besala candeguiletaco jaunarequin / eguin sunan gasoa eraten sautalaric jea / hemen cer eguinen ene sangrinaxen miserija $/ 5$ huntan eta beti sor egujten ene haur maitea / conxarat ateratu bela eguiteco eta adi ene / haur maitea costara santabarraco aroca ganer / gusijec exitu gerostit jeancoac espacatu / etea bergina ama maiteac aiseago condaxen $/{ }^{10}$ daunat pasatududan bano ene trublea / ene haur maitea orai beris gan sijaitan / bajonatit badin partitu dela hogoy eta / sorsiegun estinat deusere beriric hemenxe / nijagon jeancoaren esparanxan harc plaser $/{ }^{15}$ duben gusiaren erebixeco ene haur maitea / dominjca abijatu sijaitan harcere gan behar / dubela corsura aita grafleti eraten sijon / duacola maseterearj minxaxera hardesala / corxura minxatu dubenean bajex gogotit $/ 20$ ere beras harequin sioan gasoa orai laster / ene ama maitea gurexat estuxu asqui arebac / egorxen
$<20.2 v>$ dolore handijak etxerat etorri zitzaitanen bera bere pesunan, gaisoa eskeletarik, eta gan nintzenean, hura: "Non tzare, ene afijitu gasoa? Hartzazu kuraie, izanen dut nik zure habraren sendatzekoa behar den guzija". Eman zinan azkenean parruka eta sapela eta galderdi pare berrijak; eta Begizuribaitakoek neroni ganik zapata pare berrijak eta bi atorra, oihal pezatit hek pagatzekotan. Aita Laurentzek gaztijatzen daun goraintzi, eta Jenkoari gomendatzen habela, eta letra bat egin diozanala falta gabe. Anaia Bisentet ere bai goraintzi mila-mila, eta otoizten haute nitaz oroit hadiela, Jenkoak benedikatuko habela, ene haur maitea. Ene haur maitea, badakin Ganis etxerat nola etorri zen sarpan bortz sosekin eta ezkebiaz betea bisajarano, presune etzirunan ( $\dagger$ ) bezala; etzakinat bizirik nola egotu nintzen hura ikusi nubenean, gasoa! Eta neroni, Jop bezala, asdipat gabe... Egundano bezala, aita Laurentzek aiturik hur'ere sendarazi zinan behar den guzija emanik, zenak bijak gosta baitire larogoi libera pasaturik. Eta nirijere sokolotat eta mazapanak eta biskotxak gaisoak egortzen zijaukidan denboratit denborara; sekulan eztinan pagatuko haren borondatea bizi naizeno. Banan sendubek asko hortako egiten diten salbatzeko, eta hura halakoa dun. Ene haur maitea, Ganis ona gan tzunan kortsura, eta angelesek harturik etxatu ziztenen Espanijarat, Lisibona erraten dioten portu batera, zenak gasoa etorri baitzen onez berrehun lekoatan bere lagunekin pilala triste batean. Etzunan hura ikustea $<20.3 r>$ baizik bertze mirakulurik, buluzgorrija hurren! Egundano bezala, Kandegiletako jaunarekin egin zunan gasoa, erraten zautalarik jea hemen zer eginen ene sangrinatzen miserija huntan, eta beti zor egiten. Ene haur maitea, Kontxarat ateratu bela egiteko eta adi, ene haur maitea, kostara Santabarrako arroka ganera guzijek etsitu geroztit Jenkoak espakatu, eta Berjina ama maiteak aiseago kondatzen daunat pasatu dudan bano ene trublea. Ene haur maitea, orai berriz gan zijaitan Baionatit; badin partitu dela hogoi eta zortzi egun. Eztinat deusere berririk; hementxe nijagon, Jenkoaren esparantzan, hark plazer duben guziaren errezibitzeko, ene haur maitea. Dominika abijatu zijaitan hark ere gan behar dubela kortsura. Aita Grafleti erraten zijon duakola masetereari mintzatzera, har dezala kortsura. Mintzatu dubenean baietz gogotit ere, beraz harekin zioan gasoa: 
tuben diru gusijac eta cerori miserija / hortan asajatu behar dut nic ere çure lagunx ${ }^{\text {era }}$ / ene haur maitea jsatu tinat behin hirur $/ 25$ hogoy libera eta berxe behin larogoy libera / estauquinat gastijaxen ene sangrin gusijac / cergatit hi urrun baitaut eta badinat hire / behara jeancoac usten nabeno ene haur / maitea begui suri baitaco marilantat $\beta 0$ perxecutatuba nijalabin jcaten dudala / diruba franco hire ganic eta paga desadala / edo hi gastija haren pagaxeco hic egorxeas / badacinala dirubac eman sauquinala gurexat / fantesijan sastuba dun letra eguin dautela ${ }^{35}$ eta hic es erepustaric eguin nic pacaxen / tinat gusijac jencoac nahi baitu horla

$<20.3 v>$ estebenic gorainxi mila eta egorxen dau / bileta bat letra hunen barnean lahitunen / semijarenxat eran dionasala pagamendu / hori eguin disosala sor justuba duben besala $\rho^{5}$ ene haur maitea ganisec eta ganabrac / jcatu diten disputa ganabrac aitu dubela / esconxen haisela toqui gusijetan eta / ganisec esex eta nic eman dinat bacea / jeaincoas landan ni ama naisela eta $/{ }^{10}$ nic jeacin behar dudala lehenic eta / orduban jacinen dutela jea hala den / es ala bai jeancoac eracuxico daun cer eguin / eta bergina maiteac aguijan ene otojxa / aditucodin ene har maitea hiri cer jspira / ${ }^{15}$ gorainxi osaba sastiluri mila damu dudala / haren afesioneas gusijac jeancoac uquitu / nahi gaitubela haren familac osasuna / dubela ene haur maiteac gorainxi granganec / eta ganisec eran sijautanen hire gorainxijac $/ 20$ emateco falta gabe dominjnicac ere gorainxi / mila mila eta jeancoari gomenda disinala / ganabrac ere mila mila gorainxi eta / ganeraco ahaideta adisquide gusijec / ene haur maite maitea geldixen naun $/^{25}$ hire ama mait maitea tombarano / mari darburu / ene haur maitea enaquinan nola eman / mila saspi ehunac
"Orai laster, ene ama maitea, guretzat eztutzu aski. Arrebak egortzen tuben diru guzijak eta zerori miserija hortan, asaiatu behar dut nik ere zure laguntzera". Ene haur maitea, izatu tinat behin hirur hogoi libera, eta bertze behin larogoi libera. Eztauzkinat gaztijatzen ene sangrin guzijak, zergatit hi urrun baitaut eta badinat hire beharra Jenkoak uzten nabeno. Ene haur maitea, Begizuribaitako Marilantat pertsekutatuba nijalabin, izaten dudala diruba franko hireganik, eta paga dezadala edo hi gaztija haren pagatzeko hik egortzeaz, badakinala dirubak eman zaukinala guretzat. Fantesijan sastuba dun letra egin dautela, eta hik ez errepustarik egin nik pakatzen tinat guzijak, Jenkoak nahi baitu horla.

$<20.3 v>$ Estebenik goraintzi mila, eta egortzen dau bileta bat letra hunen barnean, Lahitunen semijarentzat, erran dionazala pagamendu hori egin dizozala, zor justuba duben bezala. Ene haur maitea, Ganisek eta Ganabrak izatu diten disputa, Ganabrak aitu dubela ezkontzen haizela toki guzijetan, eta Ganisek ezetz, eta nik eman dinat bakea, Jainkoaz landan ni ama naizela, eta nik jakin behar dudala lehenik, eta orduban jakinen dutela jea hala den. Ez ala bai, Jenkoak erakutsiko daun zer egin, eta Berjina maiteak agijan ene otoitza adituko din, ene haur maitea, hiri zer ispira. Goraintzi osaba Sastiluri, mila damu dudala, haren afezioneaz guzijak Jenkoak ukitu nahi gaitubela; haren familak osasuna dubela. Ene haur maiteak, goraintzi Granganek eta Ganisek, erran zijautanen hire goraintzijak emateko falta gabe. Dominikak ere goraintzi mila-mila, eta Jenkoari gomenda dizinala. Ganabrak ere mila-mila goraintzi, eta ganerako ahaide eta adiskide guzijek. Ene haur maite-maitea, gelditzen naun hire ama mait-maitea tonbarano. Mari Darburu. Ene haur maitea, enakinan nola eman mila zazpi ehunak.

1r duhalde : beste esku batek idatzia. 2r:7 lanxecanetu ${ }^{\text {in }}$ : irakur bedi Lanxecaneturequin (antroponimo bat). 2v:3 ganincenenean : irakur gan nintzenean. hela : irakur eta. 2v:4 afijutu : aflijitu espero genuke. $2 \mathrm{v}: 9$ olal : irakur oihal. $2 \mathrm{v}: 16$ badaqun : badaquin. $2 \mathrm{v}: 21$ asdibat : uler bedi ardit bat; ardit 'balio txikiko sos bat'. Cf. sastuba 'sartua' (3r: 34). 2v:30 diten diten : duplografia. 3r:9 etea : irakur eta. $3 \mathrm{r}: 15$ erebixeco : irakur errezibitzeko. $3 \mathrm{v}: 1$ dau 'daun'. $3 \mathrm{v}: 14$ har : irakur haur. $3 \mathrm{v}: 20$ dominjnicac: duplografia; irakur Dominicac. 


\title{
21
}

Data: $1757 / 3 / 14$

Non idatzia: Ziburu

Igorlea: Jean Lafitte Bourguignon

Hartzailea: Joanis Lafitte Bourguignon

Lotura: aita-semeak

Helmuga: Niganiche

\author{
A bertsioa \\ $<21.1$ r $>39$ \\ La presente seraRendue / a Joanix Laffitte, dit / \\ Bourguignon, Marinier / apresent al'isle Royale \\ / a Niganiche \\ $<21.2$ r> Asibourele $14^{\mathrm{e}}$ Mars 1757. \\ / Eneseme Maitea presenteco Comoditateas \\ baliatcen / nais letra haur çuri escribatceco, Eta curi \\ errateco / nahi nausquitçula cembait tresna egorri, \\ baiñan $/ 5$ guciec guibelatu naute erraten Dutela \\ Beharbada / Eta segurqui, hortic partitua çarela, \\ mentura hortan / esdausquitçut egorri \\ / Çuc egorri cignautan lettradechangeas, es nais \\ / pagatuba issatu cergatic hura pagatu behar \\ çubenac $/{ }^{10}$ baitio Es çubela haren Eguilliaren \\ funcic, / Famillia Guciec ossasuna dugu \\ Jaincoari Esquer / aguian Çuc ere haladuçu, \\ Guciec milla goransi / dautçute, Mandataria \\ pressatua da, hargatic es dautçut / Chehetassun \\ guehiago eguiten, nais Eta aita erebay $/{ }^{15}$ cure \\ aita eta ama samurrac \\ I \\ Jean Lafitte etaJeanneton \\ / Micho bourguignon
}

B bertsioa

$<21.1$ r $>39$

La presente sera rendue a Joanix Laffitte, dit Bourguignon, Marinier a present a l'Isle Royale. A Niganiche.

$<21.2$ r > A Ciboure, le 14e mars 1757.

Ene seme maitea, presenteko komoditateaz baliatzen naiz letra haur zuri eskribatzeko, eta zuri errateko nahi nauzkitzula zenbait tresna egorri, baiñan guziek gibelatu naute, erraten dutela beharbada, eta segurki, hortik partitua zarela; mentura hortan ez dauzkitzut egorri.

Zuk egorri ziñautan letra de change-az, ez naiz pagatuba izatu, zergatik hura pagatu behar zubenak baitio ez zubela haren egilliaren funtsik. Famillia Guziek osasuna dugu Jainkoari esker, agian zuk ere hala duzu. Guziek milla gorantzi dautzute. Mandataria presatua da, hargatik ez dautzut xehetasun gehiago egiten, naiz eta aita ere bai.

Zure aita eta ama samurrak, Jean Lafitte eta Jeanneton Micho Bourguignon. 


\section{2}

Data: $1757 / 3 / 14$

Non idatzia: Sara

Igorlea: Joanna de Bidart

Hartzailea: Joannes d'Etcheto

Lotura: ama-semeak

Helmuga: Innaniz (= Niganiche)

\author{
A bertsioa \\ $<22.1$ r $>172$ \\ presenteco leta hau / errendatuco caijo joannes \\ / detçheto sara olhaco / errotaco semmeari / a \\ jnnaniz jnnaniz \\ $<22.2$ r $>$ Escribatua marchoaren 14 saran 1757
}

/ Enne semme maitea harçendut libertate / Curi bilerroren marcaçeco osassunadut jain / coari Escer nere fammilla guziarecin Ceineta[n] $/ 5$ dessiraçen bainuque Curea halla baliz denbora / berean gorainçi Cure arrebec eta Coinnatac eta / amaçhic eta jcebec eta Cussinec eta ahaide adi [s] / cide guçiec dolloratuac gara hagiz jçatudu / gun berritristeaz har ${ }^{\mathrm{en}}$ gauçac ahalic un $/{ }^{10}$ gui alchaturic hunat pasaçerat Eguiçu lehen / biçico Comoitatean Ceren nihor gabe Causicen baica / ra Catalin eta bibioc gara eta maria eta arran / goiçen guelditudire hunat passaçerat Eguiçu Ceren / helduden neguco Ezbaçaiçaigu ethorcen $u z$ aha $/{ }^{15} 1$ baitecaquegu errota

$<22.2 \mathrm{v}>$ letrahau hirur garrena Egorçen dugu $x x x$ / jgorcen darosquiçug beti bianda Eçheberricoarrequin / Luqainca pusca baçuec Ez dugu passajaric jcan / deussen Egorçeco eta mari maite argainenecoc ${ }^{5}$ gorainçi finnean gueldicennaiz eta Cure ama / fidela Cure Cerbiçari joanna $\mathrm{x}$ debidart

\section{B bertsioa}

$<22.1$ r $>172$

Presenteko letra hau errendatuko zaijo Joannes d'Etcheto, Sara, Olhako errotako semeari, a Innaniz. Innaniz.

$<22.2$ r $>$ Eskribatua martxoaren 14, Saran, 1757.

Ene seme maitea, hartzen dut libertate zuri bi lerroren markatzeko. Osasuna dut Jainkoari esker nere familla guziarekin, zeinetan desiratzen bainuke zurea hala balitz denbora berean. Goraintzi zure arrebek eta koinatak eta amatxik eta izebek eta kusinek eta ahaideadiskide guziek. Doloratuak gara hagiz izatu dugun berri tristeaz. Harren, gauzak ahalik ungi altxaturik, hunat pasatzerat egizu lehenbiziko komoitatean, zeren nihor gabe kausitzen baikara. Katalin eta bi-biok gara, eta Maria eta Arrangoitzen gelditu dire. Hunat pasatzerat egizu, zeren heldu den neguko ez bazaitzaigu ethortzen utz ahal baitezakegu errota.

$<22.2 v>$ Letra hau hirurgarrena egortzen dugu. Igortzen darozkizugu beti bianda Echeberrikoarekin, lukhainka puska batzuek. Ez dugu pasaiarik izan deusen egortzeko. Eta Mari Maite Argainenekok goraintzi. Finean, gelditzen naiz eta zure ama fidela. Zure zerbitzari, Joanna de Bidart.

Ir leta : horrela. 2r:9 haren : posible da haren posesiboa zein harren 'otoi' interpretatzea. Dudazko hautu bat egiten dugu bigarrenaren alde. 2v:2 darosquiçug : horrela. 
Data: $1757 / 3 / 15$

Non idatzia: Sara

Igorlea: Piarres d'Etcheverry Mothela

Hartzailea: Joannes d'Etcheverry

Lotura: aita-semeak

Helmuga: Louisbourg

\author{
A bertsioa \\ $<23.1 \mathrm{r}>118$ \\ La Presente / Lettre soit rendüe à / joannes \\ D’Etcheverry fils / du nommé mothela / a \\ Louisbourg
}

$<23.2$ r $>$ Saran Eguina marchoaren 15. 1757.

\begin{abstract}
/ Ene seme maitea
/ Escribatçen darotçut lettra hau pressenteco commoditate / huntas baliatcea gatic, çuey nere amaren eta anayaren $/^{5}$ ossasunaren berri onac emaitea gatic; desiratçen guinduque / çuec ere hor ossassuna perfet bat bacindute. goanden / urthean çuec egorriac errecibitu guinituen; Bai eta / [...] [bi] urthe ere maitearequin hirur sey liberaco / bisquitartean maitea etçen [segur] ea hirur ala 1 [aur] $/{ }^{10}$ eman çiniotçan; hurrenecoan lettran ongui mar[c]a / çaçu. aurthen guerla dela caussa ezdarotçuegou / deus ere egorçen nihorc ere ez darocu deus ere hartu / nahi; amac milla gorainci ossaba gorrari, eta çuequin / batean hunat lehen bai lehen passa dadila; cattalin $/{ }^{15}$ bere emasteac ere othoix hori bera eguiten dio; agoretara / chanjatu gara; çure ahaide eta adisquide guciec / milla gorainci; eta particularqui monsieur haranchipy / a[ppeçac?] ossabari eta çuey, eta ni guelditcen nais [ç]uen / aita ona. Piarres D'Etcheverry.
\end{abstract}

\section{B bertsioa}

$<23.1$ r $>118$

La presente lettre soit rendue à Joannes d'Etcheverry, fils du nommé Mothela. A Louisbourg.

$<23.2$ r > Saran egina, martxoaren 15, 1757.

Ene seme maitea,

Eskribatzen darotzut letra hau presenteko komoditate huntaz baliatzeagatik, zuei nere amaren eta anaiaren osasunaren berri onak emaiteagatik. Desiratzen ginduke zuek ere hor osasuna perfet bat bazindute. Goan den urthean zuek egorriak errezibitu ginituen, bai eta [...] bi urthe ere Maitearekin hirur sei liberako. Bizkitartean Maitea etzen segur ea hirur ala laur eman ziniotzan; hurrenekoan letran ongi marka zazu. Aurthen, gerla dela kausa, ez darotzuegu deus ere egortzen; nihork ere ez daroku deus ere hartu nahi. Amak milla goraintzi osaba gorrari, eta zuekin batean hunat lehenbailehen pasa dadila. Kattalin bere emazteak ere othoitz hori bera egiten dio. Agoretara xanjatu gara. Zure ahaide eta adiskide guziek milla goraintzi; eta partikularki Monsieur Haranchipy aphezak osabari eta zuei, eta ni gelditzen naiz zuen aita ona.

Piarres d'Etcheverry.

2r:18 appeçac : aieruzko osaketa. Lehen eta azken hizkiak kasik ongi ikusten dira. Monsieur Haranchipy Saran izkribatu beste gutun batzuetan ageri da $(7,25)$, eta oso egiantzekoa da bertako apez izatea. 
Data: $1757 / 3 / 15$

Non idatzia: Senpere

Igorlea: Betri d'Etcheberry

Hartzailea: Joannes Etcheberri

Lotura: aita-semeak

Helmuga: Louisbourg

\section{A bertsioa}

\section{$<24.2 v>46$}

La presente soit rendüe / a joannes hxxx etçheberri / çhanpartier et menusier / A Louis bourg

<24.1r> Á St pée le 15 mars 1757

/ Ene semea

/ Ohore dugu curi presenteco hunen jgortceas / Ceinetan hirur garren aldia baitugu hau /5 Bainan adituac gare errencurac eguin / tutçula, estuçulla gure berriric batere / jaquiten, gure ustes esta bada gure falta / çuc es errecibitcea hirur garren aldia denas / gueros hau, bada egundaino beçain $\mathrm{u}^{\mathrm{n}}$ gui $/{ }^{10}$ desiratcen guinduque gure famillaco berriac / jaquin bacintça osasuna dugu presentean / familla guciac jaincoari esquerrac bainan / aitaso eritasun luce baten ondoan jaincoac / mundu huntaric erretiratu darocu eta hainits / behartu gare harequin eta badaquiçu lehen $/{ }^{15}$ ere aphur bat gora behera gure etçheco / miseriaren berria

$<24$. lv $>$ aditu dugu nola etçaren oraino plaçatua / eta desiratcen guinduque niholare posible bada / plaça bacinteci asqueneco letran gure ustes / ungui gomendatu çaitugu Çure famillari eta $/ 5$ Çuc ere Çure eguin ahal gucia eguiçu, ene semea / errecibitu dugu predoeneco semearequin jgorri / hirur liberacoa eta orai egorceco desiraric / hartcen baduçu ungui seguraturic jgoraçu / ecen badaquiçu cer jrrisquden orai, esta deus ere $/{ }^{10}$ berriric hemen Curi marquatceco guerla eta / miseria baicen desiratcen darotçugu osasun / on bat guc presentean dugun beçala baldin / conbeni baçaio jaincoari haren gloriarençat / eta Çure eta gure arimaren salbamenduarençat $/{ }^{15}$ Cure serbitçari Ni aita Bihots samurtasunes / bethea

\section{B bertsioa}

\section{$<24.2 v>46$}

La presente soit rendue a Joannes Etcheberri, chanpartier et menusier. A Louisbourg.

<24.1r> À St. Pée, le 15 mars 1757.

Ene semea,

Ohore dugu zuri presenteko hunen igortzeaz, zeinetan hirurgarren aldia baitugu hau. Bainan adituak gare errenkurak egin tutzula, eztuzula gure berririk batere jakiten. Gure ustez ezta, bada, gure falta zuk ez errezibitzea, hirurgarren aldia denaz geroz hau. Bada, egundaino bezain ungi desiratzen ginduke gure famillako berriak jakin bazintza. Osasuna dugu presentean familla guziak Jainkoari eskerrak, bainan aitaso eritasun luze baten ondoan Jainkoak mundu huntarik erretiratu daroku eta hainitz behartu gare harekin; eta badakizu lehen ere aphur bat gorabehera gure etxeko miseriaren berria.

$<24.1 v>$ Aditu dugu nola etzaren oraino plazatua, eta desiratzen ginduke niholare, posible bada, plaza bazintezi. Azkeneko letran, gure ustez, ungi gomendatu zaitugu zure famillari, eta zuk ere zure eginahal guzia egizu, ene semea. Errezibitu dugu Predoeneko semearekin igorri hirur liberakoa, eta orai egortzeko desirarik hartzen baduzu ungi seguraturik igorrazu, ezen badakizu zer irrisku den orai. Ezta deus ere berririk hemen zuri markatzezo, gerla eta miseria baizen. Desiratzen darotzugu osasun on bat, guk presentean dugun bezala, baldin konbeni bazaio Jainkoari, haren gloriarentzat eta zure eta gure arimaren salbamenduarentzat. Zure zerbitzari, ni, 
eta ama orobat / Besarcatcen çaituellaric bere bihots gucias / haurride guciec eta bai ahaide eta adisquide / guciec Betri d'etçheberry 20 cure anaia goan da donibanerat oficioaren jkhasterat $<24.2$ r $>$ aditcea badugu nola egorri Cintuben hogoi eta / hemerezi libera bainan guc estugu deus ere hetas / funsic eta Cerrorec eguiçu Cerbait funs aita bihotz samurtasunez bethea, eta ama orobat, besarkatzen zaituelarik bere bihotz guziaz haurride guziek eta bai ahaide eta adiskide guziek. Betri d'Etçheberry. Zure anaia goan da Donibanerat ofizioaren ikhasterat. <24.2r> Aditzea badugu nola egorri zintuben hemeretzi libera, bainan guk eztugu deus ere hetaz funtsik, eta zerrorek egizu zerbait funts. 
Data: 1757/3/15

Non idatzia: Sara

Igorlea: Martin d'Etchart Saindua

Hartzailea: Joannes d'Etcheverry

Lotura: osaba-ilobak

Helmuga: Niganiche

\author{
A bertsioa \\ $<25.1$ r $>66$ \\ La Presente / Lettre soit rendüe à joannes / \\ D'Etcheverry, neveu de / martin saindua / a \\ niganisch.
}

$<25.2$ r $>$ Saran Eguina marçhoaren 15. ${ }^{\text {an }} 1757$.

/ Ene jloba maitea

/ Escribatçen darotçut lettra hau çuri ene eta gure / familia guçiaren ossassunaren berri onac gastigatçea $/^{5}$ gatic, dessiratçen nuque çuc ere hor ossassuna / on bat baçindu; gure ere jaincoari esquer salboric / eta fichoric arribatu guinen; behinçat goardia / emoçu denboran lettra çhanjaric egorçera heldu / baçara, ea noren ganat, eta nortas tiratuac $/{ }^{10}$ eguinen tutçun; aurthen gou hemen chagrinatuac / gabilça nihorc ez sinatu nahis; oray bada Esperança / eman darocute pagatuac içanen garela. Eztarotçugu / deus egorçen guerla dela caussa, harçaçu paçientia / eta horco berriac gastiga datçu lehenbicico comoditatean, $/{ }^{15}$ gorainci gure gende guciec, eta particularrean çure / arreba Estebenic; Bai eta monsieur haranchipic eta / bere familiac; guelditçen nais çure ossaba ona / Martin D'Etchart.

$<25.2 \mathrm{v}>$ monsieur haranchipic othoisten çaitu erraiteas / samatchico semeari eztuela horren letraric batere / içan, lettra chanja bat içan duela horren partes, / bainan ezdela oraino pagatua, harçen baitu $/ 5$ ungui goardatuco tuela, harceco esperanca oray / baduela, ezdaquiela cer guethatuco den. monsieur / Beauvassin arracholacoac oray esperanca emaiten / duela. gauça bera erranen dioçu martin canderatzi / çhotilen semeari ezduela monsieur haranchipic ${ }^{10}$ errecibitu oraino diruric oray esparançan dagoela.

\section{B bertsioa}

$<25.1$ r $>66$

La presente lettre soit rendue à Joannes d'Etcheverry, neveu de Martin Saindua. A Niganisch.

$<25.2$ r $>$ Saran egina, martxoaren $15^{\text {an }} 1757$.

Ene iloba maitea,

Eskribatzen darotzut letra hau zuri ene eta gure familia guziaren osasunaren berri onak gaztigatzeagatik. Desiratzen nuke zuk ere hor osasuna on bat bazindu. Gu ere, Jainkoari esker, salborik eta fixorik arribatu ginen, behintzat. Goardia emozu denboran letra xanjarik egortzera heldu bazara, ea norenganat, eta nortaz tiratuak eginen tutzun. Aurthen gu hemen xagrinatuak gabiltza nihork ez sinatu nahiz; orai bada esperantza eman darokute pagatuak izanen garela. Eztarotzugu deus egortzen gerla dela kausa; hartzazu pazientzia, eta horko berriak gaztigadatzu lehenbiziko komoditatean. Goraintzi gure jende guziek, eta partikularrean zure arreba Estebenik, bai eta Monsieur Haranchipik eta bere familiak. Gelditzen naiz zure osaba ona, Martin d'Etchart.

$<25.2 v>$ Monsieur Haranchipik othoizten zaitu erraiteaz Samatxiko semeari eztuela horren letrarik batere izan, letra xanja bat izan duela horren partez, bainan ez dela oraino pagatua, hartzen baitu ungi goardatuko tuela, hartzeko esperantza orai baduela, ez dakiela zer gerthatuko den, Monsieur Beauvassin Arraxolakoak orai esperantza emaiten duela. Gauza bera erranen diozu Martin Canderatzi, Xotilen semeari, ez duela Monsieur Haranchipik errezibitu oraino dirurik, orai esparantzan dagoela.

2v:6 guethatuco : horrela. 
Data: $1757 / 3 / 15$

Non idatzia: Baiona

Igorlea: Cathalin Marie Berrogain

Hartzailea: Catherine Laborde, veuve de Jelos

Lotura: adiskideak

Helmuga: Louisbourg

\section{A bertsioa}

$<26.1$ r $>128$

A mademoiselle / mademoiselle catherine / laborde veuve de jellos / a louis bourc

$<26.2$ r $>$ abayonne 15 avril dije mars 1757

/ cathalina eta / ene adiscidea desiratcen dut presentecoac / causi çaitçan osasuna perfet batean $/^{5}$ çure familla guçiarecin, enea esta ona / aspaldico demboran: çhagriñac eta / persequçioneac içatu tut famillarecin / non hauçitan hari bainais: egiada / presentean aphur bat osasuna piçhca / ${ }^{10}$ bat. badudala suqhar langitac qitatu / nau. ene edaria da tiçana: arno batere / gabe. bors illabete huntan; alaba / gastia esconduda giçon prestubatecin / çerbaites fagoratçen nau. baita ene $/{ }^{15}$ seme caharrenac ere, jencoac içan / deçala nitas pietate, badaciçu hemen / ascen içatu çiñean fornitu içan nosci / qitçula boticatic escatu çiñoscidanac / contuan tut, luçe liteqe çhehetasuna $/ 20$ esplicatçea. liburuan diren arren, baita / arançaçura guan çiñean içan çintuen / sosac; hala munta dute: guciec: berrogoi / libera eta hamairu sos. badu çembait / dembora escribatu notçula. estut çure ${ }^{25}$ errepustaric içatu, etçaçula pensa / lehenagoco contua; hemen ematen dudala / eçen jacube agerretaren ecutic içatu / nituen. baita çure letra ere, ene adiscide / erraten dotçut egias çorrac egintuteta ${ }^{30}$ bihar handitan nais. estimatuco dut / prestatçen baçiñot beçala, es bada othoi / falta, eçagutu duçu ene bihoxa çure / ocasionetan. hala oroit çaite ene bihar / handias. jencoa laudatçen dut eta othoisten ${ }^{35}$ esnaçan arren abandona munduan biçi / gareiño asco icus deçaqegu. cembat icusi dut. guti iguriqiric / axegiñago

\section{B bertsioa}

$<26.1 \mathrm{r}>128$

A Mademoiselle Mademoiselle Catherine Laborde, veuve de Jellos. A Louisbourc.

$<26.2$ r > A Bayonne, 15 avril, dis-je mars 1757

Cathalina eta ene adiskidea, desiratzen dut presentekoak kausi zaitzan osasuna perfet batean zure familla guziarekin. Enea ezta ona aspaldiko denboran: xagriñak eta persekuzioneak izatu tut famillarekin, non hauzitan hari bainaiz. Egia da presentean aphur bat osasuna pixka bat badudala: sukhar lanjitak kitatu nau. Ene edaria da tizana, arno batere gabe. Bortz illabete huntan alaba gaztia ezkondu da gizon prestu batekin. Zerbaitez fagoratzen nau, baita ene seme zaharrenak ere; Jenkoak izan dezala nitaz pietate. Badakizu hemen azken izatu ziñean fornitu izan nozkitzula botikatik eskatu ziñozkidanak. Kontuan tut, luze liteke xehetasuna esplikatzea, liburuan diren arren. Baita Aranzazura guan ziñean izan zintuen sosak; hala munta dute: guziek berrogoi libera eta hamairu sos. Badu zenbait denbora eskribatu notzula; eztut zure errepustarik izatu. Etzazula pentsa lehenagoko kontua hemen ematen dudala, ezen Jakube Agerretaren eskutik izatu nituen, baita zure letra ere. Ene adiskide, erraten dotzut egiaz: zorrak egin tut eta bihar handitan naiz. Estimatuko dut prestatzen baziñot bezala, ez bada othoi falta. Ezagutu duzu ene bihotza zure okasionetan; hala oroit zaite ene bihar handiaz. Jenkoa laudatzen dut eta othoizten ez nazan arren abandona. Munduan bizi gareiño asko ikus dezakegu; zenbat ikusi dut guti igurikirik. Atsegiñago egiñen dotazu 
egiñen dotaçu diruba egorçea. eçen: bacalluba / jencoari. gomenda naçaçu ene othoixian etçare ahançia;

$<26.2 \mathrm{v}>$ letrapresentecoa ematen dotçuna, deitçenda / monsieur martin larmet capitaiña, egor datçu / horrecin othoisten çaitut: esparança hortan / gelditçen nais çure çervitçary afligitua $/ 5$ ene adiscide cathalin marie berrogain / veuve Detçheto, salutatçendut çure familla diruba egortzea ezen bakalluba. Jenkoari gomenda nazazu, ene othoitzian etzare ahantzia.

$<26.2 \mathrm{v}>$ Letra presentekoa ematen dotzuna deitzen da Monsieur Martin Larmet kapitaiña. Egordatzu horrekin, othoizten zaitut esparantza hortan. Gelditzen naiz zure zerbitzari aflijitua, ene adiskide. Cathalin Marie Berrogain, veuve d'Etçheto. Salutatzen dut zure familla.

2r:27 ecutic : menturaz escutic irakurri behar da; ala ecutic 'dirutik' ote? 
Data: 1757/3/16

Non idatzia: Azkaine

Igorlea: Marittipo de Subiet

Hartzailea: Laurens Perusqui

Lotura: senar-emazteak

Helmuga: Louisbourg

A bertsioa

$<27.1 r>4$

A Monsieur / Monsieur Laurens Perusqui, /

Marinier, / A Louisbourc

$<27.2$ r $>$ Laurenz

/ Asco denbraz egon gara zure letraren esparanzan / bainan batere ezdugu izatu; zure orde cenbait / saratarrec ceinec ikussi baitzaituzte errandaucute $\bar{\rho}$ ossaassun on bat cinduela, baetare cerbait irabaci / duzula. Guc gure berriac gaztigatcen ganaizkquitzuun / Gabriel Lecunberricoarequin eta guero Ciburu Pattineneco / semearequin, bainan biac elga anglessez hartuac / izandira, eta Lecunberricoa han hilda. Belchagno ere / ${ }^{10}$ oraino Anglaterran da. Zure semea eta alaba aguitz / ungui dira, biec mila gorainci egortzen dautzute, baetare / bere anayari ere, bertce garaitico zure ahaide guciac ere / ungui dire; Naussianeco appheza hilda orai duela sei edo / zazpi ilhabete. Hassi naiz zure zorren pagatcen eta $/ 15$ zure ontassuna asqui estatu onean da. Hemen ezda / Guerla hotsic baicin, baitugu herrico soldadoac / Bayonan, eta marinelac cortsuan dabilza eta / cerbait eguiten dute, eta bertce cenbait erregueren / cerbitzuan dire. $\mathrm{M}^{\mathrm{r}}$ Bidartec gorainci zuri eta $/{ }^{20}$ Martin chumeari. Jaincoac dizula ossaassun on bat / eta fortuna eguiteco Gracia; zure cerbitzari.

/ Marittipo de Subiet.

/ aascain le 16 mars 1757.

/ tournés s'il vous plait.

$<27.2 v>$ zuc egorri tercioa hutza errecibitu dut, ceren / urina uncian issuri cen; pastillaco macaillauac / erremetitu daitazte, bainan zure harbi pastea / ez daut oraino eman Sansonec, eta manta ere $f^{5}$ ez da oraino eguin.

\section{B bertsioa}

$<27.1 \mathrm{r}>4$

A Monsieur Monsieur Laurens Perusqui, marinier a Louisbourc

$<27.2$ r $>$ Laurenz,

Asko denbraz egon gara zure letraren esparantzan, bainan bat ere ez dugu izatu. Zure orde, zenbait saratarrek, zeinek ikusi baitzaituzte, erran daukute osasun on bat zinduela, baetare zerbait irabazi duzula. Guk gure berriak gaztigatzen ganaizkitzun Gabriel Lekunberrikoarekin, eta gero Ziburu Pattineneko semearekin, bainan biak elga anglesez hartuak izan dira, eta Lekunberrikoa han hil da. Beltxaño ere oraino Anglaterran da Zure semea eta alaba agitz ungi dira. Biek mila goraintzi egortzen dautzute, baetare bere anaiari ere, bertze garaitiko zure ahaide guziak ere ungi dire. Nausianeko apheza hil da orai duela sei edo zazpi ilhabete. Hasi naiz zure zorren pagatzen, eta zure ontasuna aski estatu onean da. Hemen ez da gerla hotsik baizin: baitugu herriko soldadoak Baionan, eta marinelak kortsuan dabiltza eta zerbait egiten dute, eta bertze zenbait Erregeren zerbitzuan dire. $\mathrm{M}^{\mathrm{r}}$ Bidartek goraintzi zuri eta Martin xumeari. Jainkoak dizula osasun on bat eta fortuna egiteko grazia.

Zure zerbitzari, Marittipo de Subiet. A Ascain, le 16 mars 1757.

Tournés, s'il vous plait.

$<27.2 v>$ Zuk egorri tertzioa hutza errezibitu dut, zeren urina untzian isuri zen. Pastillako makaillauak erremetitu daitazte, bainan zure harbi pastea ez daut oraino eman Sansonek, eta manta ere ez da oraino egin.

2r:24 tournés s'il vous plait : orriaren beste aldera pasatzeko kortesiazko gaztigua da, frantses tradizioan TSVP akronimoan ager daitekeena. 


\section{8}

Data: $1757 / 3 / 16$

Non idatzia: Ziburu

Igorlea: Cathalina Ithurriague

Hartzailea: Gabriel Ithurriague, marinier de Sare

Lotura: anai-arrebak

Helmuga: Louisbourg

\author{
A bertsioa \\ $<28.1 \mathrm{r}>57$ \\ A Monsieur / Monsieur Gabriel ithurriague / \\ marinier dulieu deSare / à Louisbourg. \\ $<28.2$ r $>$ Cibourun marchoaren $16^{\text {an }} .1757$ \\ / Ene anaya maitea \\ / Escribatcen dausquitçut presenteco bi lerro \\ hauc çuri ene / ossassunaren marcatceco \\ ceiña haguitz baita perfeta $/ 5$ Jaincoari esquer, \\ desiratcen nuque ene bihotz guciaz çurea \\ / hala balitz halaber ossaba franchiscuc eta \\ matanta / Cathalinec ossasuna dute, çure \\ aitac eta ama maiteec ere / erranen dautçut \\ haguitz direla offensatuac goanden / urthean \\ es escribatceaz, Escribatcen dautçute, Egorcen \\ $/{ }^{10}$ dausquitçut ene partes Cibouruco martin \\ filissen semearequin / attorra churi bat, \\ galcerdi firlango pare bat eta çapata / handi \\ pare bat guciac berriac, hala othoizten çaitut / \\ haurten etcherat erretira çaitecen hori da çure \\ bourassoen / desira gucia, gure berce ahaide \\ eta adisquideguciec / $/{ }^{15}$ ossassuna dute, estut \\ deus ere çuri marcatceco baicic / naicela çure \\ icusteco desira handian / Ene anaya maitea / \\ Çure arreba fidela \\ / Cathalina ithurriague
}

\section{B bertsioa}

$<28.1$ r $>57$

A Monsieur Monsieur Gabriel Ithurriague, marinier du lieu de Sare, à Louisbourg.

<28.2r> Ziburun, martxoaren 16an, 1757.

Ene anaia maitea,

Eskribatzen dauzquitzut presenteko bi lerro hauk zuri ene osasunaren markatzeko, zeiña hagitz baita perfeta Jainkoari esker. Desiratzen nuke ene bihotz guziaz zurea hala balitz. Halaber, osaba Franchiskuk eta matanta Cathalinek osasuna dute; zure aitak eta ama maiteek ere. Erranen dautzut hagitz direla ofentsatuak goan den urthean ez eskribatzeaz; eskribatzen dautzute. Egortzen dauzkitzut ene partez Ziburuko Martin Filisen semearekin athorra xuri bat, galtzerdi firlango pare bat eta zapata handi pare bat, guziak berriak. Hala, othoizten zaitut haurten etxerat erretira zaitezen, hori da zure burasoen desira guzia. Gure bertze ahaide eta adiskide guziek osasuna dute. Eztut deus ere zuri markatzeko, baizik naizela zure ikusteko desira handian, ene anaia maitea. Zure arreba fidela,

Cathalina Ithurriague. 
Data: 1757/3/16

Non idatzia: Ziburu

Igorlea: Pierre d'Etchevers

Hartzailea: Pierre Detchevers

Lotura: anaiak

Helmuga: Louisbourg

\author{
A bertsioa \\ $<29$. 1 r $>64$ \\ A Monsieur / Monsieur Pierre detchevers / \\ $\mathrm{M}^{\text {tre }}$ charpantie de navire / A Lisbourque
}

$<29.2$ r $>$ Fait a Siboure le 16 mars 1757

/ Ene anaya maitea harcen dut libertate Çury / by leroren Escribatçeco Eta denbora berean / gure osasunaren beria gastiatceco osasuna $/ 5$ dugu famila Çureac Eta Eneac Ceinac baitire / Çure Eta Ene aita Eta ama Eta areba / ganeracoan Ene familan Ere osasuna dugu / gustiec Eta Jaincoac Eman daucu fruitu bat / bainan satifationecoa jcatecotx semebat $/{ }^{10}$ galdeguiten nuben bainan aguery de Etcela / Conbeny alababat Eman dautçu Jaincoac / bainan hura asquy perfesiyonatuba / Causitcen Caicu Jaincoary Esquerac / anaya Ercibitu ditut by letra oray $/{ }^{15}$ bat Eta lehenago berçe bat Ceinac / axeguin eguin baitçaucun Çure berien / aditçeaq osasunaren partetic Eta uste / nuben asqueneco letra beraren plaçan / Çerory jchusico Cintudala hemen $/ 20$ bainan aguery da Etçela Conbeny

$<29.2 v>$ hanitx dire trabailu handiac francian / vncy Eguiten particularquy bayonan / Eta donibanen Ere bay Ecen donbanen / Eguin ditut nic neronec Corsuçaleac $/ 5$ nere planarecin bat bayonaco Eta / berçeric hirur Edo lau asquy uncy galantac / Eregueren Constricturaren planaren ganean / Eta oray Ere baditut hirur Chume / chantierean hasiac Eta handibat badut $/{ }^{10}$ hasibehara Ene Contuco Eguiteco Ceinac / 18 peça muntatuco baicitu / anaya desiratu Jcatu dut hanitxetan / Çuben byen hemen Jçatea Çeren / Çerbaiten Jrabasteco

\section{B bertsioa}

$<29.1 \mathrm{r}>64$

A Monsieur Monsieur Pierre d'Etchevers, maitre charpantie de navire a Lisbourque.

$<29.2$ r> Fait a Ciboure le 16 mars 1757.

Ene anaia maitea, hartzen dut libertate zuri bi lerroren eskribatzeko, eta denbora berean gure osasunaren berria gaztiatzeko. Osasuna dugu famila zureak eta eneak, zeinak baitire zure eta ene aita eta ama eta arreba. Ganerakoan, ene familan ere osasuna dugu guztiek. Eta Jainkoak eman dauku fruitu bat, bainan satifationekoa izatekotz seme bat galdegiten nuben, bainan ageri de etzela konbeni: alaba bat eman dautzu Jainkoak, bainan hura aski perfezijonatuba kausitzen zaiku Jainkoari eskerrak. Anaia, erzibitu ditut bi letra: orai bat eta lehenago bertze bat, zeinak atsegin egin baitzaukun zure berrien aditzeak osasunaren partetik. Eta uste nuben azkeneko letra beraren plazan zerori ikhusiko zintudala hemen, bainan ageri da etzela konbeni.

$<29.2$ v $>$ Hanitz dire trabailu handiak Frantzian, untzi egiten, partikularki Baionan, eta Donibanen ere bai, ezen Donibanen egin ditut nik neronek korsuzaleak nere planarekin, bat Baionako eta bertzerik hirur edo lau aski untzi galantak, Erregeren konstrikturaren planaren ganean. Eta orai ere baditut hirur xume xantierean hasiak, eta handi bat badut hasi beharra ene kontuko egiteko, zeinak 18 peza muntatuko baikitu. Anaia, desiratu izatu dut hanitzetan zuben bien hemen izatea, zeren zerbaiten irabazteko 
bide onac baitire $/{ }^{15}$ Eta Esparanca dut Estucula horco / amodioric Jçaren guehiago Eta / Eretiratuco Çarela ahalic lasterena / Çure familarat ganeracoan Estautcut / berceric gomendatcen Çure Jaincoary ${ }^{20}$ Jaraiquitcea baicic Eta harc / lagunduco Çaitu

$<29.3 r>$ anaya Egorcen dautcute aitac Eta / amac picunen semiarequin Çerbait / aldateco galca maripolisa athora mara / galcerdy Eta Çapata Eta Ene partes Emanen $/ 5$ dautçu martin filisen semeac Cintal / Erdico baril bat nafar Eta tulicunec / emaanen dausquitcu baril Çhume bat / agorient Eta urdajaspibat Ene Esposaren / partes Eta estucu gutci plenytu behar $/{ }^{10}$ Ceren Cerory hanat galdeguiten baitcaitugu / Eta hala Eregusituco duçu Eretiratcea / Çure familarat Eta haynitx axeguin / Eguinen duçu horen Eguitea / ganeracoan salutatcen Çaitut aitas $/ 15$ amas arebas Eta Çure ahaide gusties / Eta Ene Emasteac hanitx desira handia / du Çure Jchusteco ganeracoan guelditcen / nais Çure Cerbitcary bihotx ones / Çure anaya pierre Detchevers $/ 20$ tulicunequin Erecebituco ducu berce / letra bat Enea Eta hartan / Escribatuco dauquitcut berce / Chehetasunac bide onak baitire. Eta esparantza dut eztuzula horko amodiorik izaren gehiago, eta erretiratuko zarela ahalik lasterrena zure familarat. Ganerakoan eztautzut bertzerik gomendatzen, zure Jainkoari jarraikitzea baizik, eta hark lagunduko zaitu.

$<29.3 r>$ Anaia, egortzen dautzute aitak eta amak Picunen semiarekin zerbait aldatzeko: galtza, maripolisa, athorra, marra, galtzerdi eta zapata. Eta ene partez emanen dautzu Martin Filisen semeak kintal erdiko barril bat nafar, eta Tulikunek emanen dauzkitzu barril xume bat agorient eta urdaiazpi bat, ene esposaren partez. Eta eztuzu guzti plenitu behar, zeren zerori honat galdegiten baitzaitugu, eta hala erregusituko duzu erretiratzea zure familarat, eta hainitz atsegin eginen duzu horren egitea. Ganerakoan, salutatzen zaitut aitaz, amaz, arrebaz eta zure ahaide gustiez. Eta ene emazteak hanitz desira handia du zure ikhusteko. Ganerakoan, gelditzen naiz zure zerbitzari. Bihotz onez, zure anaia Pierre d'Etchevers. Tulikunekin errezebituko duzu bertze letra bat enea, eta hartan eskribatuko dauzkitzut bertze xehetasunak.

2r:11 dautçu : daucu espero dugu; bestenaz dautzu forma inplikatibo edo besarkatzaile gisa interpreta liteke. 2 v:3 donbanen : horrela. 2 v: 11 baicitu : baikitu irakurri behar da, eta baititu ulertu; cf. baiqitu (15, 2v). 3r:3 aldateco : irakur aldatceco. 3r:9 gutci : posible da gutci, zentzurik ez duena, zein gucti 'guztiz' irakurtzea; bigarrena hobesten dugu. 3v:10 hanat : irakur honat. 3v:22 dauquitcut : horrela. 
Data: $1757 / 3 / 16$

Non idatzia: Senpere

Igorlea: Martin Larralde, sieur de Bastidaguerre

Hartzailea: $M^{r}$ Saint Martin de Duronia Mirande

Lotura: osaba-ilobak

Helmuga: Louisbourg

\section{A bertsioa}

$<30.1$ r $>68$

A Monsieur / Monsieur St martin de / Duronia mirande, Maitre / Capitaine de navires de / a Louisbourct

$<30.1 v>$ Ene jloba jauna

/ plaçer handirequin aditu ditut Çure / fortunaren berri onac, nahis Esconçaren / partetic, eta Corsuco partetic, feliçitaçen /5 Çaitut guçies, Çeren on desiratçen bait- / tarotçut neure bihots guçias; eta / Erranen darotçut Çure ontassuna guibe- / lat haridella, Çure ama andrea gai / jçan gabes; eta asqueneco sasoina $/{ }^{10}$ galdu du, harrias porrocaturic, horti- / c jujatuco duçu, Çure ahalas lagundu / Behar duçulla Çure ama andrea; / Baldin nahi Baduçu Çure ontasun ${ }^{\mathrm{a}}$ / Conserbatua jçan dadin, jauna ene / 15 Jloba. Çure Çerbitçari nais neure / Bihots guçias. / Martin Larralde / Sieur de Bastidaguerre

/ à St pe / le 16 de mars 1757
B bertsioa

$<30.1$ r $>68$

A Monsieur Monsieur Saint Martin de Duronia Mirande, maitre capitaine de navires de. A Louisbourct.

$<30.1 v>$ Ene iloba jauna,

Plazer handirekin aditu ditut zure fortunaren berri onak, nahiz ezkontzaren partetik, eta korsuko partetik. Felizitatzen zaitut guziez, zeren on desiratzen baitarotzut neure bihotz guziaz. Eta erranen darotzut zure ontasuna gibelat hari dela, zure ama andrea gai izan gabez. Eta azkeneko sasoina galdu du, harriaz porrokaturik. Hortik jujatuko duzu zure ahalaz lagundu behar duzula zure ama andrea, baldin nahi baduzu zure ontasuna konserbatua izan dadin, jauna ene iloba. Zure zerbitzari naiz neure bihotz guziaz. Martin Larralde, Sieur de Bastidaguerre.

À St. Pée, le 16 e de mars 1757. 


\section{1}

Data: $1757 / 3 / 17$

Non idatzia: Bidart

Igorlea: Katalin Duat [Oyer Diratçabal idazlari]

Hartzailea: Pierre Latiga

Lotura: senar-emazteak

Helmuga: Louisbourg

\section{A bertsioa}

$<31.1$ r $>$ [160.11]

Lapresent Letre soit / Rendue apierre Latiga / de Louis bourc / a Louis Bourc

\section{$<31.2$ r> Bydarten eguina Mars 171757}

/ Ene esposmaitea estu faltatu nahiican / Lehen bicico ocasionehuntan Curi ene eta / ene famillaren beriac gastiatu gabe $/^{5}$ ama jaincoac ereman daut eta aita hartan / Candelas Ceinatuba dut bertce familla / gucia Vngui gare presentean desiratcennuque / halabacine Cuc egori letra gainda eta belanais $(\dagger) /$ eta bi letra erecebitutut behar orduban $/{ }^{10}$ eguin dautcut anitz Letra eta Cuc esbatere / erecebitu esta ene falta hanitz penadut / Cuc prometatu Mecac emandut eta orai / hanitz pena dut deusic ecin egoria nihorc / esdaut hartunahi berdin galdubac direla $/{ }^{15}$ berac dohacila salba edo Damna eguitentut / Biltra bentan bat espada bertcea aguiian

$<31.2 \mathrm{v}>$ aribatucodela gelditcennais Cure espos / fidel maite Katalin Duat nic oyerec / eta aitac eta Cusinac Milla ama / cahara Cure jcaba jaincoac hautatudu $/ 5$ piarres estut hemen ematen deus / gehetasunic batere Berdin Letrahauc / aribatcen badire guconec eraredautcute / jaincoac Dicula fin ona Cure ahaide / eta hauco eta adisquide guciec Milla /10 gorainci oyer Dyratcaba

\section{B bertsioa}

$<31.1 r>[160.11]$

La present letre soit rendue a Pierre Latiga, de Louisbourc. A Louisbourc.

<31.2r> Bidarten egina, mars 17, 1757.

Ene espos maitea, eztut faltatu nahi izan lehenbiziko okasione huntan zuri ene eta ene famillaren berriak gaztiatu gabe. Ama Jainkoak ereman daut, eta aita hartan kandelaz zeinatuba dut. Bertze familla guzia ungi gare presentean; desiratzen nuke hala bazine. Zuk egorri letra gain da, eta belanais ( $\dagger$ ). Eta bi letra errezebitu tut behar orduban. Egin dautzut anitz letra eta zuk ez batere errezebitu. Ezta ene falta, hanitz pena dut. Zuk prometatu mezak eman dut, eta orai hanitz pena dut deusik ezin egorria. Nihork ez daut hartu nahi, berdin galdubak direla; berak dohazila salba edo damna. Egiten tut bi letra, bentan bat ezpada bertzea agijan

$<31.2 v>$ arribatuko dela. Gelditzen naiz zure espos fidel maite, Katalin Duat. Nik, Oierek, eta aitak eta kusinak milla goraintzi. Ama zaharra, zure izaba, Jainkoak hautatu du. Piarres, eztut hemen ematen deus xehetasunik batere, berdin letra hauk arribatzen badire gizonek errare dautzute. Jainkoak dizula fin ona. Zure ahaide eta hauzo eta adiskide guziek milla goraintzi. Oier Dyratçabal.

2r:9 belanais : menturaz be(i)la nais 'haiduru naiz', bainan ez da testuinguruarekin ezkontzen. 2r:16 biltra: bi letra irakur bedi. bentan bat : horrela ikusten dugu, baina zentzua 'bietan bat' da. 2v:3 Milla : zerbaiten falta da, seguruenik goraintci. 2v:7 guconec : irakur guiçonec. 2v:10 Dyratcaba : irakur Dyratçabal. 


\section{2}

Data: $1757 / 3 / 19$

Non idatzia: Ziburu

Igorlea: Maria de Saint Martin

Hartzailea: Joanis Diharce, de Charlesenea du lieu d'Ascain

Lotura: ama-semeak

Helmuga: Louisbourg

A bertsioa

$<32.1$ r $>83$

Lapresente serarendue / aJoanis Diharce, fils / de Charlesenea, dulieudascain / marinier apresent / A Louisbourg

$<32.2$ r $>$ sibourele 19 mars 1757.

/ Ene seme Maitea

/ Errecibitu nuben çuc egorri dautaçun Lettra de / Changea, non demboraberean, Dirubac errecibitu $/ 5$ bainituben, milla Esquer Darotçut, Jaincoa / otoistucodut Cure ossasunarençat, aitac etanic / ossasun onbat dugu Jaincoari Esquer, haurideec / ere bay, anaya premua, erregueren servitsuan / da vrte huntan, aditu dugu, Monsieur fagosse $/{ }^{10}$ requin partitcera dohala, Louisbourquera goateco / aguian hor Elkar batuco duçube, Joaniz Eta / putico, Corsurat goanat dire, ahaide eta / etcheco adisquideac, ungui dire, milla gorainci / dautçugu aitac Eta nic, nais Çure ama / ${ }^{15}$ samurra

/ Maria de Saint martin

/ aitac otoisten çaitu / ahalic Lasterrena vnat ethorceas, alabaiñan / sahartuda, bota saharpare bat, Eta athorra bat egorcen $/ 20$ dausquiçut Raimond Eistoquenecoarequin

\section{B bertsioa}

$<32.1 r>83$

La presente sera rendue a Joanis Diharce, fils de Charlesenea, du lieu d'Ascain, marinier a present a Louisbourg.

$<32.2$ r> Ciboure, le 19 mars 1757.

Ene seme maitea,

Errezibitu nuben zuk egorri dautazun letra de xanjea, non denbora berean dirubak errezibitu bainituben. Milla esker darotzut; Jainkoa otoiztuko dut zure osasunarentzat. Aitak eta nik osasun on bat dugu Jainkoari esker, haurridek ere bai. Anaia premua Erregeren zerbitzuan da urte huntan. Aditu dugu Monsieur Fagosserekin partitzera dohala Louisbourquera goateko, agian hor elkar batuko duzube. Joaniz eta putiko korsurat goanat dire. Ahaide eta etxeko adiskideak ungi dire. Milla goraintzi dautzugu aitak eta nik. Naiz zure ama samurra,

Maria de Saint Martin.

Aitak otoizten zaitu ahalik lasterrena unat ethortzeas, alabaiñan zahartu da. Bota zahar pare bat eta athorra bat egortzen dauzkitzut Raimond Eistokenekoarekin. 


\section{3}

Data: $1757 / 3 / 20$

Non idatzia: Getaria

Igorlea: Betry Daguerre

Hartzailea: Martincho Daguerre

Lotura: anaiak

Helmuga: Percibiac (= Paspébiac)

\begin{abstract}
A bertsioa
$<33.1 r>70$

A Monsieur / Monsieur Le fevre Belle fille / Consul de france a Pavo pres / bonnaventure pour La remitte a / Martincho Daguerre marinier $/ 5$ faisant Lapeche de la morue En / terreneuve a / Percibiac a / Pavo
\end{abstract}

$<33.2$ r $>$ fait a guethary le $20 \ldots$ mars 1757 an

/ Enne annaia maitia Escribatcen darosquicut bi Lero hauq Curi neure / ossasunaren beria adicerat Emaitequo ossasunadut jainquoari Escer Ceinetan desira / tcen bainuque Cure hala balis Cure compainiarequin baitean gorainci gastiatcen $/ 5$ darocut hailaber aitaq Eta amaq Eta domindinaq Eta gurehaureq Emastia bedera / ci Jlabetehuntan Eri dut Eritasun serios batequin semebait jcatu dugu hura uni / detan Emanadugu 74 10s pagacen dugula Eran darosquicut heimengo beriaq / Nola Esten untchiriq hourat heldu hautaquo jende gucia Corsurait ganci / niere Corsurait nindoan Lotinent Eta Monsieur Detçheverri ondoquo $/{ }^{10}$ haumalau pecetaquo Corsusale baitean Monsieur harismendirequin parti / cequo prest guinen hemendiq Lau jlabeteren buruquo uste dut jcaren / direla 40 Corsusale Canpoan Eranendarocut Cure Letra sainderi / q nola Esten niondiq Ethorri Es Ethorcequo aparanciariq Ere Eta Estaquigu / nori adreca Cergatiq espaitauqucu jaunharen jceniq gastiatu Etaneure / ${ }^{15}$ jdurian hoube Cinduque Cegoreq jaun hairen atçamatea Eta denbora berian / tresorerait Letra dasainden tirace Luceago jcaniq Ere Lehen ere Escriba / tudarocut Monsieur Daguerrerequin Letrabait hartan barna nola tu- / dan gure

\section{B bertsioa}

$<33.1$ r $>70$

A Monsieur Monsieur Le Fevre Belle Ville, consul de France a Pavo, pres Bonnaventure, pour la remitte a Martincho Daguerre, marinier faisant la peche de la morue en Terreneuve, a Percibiac. A Pavo.

$<33.2$ r> Fait a Guethary le 20 mars 1757an.

Ene anaia maitia, eskribatzen darozkitzut bi lerro hauk zuri neure osasunaren berria aditzerat emaiteko. Osasuna dut Jainkoari esker, zeinetan desiratzen bainuke zure hala balitz zure konpainiarekin batean. Goraintzi gaztiatzen darozut, halaber aitak eta amak eta Dominddinak eta gure haurrek. Emaztia bederatzi ilabete huntan eri dut eritasun serios batekin. Seme bat izatu dugu; hura unidetan emana dugu, 74 libera eta 10 sos pagatzen dugula. Erran darozkitzut hemengo berriak. Nola ezten untzirik hurat heldu, hautako jende guzia korsurat ganki, ni ere korsurat nindoan lotinent, eta Monsieur Detçheverri ondoko hamalau pezetako korsuzale batean; Monsieur Harismendirekin partitzeko prest ginen hemendik lau ilabeteren buruko. Uste dut izaren direla 40 korsuzale kanpoan. Erranen darotzut zure letra sandderik nola ezten niondik ethorri, ez ethortzeko aparantziarik ere, eta eztakigu nori adreza, zergatik ezpaitaukuzu jaun haren izenik gaztiatu. Eta neure idurian hobe zinduke zegorrek jaun haren atzamatea, eta denbora berian tresorerat letra da sandden tiratze luzeago izanik ere. Lehen ere eskribatu darotzut Monsieur Daguerrerekin letra bat, hartan barna nola 
Letra dasaindequo sobra baçubeq Monsieur Felefeilenaq / 142tt 10s justuban gantiquox guri Eguin behar Lauquegu Cerbeites on ${ }^{20}$ Cergatiq asco galdu baitugu guq hourien ondoan berarein gainerat / usten dut niq asco urax Eguin dut Eta othois Eguiten darocut niere / hourietas desquargacequox Çu hourequin antolacias hour Etaniq / heimen Emanen diosqu tet Cure Etchequori suma houri bera nola Ere gastiatcenbaitucu / Eta hala houren beraren Escuquo senalearequin Cegoreq jkusiquo ducu nola $/ 25$ Eguin neure gorainciaq Emaren diosqucu famila guciari Eta jaun sapa / dori eta duqeren famila guciari Eta seinaren semeari Eta denbora / berean Monsieur lefefeili Escribatcen diot Egitequo houras gorainci Castiluri / familaq ossasunadubela hailaber despaldari eta Chanini Eta troubari / Eta neure jlobari Eta pumaderi Eta miselli funsean gucieri piares $\beta^{30}$ piter tiro baiteq Eremandu Corsuban mastrucen bera

$<33.2$ v $>$ curefamilaq ossasuna du jainquoari Escer Cure Esposaq salutacen / caitu hailaber amaguinarebaq Eta Cure haureq Eta katuruq / et Detcheveriq Estut presentean Curi Cer gastia beiciq / gueldicen naicela Cure anaia fidela

\section{${ }^{5}$ Betry Daguerre}

/ ohoui Eguiten darocut niq hordudan harcequoas contu / eguin darotacu sapado tudan gure letra da sanddeko sobra batzubek: Monsieur Felefeilenak 142 libera eta 10 sos justuban gantikotz guri egin behar laukegu zerbeitez on, zergatik asko galdu baitugu guk horien ondoan. Beraren gainerat uzten dut; nik asko urrats egin dut, eta othoitz egiten darotzut ni ere horietaz deskargatzekotz, zu horrekin antolatziaz hor, eta nik hemen emanen diozkatet zure etxekori suma hori bera nola ere gaztiatzen baituzu, eta hala horren beraren eskuko senalearekin zegorrek ikhusiko duzu nola egin. Neure goraintziak emaren diozkazu famila guziari eta jaun Sapadori eta Dukeren famila guziari, eta Seinaren semeari, eta denbora berean Monsieur Lefefeili eskribatzen diot egiteko huraz. Goraintzi Zastiluri, familak osasuna dubela; halaber Despaldari eta Chanini eta Trubari eta neure ilobari eta Pumaderi eta Miselli, funtsean guzieri. Piarres Piter tiro batek ereman du, korsuban mastru zen bera.

$<33.2 v>$ Zure familak osasuna du Jainkoari esker. Zure esposak salutatzen zaitu, halaber amaginarrebak eta zure haurrek eta Katuruk eta Detcheverrik. Eztut presentean zuri zer gaztia, beizik gelditzen naizela zure anaia fidela,

Betry Daguerre.

Othoi egiten darotzut nik hor dudan hartzekoaz kontu egin darotazu Sapado.

Ir Belle Fille: Belle Ville. 2r:4 cure : çurea irakurri behar da. 2r:8 ganci : irakur bedi ganki; cf. joaki. 2r:25 diosqucu : testuinguruak diozkazu eskatzen du. 2r:27 Castiluri : irakur Çastiluri; cf. Sastiluri < Sagastiluri (20, 3v). 2v:6 ohoui : othoi irakurri behar da. 


\section{4}

Data: $1757 / 3 / 21$

Non idatzia: Donibane Lohizune

Igorlea: Tereçha Labadija

Hartzailea: Joanis Dupui

Lotura: ama-semeak

Helmuga: Louisbourg

\section{A bertsioa}

$<34.1$ r $>129$

La present soit rendu / a joanis dupuj mattallot / a louis bourqe

$<34.2$ r $>$ donibanen martçhoaren 2 linan egiñgña 1757

/ Ene seme maitia jscribatçen / dausqitçut bi lero hauc çuri ene eta familla / gusijaren ossasuna marqatçeco ossasuna dugu $/ 5$ jainquari esqer desiratçen nuqe çuria hala / balixs ene bijoxs gusijas badaqisu ene estatuba / çein pobreaden eta ene ahalac çein çumiac / diren ungi mortifiqatuba gelditçen nais / segurqi çuri ene amudijuaren marqa $1^{10}$ egori nahija egortçen dautçudan baingno / nobleqijago egortçen dautçut beras ahal / dagidana ustaritçhen semiareqin qapote bat / eta athora bat çhurija eta çhano bat qopotiac / horadura gorijadu esin hedatu nais gehijago $/ 15$ egortçerat martchoaren 9an eresibitu / dut çuq lehenbisi egin çinduben letra / eta bigarena estut jsatu salutatçen çaitus te $_{\text {çure bi }}$ arebe eta osaba çhopitec eta matanta / gusijec eta gaiñgñeraco ahaide gusijec

$<34.2 v>$ eranen dijosu çure qusiñgña bernat dupujri / amac eta arebac goraintçj ossasun dutela / gaingneraquan gomendatçen dautçut orhoit / çaitesen bethi jainquas eta bisi çaitesen $/ 5$ jainquaren beldurtasunian esen jainquari / daraijonac jainquabain atçematentu bere / contcolasijone gusijac eta jainco handijac / estijotça haquori faltatçen bere grasija eta / benedisijone seindubac jsan çaite beras bethi / ${ }^{10}$ jainquas orhoituba eta gero çure ama / gaçhuac duben dessira çure jqustequas / othoisten çaitut jsan desaçun amarentçat / behar dusun atentçijoni eta amaren sthifatceco

\section{B bertsioa}

$<34.1$ r $>129$

La present soit rendu a Joanis Dupui, mattallot a Louisbourqe.

$<34.2$ r > Donibanen, martxoaren 2 linan egiña, 1757.

Ene seme maitia, iskribatzen dauzkitzut bi lerro hauk zuri ene eta familla guzijaren osasuna markatzeko. Osasuna dugu Jainkuari esker; desiratzen nuke zuria hala balitz ene bijotz guzijaz. Badakizu ene estatuba zein pobrea den eta ene ahalak zein xumiak diren. Ungi mortifikatuba gelditzen naiz segurki, zuri ene amudijuaren marka egorri nahija, egortzen dautzudan baiño noblekijago egortzen dautzut, beraz, ahal dagidana: Uztaritzen semiarekin kapote bat eta athorra bat, xurija, eta txano bat. Kopotiak horradura gorrija du. Ezin hedatu naiz gehijago egortzerat. Martxoaren 9an errezibitu dut zuk lehenbizi egin zinduben letra, eta bigarrena eztut izatu. Salutatzen zaituzte zure bi arrebek eta osaba Xopitek eta matanta guzijek, eta gaiñerako ahaide guzijek.

$<34.2 v>$ Erranen dijozu zure kusiña Bernat Dupuiri amak eta arrebak goraintzi, osasun dutela. Gaiñerakuan, gomendatzen dautzut orhoit zaitezen bethi Jainkuaz eta bizi zaitezen Jainkuaren beldurtasunian, ezen Jainkuari darraijonak Jainkuabain atzematen tu bere kontsolazijone guzijak, eta Jainko handijak eztijotza halakoari faltatzen bere grazija eta benedizijone seindubak. Izan zaite, beraz, bethi Jainkuaz orhoituba, eta gero zure ama gaxuak duben desira zure ikustekuaz. Othoizten zaitut izan dezazun amarentzat behar duzun atentzijonia, eta amaren 
/ duçun borondatia ahal dagiçun besain /15 labursqi çure batistijo seinduba hartu / duçun leqhurat eretiratçeco çure amari / sathifassijone ematerat jainquaren / grasijareqin batian gomendijo huntan usten / çaitut esparantcan sathifasijone emanen $/{ }^{20}$ dautasula / cure çerbitcari gelditçen / nais cure ama tereçha labadija

$<34$. lr> laregi çuben lijhenequori emastiac goraintçi sathifatzeko duzun borondatia ahal dagizun bezain laburzki zure batistijo seinduba hartu duzun lekhurat erretiratzeko zure amari sathifazijone ematerat. Jainkuaren grazijarekin batian, gomendijo huntan uzten zaitut, esparantzan sathifazijone emanen dautazula. Zure zerbitzari gelditzen naiz. Zure ama, Tereçha Labadija.

$<34.1$ r $>$ Larregi zuben lijhenekori $(\dagger)$ emaztiak goraintzi.

2r:18 arebe : irakur arrebec. $2 \mathrm{v}: 8$ haquori : halaquoari proposatzen dugu. $2 \mathrm{v}: 13$ atentçijoni : irakur atentçijonia. sthifatceco : horrela. 


\section{5}

Data: $1757 / 3 / 22$

Non idatzia: Getaria

Igorlea: Catharine Desclaus

Hartzailea: Martin de Heuty, sieur de Mariltchenea

Lotura: ama-semeak

Helmuga: Louisbourg

\section{A bertsioa}

$<35.1 r>63$

Lapresente Lettre soite / Reandeue a Martin de / heuty sieur de mariltçhene / apresente Reste a / Louisbourq de Louisbourq

$<35.2$ r > fait aguethary cé 22 marz 1757

/ Enne seme Maitea Estut faltatunay / jçatu presenteqo oqasione huntan çury By Lero / Esqribatu gabe Eta Cury Ene ossasuna Beria ${ }^{5}$ gastiatu gabe çein ${ }^{e}$ tan Baita ona jainqoary / Esquer desiraxen nuque çureahalla Balix / Çure conpaniarequin Batean Enne seme / Maitea sallutaxen Çaitut Bihox Çamur / Batequin jainqo handiaren partes othois $/{ }^{10}$ othoisten Çaitut Ethor çaquisquiq Etçherat / Estut vrreriq Eta Es çilariq galdexen niq / Çubaiçiq çhutiq nagollariq hiraxen hary / nais $\mathrm{cu}$ jqusinais çu çare Enne Erreçurxagusi ${ }^{\mathrm{a}}$ / othoisten Çaitut Esnaçaçula aqabaras

${ }^{15}$ Estut presentean Çury Çer gastia / Baiçiq naicella Cure Cerbixari Cure / ama orai Eta Bethiere qatarine / desclaus

\section{B bertsioa}

$<35.1$ r $>63$

La presente lettre soite reandeue a Martin de Heuty, sieur de Mariltchenea. A presente reste a Louisbourq, de Louisbourq.

$<35.2$ r> Fait a Guethary ce 22 mars 1757.

Ene seme maitea, eztut faltatu nai izatu presenteko okasione huntan zuri bi lerro eskribatu gabe eta zuri ene osasuna berria gaztiatu gabe, zeinetan baita ona Jainkoari esker. Desiratzen nuke zurea hala balitz zure konpaniarekin batean. Ene seme maitea, salutatzen zaitut bihotz samur batekin. Jainko handiaren partez othoizten zaitut: ethor zakizkik etxerat. Eztut urrerik eta ez zilarrik galdetzen nik, zu baizik xutik nagolarik; hiratzen hari naiz zu ikusi naiz. Zu zare ene errezurtza guzia; othoizten zaitut ez nazazula akabaraz.

Eztut presentean zuri zer gaztia, baizik naizela zure zerbitzari. Zure ama, orai eta bethiere, Qatarine Desclaus. 
Data: $1757 / 3 / 22$

Non idatzia: Azkaine

Igorlea: Gachina St Pée

Hartzailea: Catherine (veuve de) Gelos

Lotura: koinatak

Helmuga: Louisbourg

\author{
A bertsioa \\ $<36 a .1 r>9$ \\ A Mademoisselle mademoisselle / Catherine \\ gelos / Veuve / a Louisbourg / founs de labay \\ $<36 a .2 r>$ Ascainen Eguina marsoaren 22an \\ 1757
}

/ Ene coinata maitea harcendut Libertate sury by / Leroren Escribatçeco osasuna dugula famila gusiac / Eta desiratcen nuce surea osasuna puerfet bat famila $/^{5}$ gustiarecien batean. Cuc hortic Egori presentac Eresibitua / ditut picunecin hamabi Libera Eta michelecin berse / hamabi Libera Eta nic suri Egortcen darotçut Esagutça / chume bat ${ }^{\text {picunecin }}$ urdai aspibat Eta [barratua] 2 harilco jostal hary / eta baratçeco hasiac Eta sansun hiriart sure osabaren $/{ }^{10}$ Bateleco harotcarecin urdai aspi bat Eta bi jostal / hari harilco eta baratceco hasiac amac goraintçi Eta / gure semeac Eta alabac Eta Coinata piarresec Eta / gachinac Eta haren amac Coinata piarres herianda Eta / trabailuban harida bere ofisioan oraino Esta isatu Corsuan $/{ }^{15}$ sure sapata Eguileac ni presatcen nau Eta gastia dasu ser / Eguin ahal desacedan lehenbisico Comoitatean Eta / Egori nahi narotçun serbait guehiago bainan denborac / Causatu baitu oraino guerlaren aparantcia handia da / Baionan Eta donibanen badire hemesorsi Corsucale untçy ${ }^{20}$ istileroan Eta Corsurat goanac guehiago Esta hemen / Berse negosiori Corsua Eta Corsua baisic Eta bisia / garastia oguia asci arasoinda bainan arnoa eta gacia dira / garastia. Estut presentean guehiago suri declaratçeco / Ene Coinata maitea baisic naisela sur serbitcary ${ }^{25}$ Bihotz gustias / gachina Stpe

\section{B bertsioa}

$<36 \mathrm{a} .1 \mathrm{r}>9$

A Mademoisselle Mademoisselle Catherine Gelos, veuve. A Louisbourg, founs de la bay.

$<36 a .2$ r> Azkainen egina, marsoaren 22an, 1757.

Ene koinata maitea, hartzen dut libertate zuri bi lerroren eskribatzeko. Osasuna dugula famila guziak, eta desiratzen nuke zurea osasuna puerfet bat famila guztiarekin batean. Zuk hortik egorri presentak errezibituak ditut: Picunekin hamabi libera, eta Michelekin bertze hamabi libera. Eta nik zuri egortzen darotzut ezagutza xume bat: Picunekin urdaiazpi bat eta 2 harilko jostal hari eta baratzeko hasiak, eta Sansun Hiriart zure osabaren bateleko harotzarekin urdaiazpi bat eta bi jostal hari harilko eta baratzeko hasiak. Amak goraintzi, eta gure semeak eta alabak eta koinata Piarresek, eta Gachinak eta haren amak. Koinata Piarres herrian da eta trabailuban hari da bere ofizioan; oraino ezta izatu korsuan. Zure zapata egileak ni presatzen nau, eta gaztiadazu zer egin ahal dezakedan lehenbiziko komoitatean. Eta egorri nahi narotzun zerbait gehiago, bainan denborak kausatu baitu. Oraino gerlaren aparantzia handia da Baionan, eta Donibanen badire hemezortzi korsuzale untzi istileroan, eta korsurat goanak gehiago; ezta hemen bertze negoziorik korsua eta korsua baizik. Eta bizia garastia: ogia aski arrazoin da, bainan arnoa eta gazia dira garastia. Eztut presentean gehiago zuri deklaratzeko, ene koinata maitea, baizik naizela zure zerbitzari. Bihotz guztiaz,

Gachina St. Pe.

2r:5 Eresibitua : testuinguruak plurala eskatzen du. 2r:24 sur : sure irakur. 


\section{$36 b$}

Data: $1757 / 3 / 22$

Non idatzia: Azkaine

Igorlea: Pierre Etchegaray

Hartzailea: Catherine (veuve de) Gelos

Lotura: koinatak

Helmuga: Louisbourg

\section{B bertsioa}

$<36$ b.2v> Ene koinata maitea, osasuna dut eta desiratzen nuke zurea osasuna puerfet bat izatea famila guztiarekin batean. Herenegun ethorri naiz Baionatik, trabailuan hariturik zure osaba Monsieur Labordaren batelean eta goletan, eta orai Donibanerat noha trabailurat. Semea Baionan dugu eskolan eta osasuna du, eta guk ere osasuna dugu famila guztiak. Salutatzen dut zure ama eta Betriko eta zure aizpa eta apa eta Luisa, eta hor diren ene adiskide guztiak. Eta gelditzen naiz zure zerbitzari. Bihotz onez, zure koinata maitea,

Pierre Etchegaray. 
Data: $1757 / 3 / 22$

Non idatzia: Donibane Lohizune

Igorlea: Gana Haurra de Fumat

Hartzailea: Adrien Salla

Lotura: ama-semeak

Helmuga: Louisbourg

\author{
A bertsioa \\ $<37.1$ r $>99$ \\ La presente letre / soit Rendüe a Monsier / \\ adrien de salla marini / er presentement / A \\ Louisbourq
}

$<37.2$ r $>$ Donibanen marz $22^{\text {an }} 1757$

\begin{abstract}
/ Nere seme maitia
/ presenteco occasionias baliatuba / jsan nadintçat hartudut moment $/ 5$ bat sury by Lerro hauquietan Gure / ossassuna onas partalier eguiteco / deliberacionia desiratcen nuque suria / presentecoan Gauça berian Causi baleça / eranen dautçut nola erecibitu Guin $/{ }^{10}$ duben Letrade Chanjaren diruba / eta deliberacionetan Gare diru hura / berry baten Gagnian emateco, eta / esin ausa sartatu Gare sury deuser[e] / egortçerat sergatic pena handia / 15 dela jdouritçen sait horat sal / boric ethortcia, asa ( $†$ ) sure / serbitcary Guelditcen nais
\end{abstract}

$<37.2$ v $>$ sure ama fidela Ganahau / ra de fumat / Aitac eta familla Guciac / milla Goraintcy dautcu $/ 5$ sure adisquide guciec ere / bay, adrien angueletarandela / adituric milla doloretan gare / jaincoary othoitz eguinendiogu / salboric ossassunan jdouc sait / ${ }^{10}$ çatela

2r:16 asa : horrela; eta espero genezake.

\section{B bertsioa}

$<37.1 r>99$

La presente letre soit rendüe a Monsier Adrien de Salla, marinier presentement a Louisbourq.

$<37.2$ r $>$ Donibanen, marz 22an 1757.

Nere seme maitia,

Presenteko okhasioniaz baliatuba izan nadintzat, hartu dut moment bat zuri bi lerro haukietan gure osasuna onaz partalier egiteko deliberazionia. Desiratzen nuke zuria presentekoan gauza berian kausi baleza.

Erranen dautzut nola errezibitu ginduben letra de xanjaren diruba, eta deliberazionetan gare diru hura berri baten gañian emateko, eta ezin ausartatu gare zuri deusere egortzerat, zergatik pena handia dela iduritzen zait horrat salborik ethortzia, asa $(\dagger)$ zure zerbitzari gelditzen naiz.

$<37.2$ v $>$ Zure ama fidela, Gana Haurra de Fumat. Aitak eta familla guziak milla goraintzi dautzu; zure adiskide guziek ere bai. Adrien Angeletarran dela aditurik, milla doloretan gare; Jainkoari othoitz eginen diogu salborik osasunan iduk zaitzatela. 
Data: $1757 / 3 / 23$

Non idatzia: Getaria

Igorlea: Joana Duhalde

Hartzailea: Janne Castillou

Lotura: senar-emazteak

Helmuga: Louisbourg

\section{A bertsioa}

$<38.1$ r $>20$

A Monsieur / Monsieur / janne qastillou metre / de Grabe pour mosieur / Laborde / a Louis bourq

$<38.2$ r $>$ Getharian Egina marschoaren 23 1757

/ Ene / Espos maitia Estut faltatu nahi jcan presenteqo oqhasione hau / Curi aditcerat Eman gabe ene Estatubaren beria Ceinetan ${ }^{5}$ presentian hanis miserable baiqare ni Eta alaba / goanahaura chumia bainan desiratcen nuque handisqi / Letra huneq Curia disposicione hobian qausitcia sallutatcen / Caitut ene bihotc gucias Eta halaber salutatcen Caituste / Cure haur gucieq Eta partiqularqi alaba Caharenaq $/{ }^{10}$ salutatcen Caituste Eta Cure hauco ahaideadisqide / gucieq mila gorainci hachareneqo jauna partituda / qorsurat masans harismendireqin Egun Erecebitudugu / Cure letra francian gaindi letra sangia barnian baina ${ }^{\mathrm{n}} /$ aurthen Estugu jçatu Cure letrariq batere bia baiciq $/{ }^{15}$ Eta heq letra sanjaq barnian Eta guq Egiten ditugu / qomoditate gucietan letraq marqatcen darotacu / Estucula qanigonequin jçatu Letrariq bainan egin / gintuben Ceinetan aispa nana miaristcen baitugu / nesqato bodrireqin Eta bodriri Eman gindiotcan $/{ }^{20}$ letraq Eta nola Choraqoan presabat egin baitcuten / hartan bodri Ethoricen Eta Eran Caroqun jtsasoan / jtsasorat Etchatu citustela letraq angelesen / beldures Eta oai ere horat particerat doha

$<38.2 v>$ tuliquneqin jçatu ditugu qutcha chumia Eta qartbat / Eta baqalu paqabat Eta muchil informatu dugu / Eja Ceren Esqasa ducun Eta Eran daroqu Estucula / deusen

\section{B bertsioa}

$<38.1$ r $>20$

A Monsieur Monsieur Janne Qastillou, metre de grabe pour mosieur Laborde. A Louisbourq.

$<38.2$ r $>$ Getharian egina, martxoaren 23, 1757.

Ene espos maitia, eztut faltatu nahi izan presenteko okhasione hau zuri aditzerat eman gabe ene estatubaren berria, zeinetan presentian hanitz miserable baikare ni eta alaba Goana Haurra xumia, bainan desiratzen nuke handizki letra hunek zuria disposizione hobian kausitzia. Salutatzen zaitut ene bihotz guziaz, eta halaber salutatzen zaituzte zure haur guziek, eta partikularki alaba zaharrenak; salutatzen zaituzte eta zure auzo, ahaide, adiskide guziek mila goraintzi. Hachareneko jauna partitu da korsurat Masans Harismendirekin. Egun errezebitu dugu zure letra Frantzian gaindi, letra sanjia barnian. Bainan aurthen eztugu izatu zure letrarik batere, bia baizik; eta hek letra sanjak barnian. Eta guk egiten ditugu komoditate guzietan letrak. Markatzen darotazu eztuzula Qanigonekin izatu letrarik, bainan egin gintuben, zeinetan aizpa Nana Miarritzen baitugu neskato Bodrirekin, eta Bodriri eman gindiotzan letrak, eta nola Chorakoan presa bat egin baitzuten, hartan Bodri ethorri zen eta erran zarokun itsasoan itsasorat etxatu zituztela letrak, angelesen beldurrez. Eta oai ere horrat partitzerat doha.

$<38.2$ v $>$ Tuliqunekin izatu ditugu kutxa xumia eta kart bat, eta bakalu paka bat. Eta Muxil informatu dugu eia zeren eskasa duzun, eta erran daroku eztuzula deusen 
Esqasiq jcateqos capata parebat egorceqo ${ }^{5}$ mehiac bainan Egortcen ditugu Curetcat / tuliqunequin baril bat nafar eta capata parebat / Eta Larmeteqin haren hardeareqin athora bat / Eta capata parebat jnqoaq dicula Erecebitceqo gracia / Cure jqusteqo desira handian gare guciaq afligitubaq $/{ }^{10}$ handisqi qanigonen uncian marqatu narotcun / gure seme maitiaren doloria eta migel harismendiq / gastiatu caroqun granbitatiq nola miliq Eman / Ciotcan anaiari Eta belatcen semeari berehun / Eta hirur hogoi libera bainan gure semiaq $/{ }^{15}$ Esomen du Erecebitu batere haren qonpaniatiq / Ethori diren giconeq Eran daroqute Eta hor / hartubaq ditubelaqoan paga Estetcacun / gastiatcen darotcugu gelditcen nais cure / Cerbitcari Cure Espos fidela orai Eta bethi ${ }^{20}$ Cure aldera bihotc ones bethia

/ Joana duhallde eskasik; izatekoz zapata pare bat egortzeko, mehiak. Bainan egortzen ditugu zuretzat Tuliqunekin barril bat nafar eta zapata pare bat, eta Larmetekin, haren hardearekin, athorra bat eta zapata pare bat; Jinkoak dizula errezebitzeko grazia. Zure ikusteko desira handian gare guziak, aflijitubak handizki. Qanigonen untzian markatu narotzun gure seme maitiaren doloria, eta Migel Harismendik gaztiatu zarokun Granbitatik nola Milik eman ziotzan anaiari eta Belatzen semeari berrehun eta hirur hogoi libera, bainan gure semiak ez omen du errezebitu batere. Haren konpaniatik ethorri diren gizonek erran darokute, eta hor hartubak ditubelakoan, paga eztetzazun gaztiatzen darotzugu. Gelditzen naiz zure zerbitzari. Zure espos fidela, orai eta bethi, zure aldera bihotz onez bethia,

Joana Duhalde. 
Data: $1757 / 3 / 23$

Non idatzia: Urruña

Igorlea: Haraneder apeza

Hartzailea: Pierre Echegoyen

Lotura: osaba-ilobak

Helmuga: Louisbourg

A bertsioa

$<39.2 v>112$

La presente soit rendue / a pierre echegoyen demeurant / a louis bourc.

/ A Louisbourc.

$<39$. 1r> Ene hilloba maitea

/ uste nuben aditu dembora gucietan Çutaz / guicon beharden becalaco bat hicaren ciñela. / bizquitartean contrarioa aditçen dut; ainitc ${ }^{5}$ gare doloratuac; Çutazco gaucen aditçiaz / ez dut dudatçen Compania gaistoen effetu batçuec / direla horiec Çorigaitçez hiçan Çarela herri / hortan bainan Cer eguin prentian? errepa / ratçerat enxaiatu behar da iraganaren $/{ }^{10}$ oraino gastea Çare hortaracotc en haur / maitea, moyenic hoberena Çait alde hunta / rat passatçea; ethortcen baçare borondate / on batez betea; enxaiatuco gare Gaucen / erremediatçerat; eta guc hiçaren dugu /15 çure alderaco bihotç eçagutu daucuçuna / ez deçaçula beraz falta ethortcetic çure

$<39.1 \mathrm{v}>$ anaiarequin bertçe alde salvamenduaz / çinçinez pensatu beharda. ez dut uste hor / hambat ongui eguin ahal deitequen; $\mathrm{M} /$ iriberri amaren dioscatçu ene erespetuac. $I^{5}$ eta hiçatu nituela hirur ogoi libera mar / çans çenarenac; bainan aditu nuela / oraino gueiago ere baçela; othoisten dudala / deusic baldin badu egortçeaz çerbait funx / oneco guiconequin; lehen bai lehen. erranden $/ 10$ marçans çenaren humeren alchatceco. egui / tçu gauca Guciac funx onez; horren desira / eta esparantçarequin guelditçen naiz. / considerationerequin / ene hilloba maitea. / ${ }^{15}$ çure cervitçari humilla / eta obedienta. / Haraneder apeça

/ A Urrugne / le 23 mars 1757 po çure amarochi handisqui hicustea desiratçen / caituenac eta gure haurra mariac eguiten daus $<39.2$ r $>$ quitçute bere conplimenduac

\section{B bertsioa}

$<39.2 \mathrm{v}>112$

La presente soit rendue a Pierre Echegoyen, demeurant a Louisbourc.

A Louisbourc.

$<39.1$ r $>$ Ene hilloba maitea,

Uste nuben aditu denbora guzietan zutaz gizon behar den bezalako bat hizaren ziñela. Bizkitartean kontrarioa aditzen dut; ainitz gare doloratuak zutazko gauzen aditziaz. Ez dut dudatzen konpania gaiztoen efetu batzuek direla horiek; zorigaitzez hizan zarela herri hortan. Bainan zer egin presentian? Erreparatzerat entsaiatu behar da iraganaren, oraino gaztea zare. Hortarakotz, ene haur maitea, moienik hoberena zait alde huntarat pasatzea. Ethortzen bazare borondate on batez betea, entsaiatuko gare gauzen erremediatzerat, eta guk hizaren dugu zure alderako bihotz ezagutu daukuzuna. Ez dezazula, beraz, falta ethortzetik zure

$<39$. lv> anaiarekin. Bertze alde, salbamenduaz zin-zinez pentsatu behar da: ez dut uste hor hanbat ongi egin ahal deiteken. M. Iriberriri emaren diozkatzu ene errespetuak, eta hizatu nituela hirurogoi libera Marçans zenarenak, bainan aditu nuela oraino geiago ere bazela; othoizten dudala, deusik baldin badu, egortzeaz zerbait funts oneko gizonekin, lehenbailehen, erran den Marçans zenaren humeren altxatzeko. Egitzu gauza guziak funts onez. Horren desira eta esparantzarekin gelditzen naiz, konsiderazionerekin, ene hilloba maitea, zure zerbitzari humilla eta obedienta, Haraneder apeza.

A Urrugne, le 23 mars 1757. Zure amarotxi handizki hikustea desiratzen zaituenak eta gure Haurra Mariak egiten dauzkitzute $<39$. 2 r $>$ bere konplimenduak. 
Data: $1757 / 3 / 23$

Non idatzia: Ahetze

Igorlea: David Borrotra

Hartzailea: Martin Borrotra

Lotura: aita-semeak

Helmuga: Louisbourg

A bertsioa

$<40.1$ r $>17$

La presente soit Rendüe à / Monsieur De Lalongue / Bourgois, pour Remettre à / martin Borrotra son garson / sil Lui plait, de Louisbourt / a Louisbourct

$<40.2$ r $>$ ahetze le $24^{\text {me }}$ de mars 1757

/ Ene seme maitea Erreçevitu dut Çure / lettra joanden abendoaren $5^{\text {an }}$ eguina, / Çeinetan plaçer eta axeguin jçan $/ 5$ Baitut Çure berri onen aditçeas, eta / Estut berçe lettraric batere erreçevitu / Çu horras gerostic, Bainan hitçes Çure / Berriac aditçen nituen urtheguçian, / eta ossasuna dut jaincoari esquer, eta / ${ }^{10}$ desiratçen darotçut Çuri ere gauça / Bera, fortuna onbatequin neure bihots / guçias, baita Çure aitabitchic, eta Çure / amibitchic, Bere famillequin ossasuna / dute eta dugu, eta milla gorainçi dauçute $/{ }^{15}$ Eta bay ene espossac, eta Çure ahaide eta / adisquide guçiec, eta Çuri hemengo berri- / en adiarasteco, segurda aditu içan tucula / hemengo Berri tristiac, ehaile gaisçoa preso / harturic jondone laurendy egunian, 1755 . $^{\text {co }}$

$<40.2 \mathrm{v}>$ urthean, parisat eramadute, Sabat dorreco / Cena norbaitec hilçea delamedio, eta by / hilabete badu jendec daraçatela, bidean / heldu dela libro bere etcherat, Baignan $/ 5$ oraino esta agueri gaisçoa, eta ostaleriaco / premua urthe berian jondoni jauni ingu- / ruan presso harturic toulon nen da condena- / turic galleretarat seculacots, adisquideac / ongui mellaturic Es urcatçeco. eta diote $/ 10$ denbora bates harequin jbili Çen guiçon bat / orobat hura beçalla jujamendu beras / condenatua della, amicolla ohiaren colpatcea eta / seroraren leiho hausteco sujeta delamedio, / eta itxasoan beçala leihorrean ere fortunac
B bertsioa

$<40.1 r>17$

La presente soit rendüe à Monsieur de Lalongue, bourgois, pour remettre à Martin Borrotra, son garson, s'il lui plait, de Louisbourt. A Louisbourct.

$<40.2$ r $>$ Ahetze, le $24^{\text {me }}$ de mars 1757.

Ene seme maitea, errezebitu dut zure letra, joan den abendoaren 5an egina, zeinetan plazer eta atsegin izan baitut zure berri onen aditzeaz. Eta eztut bertze letrarik batere errezebitu zu horraz geroztik, bainan hitzez zure berriak aditzen nituen urthe guzian. Eta osasuna dut Jainkoari esker, eta desiratzen darotzut zuri ere gauza bera fortuna on batekin neure bihotz guziaz, baita zure aitabitxik eta zure amabitxik bere famillekin osasuna dute eta dugu, eta milla goraintzi dautzute. Eta bai ene esposak, eta zure ahaide eta adiskide guziek. Eta zuri hemengo berrien adiarazteko, segur da aditu izan tuzula hemengo berri tristiak. Ehaile gaixoa preso harturik Jondone Laurendi egunian, $1755 \mathrm{eko}$

$<40.2 v>$ urthean, Parisat erama dute, Sabat dorreko zena norbaitek hiltzea dela medio, eta bi hilabete badu jendek darazatela bidean heldu dela libro bere etxerat, baiñan oraino ezta ageri gaixoa. Eta Ostaleriako premua, urthe berian Jondoni Jauni inguruan preso harturik, Toulonen da kondenaturik galeretarat sekulakotz, adiskideak ong melaturik ez urkatzeko. Eta diote denbora batez harekin ibili zen gizon bat, orobat, hura bezala jujamendu beraz kondenatua dela, Amikola ohiaren kolpatzea eta Seroraren leiho hausteko sujeta dela medio. Eta, itsasoan bezala, leihorrean ere fortunak arribatzen dire: 
$/ 15$ arribatçen dire, Betrieneco jaungaisçoa / malobran hari dela lur peçabat gainera / Eroriric lehertu jçanda joanden udan, / Eta oren baten buruco hil Confesaturic, / Çure Çervitçari guelditçen nais ene seme ${ }^{20}$ maitea david Borrotra, Çure aita guçis / fidella eta obedienta,

2r:13 amibitchic : irakur bedi amabitchic.

\section{1}

Data: $1757 / 3 / 24$

Non idatzia: Donibane Lohizune

Igorlea: Machume Basterreche

Hartzailea: Esteben Lafontaine

Lotura: ama-semeak

Helmuga: Louisbourg
Betrieneko jaun gaixoa, malobran hari dela, lur peza bat gainera eroririk lehertu izan da joan den udan, eta oren baten buruko hil konfesaturik. Zure zerbitzari gelditzen naiz, ene seme maitea. David Borrotra, zure aita guziz fidela eta obedienta.

\section{B bertsioa}

$<41.1$ r $>74$

La presante soit rendue a Estében Lafontaine, fils de Saint Jean de Luz. A Loüisbourg.

<41.2r> A Saint Jean de Luz, le 24 mars 1757.

Neure seme maitia,

Satisfatuba izan ondoan zuk azken egin letraz, nolha zindoazen Louisbourqerat partitzerat, okasionia faborable atzemanik, eskribatzen darozkitzut bi lerro hauk zuri satisfatzerat emaiteko neure osasuna zure ahaide guziekin batian, zeinak desiratzen bainuke presenteko hunek hala aurkhi bazintza. Othoizten zaitut, hortik laster ilkhitzerat egizu, ezen badakit lekhu horrek zer ondorio duben, eta nik ez dut bertze errezurtzarik baizik zure esparantza. Jainkoa othoiztuko dut, arren eman diezazun hunat ethortzeko xedia eta, etsaietarik libraturik, didan zure ikusteko atsegina. Gelditzen naiz zure ama,

Machume Basterreche.

Zure ahaide, amatxik eta guziek milla goraintzi; halaber Dantxoxurik eta zure adiskide guziek. 


\section{2}

Data: $1757 / 3 / 26$

Non idatzia: Getaria

Igorlea: Sabadina de Clauset

Hartzailea: Martin de Darango, sieur de Piarrenea

Lotura: ama-semeak

Helmuga: Louisbourg

\section{A bertsioa}

$<42.1$ r $[160.10]$

Lapresente lettre soite / Reandeue aMartin de / Darango sieure de pirraenea / apresente Reste aLouisbour[g] / De Louisbourg

<42.2r> fait aguethary çé 26 Marz 1757

/ Enne seme maitea Estut faltatu / nahy jcatu presenteqo oqasione huntan / çury Enne Eta Enne familla gusiaren ossasu $/ 5$ na Beria gastiatu gabe ossasunadugu / jainqoary Esquer desiratxen guinduque Çurea / halla Balix, Çure conpaniarequin batean / sallutaxen caitugu familla gusiaq / generalean gaineraqo cure aide adisquide $/{ }^{10}$ gusieq Milla gorainxy Enne seme maitea / çure jqusteqo desirahandibat dut Eta / othoisten çaitut jçan sasu Cuq Ere gauça / Bera Estut presentean Cury Cer gastia / Baiçiq naicella cure cerbitxari cureama $/ 15$ fidella Eta Leialla Sabadinade / Clauset
B bertsioa

$<42.1$ r $[160.10]$

La presente lettre soite reandeue a Martin de Darango, sieure de Pirraenea, a presente reste a Louisbourg. De Louisbourg.

$<42.2$ r $>$ Fait a Guethary ce 26 marz 1757.

Ene seme maitea, eztut faltatu nahi izatu presenteko okasione huntan zuri ene eta ene familla guziaren osasuna berria gaztiatu gabe. Osasuna dugu Jainkoari esker; desiratzen ginduke zurea hala balitz zure konpaniarekin batean. Salutatzen zaitugu familla guziak jeneralean; gainerako zure aide-adiskide guziek milla goraintzi. Ene seme maitea, zure ikusteko desira handi bat dut, eta othoizten zaitut, izan zazu zuk ere gauza bera. Eztut presentean zuri zer gaztia, baizik naizela zure zerbitzari. Zure ama fidela eta leiala, Sabadina de Clauset. 


\section{3}

Data: $1757 / 3 / 26$

Non idatzia: Getaria

Igorlea: Joana Aprendisdeguy

Hartzailea: Martin de Darango, sieur de Piarrenea

Lotura: senar-emazteak

Helmuga: Louisbourg

\section{A bertsioa}

$<43.2 \mathrm{v}>33$

Lapresente Lettre soite / Reandeue aMartin de / darango sieure de pirraenea / apresente Reste a Louisbourq / De Louisbourq

<43.1r> fait aguethary çé 26 Marz 1757

/ Enne Espos Bihox Maitea

/ Estut faltatu nahy jçatu presenteqo oqasione / hau Çury Enne Eta famillaren ossassuna Beria / $/ 5$ çury aditçerat Eman gabe çeinetan Baita onna / jainqoary Esquer Desiratçen Baiquinduque Çurea / halla Balix cure conpaniarequin Batean Enne / Espos Bihox Maitea sallutaxen caitut Bihox / samur Batequin semeaq Eta aitaq Eta amaq/10 annaia arrebaq gauça Bera maulioneqo Eta / mutçhurdineneqo famillaq gauça Bera Enne / Espos Bihox Maitea segurqui Esnuben Vste / aurtengo huntan Esçintudalla jqusiqo Erran nahy / gure jainqoary Esçixaiolla comeny jqusiada / 15 gure gastetasuna hulla pasatu Behar dugulla / jainqoaq digulla grasia çaharxea harenglorian / Eremaiteq Enne Espos Bihox Maitea horay artean / Egotu nais segurquy hunguy hagoranduriq Eta / Bisquitartean satifatu nais Esçarella heldu ${ }^{20}$ Enne Espos Bihox maitea jainqoaq nahy badu / Es dieçaçudala guehiago hunelaqo Bihox miniq / Eman othoisten Çaitut Eguiada partitu Bacine / patraqanequin Eta horay angueletan daire

$<43.1 v>$ halleriqere jqusiada Esçarella Errisqu hartan / Enne Espos Maitea hanix changrinetan nais / presentean nahy nauxuque çerbeit Egorry Eta / Bisquitartean nihorq Estautaut Emaiten conselluriq / $/ 5$ Emaiten jrisqu handibat della Enne Espos Maitea / Esparanxadut gure jainqoaq Emaren

\section{B bertsioa}

$<43.2 \mathrm{v}>33$

La presente lettre soite reandeue a Martin de Darango, sieure de Pirraenea, a presente reste a Louisbourq. De Louisbourq.

<43.1r> Fait a Guethary ce 26 marz 1757.

Ene espos bihotz maitea,

Eztut faltatu nahi izatu presenteko okasione hau zuri ene eta famillaren osasuna berria zuri aditzerat eman gabe, zeinetan baita ona Jainkoari esker; desiratzen baikinduke zurea hala balitz zure konpaniarekin batean. Ene espos bihotz maitea, salutatzen zaitut bihotz samur batekin; semeak eta aitak eta amak, anaia-arrebak gauza bera; Maulioneko eta Mutxurdineneko famillak gauza bera. Ene espos bihotz maitea, segurki ez nuben uste aurtengo huntan ez zintudala ikusiko, erran nahi gure Jainkoari ez zitzaiola komeni. Ikusia da gure gaztetasuna hula pasatu behar dugula; Jainkoak digula grazia zahartzea haren glorian eremaiteko. Ene espos bihotz maitea, horai artean egotu naiz segurki hungi hagorandurik, eta bizkitartean satifatu naiz ez zarela heldu. Ene espos bihotz maitea, Jainkoak nahi badu ez diezazudala gehiago hunelako bihotz minik eman, othoizten zaitut. Egia da partitu bazine Patraqanekin eta horai Angeleterran dire.

$<43.1 v>$ Halerik ere, ikusia da ez zarela errisku hartan. Ene espos maitea, hanitz xangrinetan naiz. Presentean nahi nautzuke zerbeit egorri, eta bizkitartean nihork eztaut konsellurik emaiten, irrisku handi bat dela. Ene espos maitea, esparantza dut gure Jainkoak emaren darozkitzula zeinbeit ispirazione on hunat lehenbiziko 
darosquixula / çeinbeit jspirasione on hunat Lehenbiciqo qomodit ean $_{\text {/ Ethorxeqo }}$ segurquy ninere partetiq hunguy adresa / tuqo naxaio hothoy conply decalla çer Ere baixaio $/{ }^{10}$ comeny Eta hura.

/ Enne Espos Maitea / Estut presentean Çury / çergastia alefin Cure / jqusteqo çhangrines $/ 15$ Vrxen hary naicella / Çure Çerbixary çure / Espos fidela horay eta / Bethiere joannade / Aprendisdeguy komoditatean ethortzeko segurki. Ni, nire partetik, hungi adrezatuko natzaio, hothoi konpli dezala zer ere baitzaio komeni, eta hura.

Ene espos maitea, eztut presentean zuri zer gaztia, alefin zure ikusteko xangrinez urtzen hari naizela. Zure zerbitzari, zure espos fidela horai eta bethiere, Joanna de Aprendisdeguy.

1r:17 Eremaiteq : irakur bedi Eremaiteqo. 1r:23 angueletan : Angueleterran. 1v:4-5 Eztautaut : irakur eztaut. Aditz nagusia bi aldiz emana da; bigarrena ematea proposatzen dugu: estaut conselluriq emaiten. lv:7 qomodit ${ }_{\text {ean }}$ : irakur qomoditatean. 
Data: $1757 / 3 / 26$

Non idatzia: Bidart

Igorlea: ? (arreba)

Hartzailea: Gracian Goute

Lotura: anai-arrebak

Helmuga: Louisbourg

A bertsioa

$<44.1$ r $>48$

A Monsieur / Dominique goute / apresant a Lussiburc / a Lissiburc

<44.2r> Bidartten Egina martçoaren 261757

/ Ene anaia maitea hartçen dut libertad çuri bilerroren / Escribatcequo Eta famlilaquo berrien curi aditçerat / Ematequo ossasuna dugu jainquoari Esquer ceinetan $/^{5}$ Desiratcen baiquinduque curea halla ballis / hirur letra jçatu ditugu Eta nic Egorridut lehen / bat amac biia eta connatac bat Eta orai hirrur bat / banna bat marsanç handiarequin Eta bertçe bat / larrametequin Eta bertçebat tulliqunnequin $/^{10}$ asquenequo letran Escribaturic helduçarela Etcherat / Vda hastean possiblebada hargatic Cerbeit Egorriqoqo gindubenaç / Ecin irisquatugare Egortçerat chasquanarenequo jaunna / Eta hartubac dire garnesein Eta deussic ballin baduçu / Eseiia çaite letra chaniaç ahallic hobequiena Eguinniç $/ 15$ bei untcitan Egortcerat Eta niholere possiblebada Cato / Etcherat gure jcusterat anac Eta cunnatac milla / gorrantci Eta connatac othoi catoçela Etcherat

$<44.2$ v $>$ Etçhortçerat possiblebada niholere hemenere badela jnobres $f$. . go $(\dagger)$ / nahidubenac chortçurat Eta nahidubenac martchantean ...6 60 tt / jlabetean Eta chortçurat hilabetenentça ... 150 tt / nahidutena Eguiten dute cato ahal badguiçu Etcherat cureama $/ 5$ maitea lehennic Eta gerogu hurren çuc aditcerat Emandaroquigutçun / berriac aditu Eta ondoban cu horquo miserietaric Etoria jcusinahis / Etcherat cato Etcherat bi seme jcatutugu lehen biçquoa hil chen sortuta / cortçigarren Egunean Eta bertçea haur gallant bat dugu Elqaarri Eguinen / diogu beguitarte

\section{B bertsioa}

$<44.1$ r $>48$

A Monsieur Dominique Goute, a presant a Lussiburc. A Lissiburc.

<44.2r> Bidarten egina, martzoaren 26, 1757.

Ene anaia maitea, hartzen dut libertad zuri bi lerroren eskribatzeko eta famillako berrien zuri aditzerat emateko. Osasuna dugu Jainkoari esker, zeinetan desiratzen baikinduke zurea hala balitz. Hirur letra izatu ditugu, eta nik egorri dut lehen bat, amak bija eta koñatak bat, eta orai hirur, bana bat Marsanç handiarekin, eta bertze bat Larrametekin, eta bertze bat Tulliqunekin. Azkeneko letran eskribaturik heldu zarela etxerat, uda hastean posible bada, hargatik zerbeit egorriko gindubenaz ezin irriskatu gare egortzerat. Xaskanareneko jauna eta hartubak dire Garnesein. Eta deusik balin baduzu, eseija zaite letra xaniak ahalik hobekiena egiñik bi untzitan egortzerat, eta niholere posible bada zato etxerat gure ikusterat. Amak eta kuñatak milla gorantzi, eta koñatak othoi zatozela etxerat,

$<44.2 v>$ ethortzerat posible bada niholere, hemen ere badela inobres $f . . . g o(\dagger)$, nahi dubenak khortsurat eta nahi dubenak martxantean 60 libera ilabetean, eta khortsurat hilabetentzat 150 libera; nahi dutena egiten dute. Zato ahal badagizu etxerat. Zure ama maitea lehenik eta gero gu hurren, zuk aditzerat eman darokigutzun berriak aditu eta, ondoban zu horko miserietarik etorria ikusi nahiz etxerat; zato etxerat. Bi seme izatu tugu; lehenbizkoa hil tzen sortu ta zortzigarren egunean, eta bertzea haur galant bat dugu. Elkarri eginen diogu begitarte. Zato etxerat. Presentian ez dut 
cato Etcherat $/{ }^{10}$ presseintian Eçdut curi ceraditçera Eman guelditçeinais cure cerbitçari / fidel bihosones cure arebamaitea / Eta bertçe fammilla gucia orobat. / piarre hiribarren graçian goute maria bastres / othoi cato Etçherat

\section{5}

Data: $1757 / 3 / 26$

Non idatzia: Donibane Lohizune

Igorlea: Estonta Durquiet

Hartzailea: Martin Durquiet

Lotura: anai-arrebak

Helmuga: Louisbourg

\author{
A bertsioa \\ $<45.1$ r $>123$ \\ A Monsieur / Monsieur martin durquie / \\ Durquiet / A Louis burq \\ $<45.2$ r $>$ marchoaren 26an donibanen Eguina \\ 1757
}

\section{/ Ene anaja maitea}

/ iscribatcen dausquitçut bi Lerro hauc curi / gure osasunaren marcatceco ceinetan $/^{5}$ hanits on baita jaincoari esquerrac desiratcen / nuque çuria hala balits hanits pena sofritu / dut çuc amari Causatu dioçun changrinas / Çure eta ene ganic esdut mereci changrinic / icatea exenplu harçaçu eta icus açu nola $/{ }^{10}$ jaincoac Cuc haren aldera iduqui duçun / Conduita bera çure aldera iduqui duen / othoisten çaitut beras horiec guciac / ahanciric jaincoas orroitcea eta amari / eta guri çure icusteco atceguina laster $/ 15$ ematea ecen ama gaichoa çure icus mina / beldur nais mundutic eraman decan / esdu cutasco aiphamenic eta suspiraric / baicen eta othoy haren amudiori / ihardets diocaçu anaja ganistoc gorainci ${ }^{20}$ gure burasoa uste dut haren aldetic hanits / icanen den consolatua ecen halaco manerac / ditu guelditcen nais çure cerbitçari çure / arreba estonta durquiet zuri zer aditzera eman; gelditzen naiz zure zerbitzari fidel. Bihotz onez, zure arreba maitea, eta bertze familla guzia orobat: Piarre Hiribarren, Graçian Goute, Maria Bastres. Othoi zato etxerat.

\section{bertsioa}

$<45.1$ > $>123$

A Monsieur Monsieur Martin Durquiet. A Louisburq.

$<45.2$ r > Martxoaren 26an, Donibanen egina, 1757.

Ene anaia maitea,

Iskribatzen dauzkitzut bi lerro hauk zuri gure osasunaren markatzeko, zeinetan hanitz on baita Jainkoari eskerrak; desiratzen nuke zuria hala balitz. Hanitz pena sofritu dut zuk amari kausatu diozun xangrinaz. Zure eta eneganik ez du merezi xangrinik izatea. Etsenplu hartzazu, eta ikusazu nola Jainkoak zuk haren aldera iduki duzun konduita bera zure aldera iduki duen. Othoizten zaitut, beraz, horiek guziak ahantzirik, Jainkoaz oroitzea eta amari eta guri zure ikusteko atsegina laster ematea, ezen ama gaixoa zure ikusminak beldur naiz mundutik eraman dezan. Ez du zutazko aiphamenik eta suspirarik baizen, eta othoi haren amudiori ihardets diozazu. Anaia Ganistok goraintzi. Gure burasoa uste dut haren aldetik hanitz izanen den konsolatua, ezen halako manerak ditu. Gelditzen naiz zure zerbitzari. Zure arreba, Estonta Durquiet.

1r durquie Durquiet : duplografia. Bigarrena hautatu behar da. 
Data: $1757 / 3 / 28$

Non idatzia: Donibane Lohizune

Igorlea: Maria de Bordachipi

Hartzailea: Pierre Lahitun

Lotura: ama-semeak

Helmuga: Louisbourg

\begin{abstract}
A bertsioa
$<46.1 \mathrm{r}>90$

A Monsieur / Monsieur pier / Lahitun den la navire / leroia / A louisbourque

$<46.2$ r $>$ Donibanen Eguina marchoaren 28ean 1757 ean

/ Ene ceme maitea escrjbacen dausquiçut / bj lero curj marquaceco gure ossasunaren berjjac / ossasundugu jancoary esquer ceinetan deçiratcen I5 baiquinduque curja halabalix abustinnec çalu / tacen caitu bere bjjox gusijas eta enbarqadanda / [co]rxurat lixardj baitaco jaunarequin baiionaco / barandire denbora onarenbeiradaude ene haur / maitea harcasu quraiie egundaino baino boronda $/^{10}$ te onetan da cure ossaba cure alderat jancoac / eman dauqu gero obligacjjonen pagatcecoa / salutatcen çaitu gallantac ossasunadu bere / familla gusijarequin jdurjquicen nuben brestetic / cure partijadaco letra çeinetan axeguin hartuco $/ 15$ bainuben gasina chipjtonecoa enequindago / nescato lafontenj emanen diioxoxu ene eta chjpj / toren gorainxjjac estebenj adjjaracico diiosu / jthurbouruco nescachac gastiac haren diruben / beira daudecela esconçeco eguindecala fortu ${ }^{20}$ hainix emastequi alargun batec gastigacendu
\end{abstract}

$<46.2 \mathrm{v}>$ ceina baita marja hirj berj eta quraiie har / decala amac horj ethorj orduco emastegaiia / billatuco diioela ene ceme maite othoisten / çaitut hor abuçatugabe lehen bai lehen $/ 5$ etcherat ethocias cure eguin ahalac eguixu / jancoa çalborj ekarçen çaitubenian chanja / tubac gare moicorenrat estut berceric curj / marcaçeco decjracen dauçut ossasuna perfet / bat eta gueldjcen nais cure cerbjcarj çure $/{ }^{10}$ ama fidela / marja de bordachipj

\section{B bertsioa}

$<46.1$ r $>90$

A Monsieur Monsieur Pier Lahitun, de la navire Le Roia. A Louisbourque.

$<46.2$ r $>$ Donibanen egina, martxoaren 28ean, 1757ean.

Ene seme maitea, eskribatzen dauzkitzut bi lerro zuri markatzeko gure osasunaren berriak. Osasun dugu Jankoari esker, zeinetan deziratzen baikinduke zuria hala balitz. Abustinek salutatzen zaitu bere bihotz guzijaz, eta enbarkadan da kortsurat Lizardibaitako jaunarekin. Baijonako barran dire, denbora onaren beira daude. Ene haur maitea, hartzazu kuraije, egundaino baino borondate onetan da zure osaba zure alderat. Jankoak eman dauku gero obligazijonen pagatzekoa. Salutatzen zaitu Gallantak, osasuna du bere familla guzijarekin. Idurikitzen nuben Brestetik zure partijadako letra, zeinetan atsegin hartuko bainuben. Gasina Chipitonekoa enekin dago neskato. Lafonteni emanen dijotzotzu ene eta Chipitoren goraintzijak. Estebeni adijaraziko dijozu Ithurburuko neskatxak gaztiak haren diruben beira daudezela, ezkontzeko egin dezala fortuna hainitz. Emazteki alargun batek gaztigatzen du,

$<46.2$ v > zeina baita Maria Hiriberri, eta kuraije har dezala, amak hori ethorri orduko emaztegaija billatuko dijoela. Ene seme maite, othoizten zaitut hor abuzatu gabe lehenbailehen etxerat ethortziaz; zure eginahalak egitzu. Jankoa salbori ekhartzen zaitubenian xanjatubak gare Moikorenerat. Eztut bertzerik zuri markatzeko Deziratzen dautzut osasuna perfet bat, eta gelditzen naiz zure zerbitzari. Zure ama fidela, Maria de Bordachipi.

2r:19 fortu : irakur bedi fortuna. 2v:5 ethocias : horrela. 2v:7 moicorenrat : irakur Moicorenerat (etxe-izena da). 
Data: $1757 / 3 / 29$

Non idatzia: Donibane Lohizune

Igorlea: Marie Ditourriague

Hartzailea: Estebe de Echegaray

Lotura: ama-semeak

Helmuga: Louisbourg

A bertsioa

$<47.2 \mathrm{v}>96$

La presante ce sera / randue a estebe / de echegaray de sare / a presant aloisbourq / a Louis bourq

$<47.2$ r $>$ A sare ce 29 de mars 1757

/ ene seme maitia

/ escribacendarocout letra hau couri nere / osasounarern marqaceqo ceinetan ona / $/ 5$ baitout nere famila gouciareqin bati[an] / desiracennouque couria hala balix / aita maitiareqin batian erecibi[tou] / tout coubeq egori gouciaq couben erep [ousta] / batian oungi pena senticendout coubeq ene $/ 10$ letrariq es erecibiceas estaene falta / haur maitia esta ouciriq partitou non / estoudan escribatou ene familaren / beriaq damou dout ceren estoucoun / erecibitou coure letren erepoustaq $/ 15$ aditou dout ene seme maitia aitaq eman $<47$. 1r $>$ caitoubela toqi onbatian otoy obedicacou / coure aita marqatou darot asqo gauca / behar cindouqiela eta ecin fagoreriq / egin ene haur maitia penca cacoube ${ }^{5}$ couq eta aitaq cerpenetan ahal naitequen / nahi coubei palacer egin gauca goucies / eta ecin egin oray marqacen toudan nex / baiciq egorcen dar[ocou]t baril bat ceinetan / betri harispeqoareqin labordaregoleta / ${ }^{10}$ ceinetan baitire ourdaiaspibat louqainqa / pagabat gasnabat belhar goutibat marsans / handiareqin gorcen darosqicout aitarencant / eta courecat galcerdi parebana athorabat / courecat capata pare bana christoa hadiqo ${ }_{\text {sep }}$ $(\dagger) / 15$ chanichonenen coletan bayonatiq aitari erocou / nola marqa carotanegorceqo 12 libera / cholat ene oustes hiriarteqin egori ouste / nitouben bainan bordelen gelditou da
B bertsioa

$<47.2 \mathrm{v}>96$

La presante ce sera randue a Estebe de Echegaray de Sare, a presant a Loisbourq. A Louisbourq.

<47.2r> A Sare, ce 29 de mars 1757.

Ene seme maitia,

Eskribatzen darozut letra hau zuri nere osasunaren markatzeko, zeinetan ona baitut nere famila guziarekin batian; desiratzen nuke zuria hala balitz aita maitiarekin batian. Errezibitu tut zubek egorri guziak, zuben errepusta batian ungi pena sentitzen dut zubek ene letrarik ez errezibitzeaz. Ezta ene falta, haur maitia: ezta untzirik partitu, non ez tudan eskribatu ene familaren berriak. Damu dut, zeren eztuzun errezibitu zure letren errepustak. Aditu dut, ene seme maitia, aitak eman $<47$. lr $>$ zaitubela toki on batian. Otoi, obedizazu zure aita. Markatu darot asko gauza behar zindukiela, eta ezin fagorerik egin. Ene haur maitia, pentsa zazube zuk eta aitak zer penetan ahal naiteken, nahi zubei palazer egin gauza guziez, eta ezin egin orai markatzen tudanetz baizik. Egortzen darozut barril bat, zeinetan Betri Harispekoarekin Labordaren goleta, zeinetan baitire urdaiazpi bat, lukainka paga bat, gazna bat, belhar guti bat. Marsans handiarekin gortzen darozkitzut aitarentzat eta zuretzat galtzerdi pare bana, athorra bat zuretzat, zapata pare bana, Kristoa hadiko sep $_{\text {. }}$ $(\dagger)$ Chanichonenen koletan Baionatik. Aitari errozu nola marka zarotan egortzeko 12 libera xokolat; ene ustez Hiriartekin egorri uste nituben, bainan Bordelen gelditu da, 
$<47.1 v>$ hortaraqox egorcen diosqat ganisoneqin / bayonatiq oungi precotioniaq hartouriq / parti caistecte ene maitiaq gerla handi / baten aparanciaq dire hemen angelesq $/ 5$ hartou touste saratarceinbait oray ere / gouardia emocoube coben boroubei eichoqoq / aitarochiq mila goraici mondou huntouariq / goaten caigou coure aitarochiq elordiqoq / mila gorainci coure anaja mastaneq goraicic $/{ }^{10}$ bayonan da canonier bethi galdiareqin / coure anaya arebeq milagorainci geldicen / naic coure ama maitia / Marie ditouriage

/ besarqacacou coure aita ene /15 partes milia gorainci diodala
$<47.1 v>$ hortarakotz egortzen diozkat Ganisonekin Baionatik, ungi prekozioniak harturik. Parti zaiztezte, ene maitiak, gerla handi baten aparantziak dire hemen. Angelesek hartu tuzte saratar zeinbait; orai ere guardia emozube zuben burubei. Etxekok, aitarotxik mila goraintzi, mundu huntarik goaten zaigu. Zure aitarotxik Elordikok mila goraintzi. Zure anaia Mastanek goraintzik; Baionan da kanonier, bethi galdiarekin. Zure anaia-arrebek mila goraintzi. Gelditzen naiz zure ama maitia,

Marie Ditourriague.

Besarkazazu zure aita ene partez, milia goraintzi diodala.

2r:11 ouciriq : irakur bedi ounciriq. 1r:9 labordaregoleta : Labordaren goleta (untzi mota bat). lr:12 aitarencant : irakur bedi aitarentçat. lr:17 cholat : chocolat. lv:6 eichoqoq : eicheqoq 'etxeko(e)k' proposatzen dugu. 


\section{8}

Data: 1757/4/1

Non idatzia: Ahetze

Igorlea: Joannes Larralde

Hartzailea: Betry Larralde

Lotura: aita-semeak

Helmuga: Iganis (= Niganiche)

\section{A bertsioa}

$<48.1$ r $>87$

Lapresente Lettre / soit Rendue A / Monsieur Betry / Larralde qui lest / apresent Jganis a terneube / Á Jnanis

$<48.2$ r $>$ Fait ahetx le 1 avril 1757

/ Enez semaiz maitea harcendout livertatez / souri by Leroren Jscribatceco Eta denbora berean / henbego berrien gastiatcequo ossasounadougou $/ 5$ Jaincoary Esquer desiratcen guidouque sourez / hala balis goureaz besala / ounguida arebca domins senara corsoubandou / Eguintoutez hirour presa serbaiten Esparança / Doutez anaya biác Espaniandirez. / 10 ossasounarequin direz areba mariatoac / mila goraincy gousien partes ossasounadougou / amac milla goraincy sou Jqusy nahis / sangrignean dagoela / ahaidez Eta adisquidez gousiez goraincy $/{ }^{15}$ aguereco semeary mila goraincy berez familac / amac Eta ahaidez gousiec. / aguereco bianayac corsouban direz / Corsouçalec serbait Eguiten doutez / sourez servitçari guelditcen nais / ${ }^{20}$ Enez semay maitéa sou Jcusiateragnoco / chagrignian Joannez Larralde

\section{B bertsioa}

$<48.1$ r $>87$

La presente lettre soit rendue a Monsieur Betry Larralde, qui lest a present Iganis, a Terneube. Á Inanis.

$<48.2$ r $>$ Fait a Ahetz, le 1 avril 1757

Ene seme maitea, hartzen dut libertate zuri bi lerroren iskribatzeko, eta denbora berean hebengo berrien gaztiatzeko. Osasuna dugu Jainkoari esker; desiratzen ginduke zure hala balitz, gurea bezala. Ungi da, arrebak Domins senarra korsuban du. Egin tute hirur presa, zerbaiten esparantza dute. Anaia biak Espanian dire, osasunarekin dire. Arreba Mariatoak mila goraintzi, guzien partez osasuna dugu. Amak milla goraintzi, zu ikusi nahiz sangriñean dagoela. Ahaide eta adiskide guziek goraintzi. Agerreko semeari mila goraintzi bere familak, amak eta ahaide guziek. Agerreko bi anaiak korsuban dire; korsuzalek zerbait egiten dute.

Zure zerbitzari gelditzen naiz, ene seme maitea zu ikusi arterañoko xagriñian. Joannez Larralde.

2r:4 henbego : irakur bedi hebengo. 2r:7 arebca : irakur arrebac. 
Data: ?

Non idatzia: ?

Igorlea: Francha Barrere

Hartzailea: Pierre Hayete

Lotura: senar-emazteak

Helmuga: Louisbourg

\section{A bertsioa}

$<49.1$ r $>117$

Monsieur / Monsieur Pierre hayete / maitre cordonnié apresante / A Louisbourg

\section{$<49.2 \mathrm{r}>$ Ene Espoz maitia $=$}

/ Baliatçen nais Presenteco Comoitate hunaz Çuri / satifazione emateco Çenbat consolasione eta boscario / requin Causitcen naisen aditçias Çure ossasunaren $/ 5$ berriac seiña satifatu bainaute çure ganic ereçibitu / ditudan bortz Letretec, arosoiñeiquin diot haiñitz Conzo / laziones bethia Causitçen naizela Çure ossasuna onar / en berrien aditçia Çeren presentian ÇurePresençiaz / Landan ez bainuen desiratçen bertçe ontaçunic eta abe $/ 10$ aberastasunic baizen çure ossasunaren satifazionias / bada nic ere satifatçen Çaitut gurias = seña baitugu / haiñitz perfecta Jaincoary esquer eta hala desira / tçen nuque ene bihotz guçias çuria hala balix eta / horen conserbasioniaren intençionetara Jaincoa $/{ }^{15}$ Erequedituco dut eguin ahaldeçaquedan molde diferent / Guçies diçula Lehenic ossasuna izpirituala eta gue / ro ) temporala bay diot. / Lehenic izpirituala eta Guero temporala Çergatic / hura gabe ez baicare arbola idor fruituric ecars ${ }^{20}$ en ) ezduen bat baizen seiña arbola fruituric ecars- / en ) ezduena Condenatua baita picatçerat eta Çurat / hartiquitçerat eta idia Justu huntas seguratçen Gaitu

$<49.2$ v > Jesus Christoc bere Evangeliguan; Comprendiarasten / dauqularic hitz Labur hautas gugarela arbola hura / eta esbaitugu Fruitu onac ecartçen Condenatuac izaren / izaren garela; eta nola Fruitu on-hequin ecarseco $/ 5$ ez-baitugu deuseure inportantago; ossasuna izpiritu / ala baiño hargatic desiratçen dautçut Lehenic eta / Guçien gaiñetic;

\section{B bertsioa}

$<49.1$ r 117

Monsieur Monsieur Pierre Hayete, maitre cordonnié, a presante a Louisbourg.

$<49.2$ r $>$ Ene espos maitia,

Baliatzen naiz presenteko komoitate hunaz zuri satifazione emateko, zenbat konsolazione eta bozkariorekin kausitzen naizen aditziaz zure osasunaren berriak, zeiña satifatu bainaute zureganik errezibitu ditudan bortz letrek. Arrozoiñeikin diot haiñitz konsolazionez bethia kausitzen naizela zure osasuna onaren berrien aditzia, zeren presentian zure presentziaz landan ez bainuen desiratzen bertze ontasunik eta aberastasunik baizen zure osasunaren satifazioniaz. Bada, nik ere satifatzen zaitut guriaz, zeña baitugu haiñitz perfekta Jainkoari esker, eta hala desiratzen nuke ene bihotz guziaz zuria hala balitz. Eta horren konserbazioniaren intentzionetara Jainkoa errekedituko dut, egin ahal dezakedan molde diferent guziez, dizula lehenik osasuna izpirituala, eta gero tenporala.

Bai, diot lehenik izpirituala eta gero tenporala, zergatik hura gabe ez baikare arbola idor fruiturik ekartzen ez duen bat baizen, zeiña arbola fruiturik ekartzen ez duena kondenatua baita pikatzerat eta zurat hartikitzerat. Eta idia justu huntaz seguratzen gaitu

$<49.2 v>$ Jesus Kristok bere Ebanjeliguan, konprendiarazten daukularik hitz labur hautaz gu garela arbola hura, eta ez baitugu fruitu onak ekartzen kondenatuak izaren garela; eta nola fruitu on hekin ekartzeko ez baitugu deusere inportantago, osasuna izpirituala baiño hargatik desiratzen dautzut lehenik eta guzien gaiñetik, osasuna ezin aski 
ossasuna ezin asqui presadaitequen / hura; seiña gabe ez baicare deusic nic baiño / hobequidaquiçun beçala gauça guçiac harequin badi / ${ }^{10}$ tugula ez bedi beras seculan aparta gure ganic gure / tçat haiñ inportant de perla presiatu hura biçia / galduco badugu ere haren sustengutan eta çhedehori / ec ) gure bihotzetan Vngui fincatuac baitugu, seguratuac / izan bihardugu temporalian ere nola ezdaquigula / ${ }^{15}$ abantçatuaz garen garela eta ezparantça dut eguia / inportant horiec Çure bihotzian hobequi imprimatuac / eta seguituac direla enian nic baiño =

/ Guçia suprenitua nais çuc ez markhatçia deuz / Etcherat etorseco Conturic non haiñitz afligitçen ${ }^{20}$ bainau gauça horec; eta othoisten çaitut eguidaçun / haren bertçe Atçeguin haurten etcherat etorsia / Erregueren Vntcy batian munduan Posible bada $=$ Çure / Letretan markhatçen dausquidatçun Letrade çhange / eta bacaillau guçiac ereçibitutut eta othoisten çaitut $/ 25$ comoitate guçietan egorsias posible bada qintal bana / ezen hemen ere gauça guçiac Garastia dire

$<49.3 r>$ Ezdut bada ene Vstes çu hemen çiñeinian baiño Prodigali / tate gihiago eguiten baiñan den gutienetic ere famillac / asco bihardu çuc Vngui daquiçun beçala baiñan harçaçu / Quraie haurre galant batçuen hasten hari çare eta $/ 5$ iqusten baçintu segurnais Content çintesquela Joanis / Galant Vngui eraqursen eta mesa Laguntçen ikasiric / Escribatçen harida seiña Letra hau hari sinarasten / diot eta nauçia haiñitz Content du; oyer guçia çure / Patroiña hemenda orobat alaba Çumia =

$/{ }^{10}$ piarres millafrancarra ganic ereçibitutut $80^{\text {tt }}$ / Çuc martinican çalzeco emançiñoiscan 15 sapata / pareren Alderat berogoy eta bortz nasos çaldu / omentu, eta haren ganic ereçibitu beçain Laster / Lapeirery emanioscan = harismendy ganic ereçi $1{ }^{15}$ bitututçun Çolac Gana Dargainganic Çiren seiña / Eman baitioscat 140tt Çhabat erotaçharecoary / Bertçe 140tt gaiñeiraco hehun eta / hogoi Liberequin guelditçen nais ene famillaireq / uin ) etorquiçuneco Çure zocorriaren esparançan $/ 20$ desiratçen preza daiteken hura, zeiña gabe ez baikare deusik, nik baiño hobeki dakizun bezala, gauza guziak harekin baditugula. Ez bedi, beraz, sekulan aparta gureganik guretzat haiñ inportant den perla preziatu hura, bizia galduko badugu ere haren sustengutan. Eta xede horiek gure bihotzetan ungi finkatuak baitugu, seguratuak izan bihar dugu tenporalian ere, nola ez dakigula abantzatuaz garen garela, eta ezparantza dut egia inportant horiek zure bihotzian hobeki inprimatuak eta segituak direla enian nik baiño.

Guzia suprenitua naiz zuk ez markhatzia deus etxerat etortzeko konturik, non haiñitz aflijitzen bainau gauza horrek; eta othoizten zaitut egidazun harenbertze atsegin haurten etxerat etortzia Erregeren untzi batian, munduan posible bada. Zure letretan markhatzen dauzkidatzun letra de change eta bakaillau guziak errezibitu tut, eta othoizten zaitut komoitate guzietan egortziaz, posible bada, kintal bana, ezen hemen ere gauza guziak garastia dire.

$<49.3 r>$ Ez dut, bada, ene ustez zu hemen ziñenian baiño prodigalitate gihiago egiten, baiñan den gutienetik ere famillak asko bihar du, zuk ungi dakizun bezala. Baiñan hartzazu kuraie: haurre galant batzuen hazten hari zare, eta ikusten bazintu segur naiz kontent zintezkela. Joanis galant ungi erakurtzen eta meza laguntzen ikasirik, eskribatzen hari da, zeiña letra hau hari sinarazten diot, eta nausia haiñitz kontent du. Oier guzia zure patroiña hemen da, orobat alaba xumia.

Piarres milafrankarraganik errezibitu tut 80 libera, zuk Martinikan saltzeko eman ziñoizkan 15 zapata pareren alderat. Berrogoi eta bortzna sos saldu omen tu, eta harenganik errezibitu bezain laster Lapeireri eman niozkan. Harismendyganik errezibitu tutzun zolak Gana Dargainganik ziren, zeiña eman baitiozkat 140 libera. Xabat Errotaxarrekoari bertze 140 libera. Gaiñeirako ehun eta hogoi liberekin gelditzen naiz, ene famillarekin etorkizuneko zure sokorriaren esparantzan. Desiratzen 
nuquen haren Çuri Çerbeit Laguntçen / Eguitia famillairen hasteco deus ezqutan izan / gabe ezda deuzere irabasteco molderic eta othoisten / Çaitut egorçias Lehenbicico Comoitian 100 esqutuco / Letrade çhange bat irabas deçadan nic ere bi illaibeteta ${ }^{\text {co }}{ }^{25}$ oguia ezparança dut orai artian beçala hemendic $/$ harat ere fagoratuco nauçula $=$

$<49.3 v>$ Egortçen dausquitçut masans handiarequin barille / bat nafar Vrday aspi 2 galtçardy pare belar / piscabat eta biper pisca bat $=$ Toliqunequin $/$ Vrday aspi bat eltçe handy bat zahesqui horen ${ }^{5}$ contra maistruarequin 30 Laurdeneco baril bat / agorient eta galtçardy pare bat = martin Larumen / tequin urday aspi bat eta 30 laurdeneco barill / bat agorient = Mr Daguerreri escribatçerat nua / hia plaser dautçun eguin atçeguin ekarçia 40 $/{ }^{10}$ Laurdeneco barill bat Arno çuc hor pagatçeco / edo nic hemen ezdaquit azetatuco duen azetatçen / badarot emaren dautçu salbamendua duelaric $=/$ ene Letra batequin $=$

/ horiec dire nic Egor ahal dietçaquedatçun guçiac $/ 15$ presentian desiratçen nuquen harren haiñitz / gihiagoren egortçia ezin gihiago egor dieçaçuquet / eta Vste dut Çeronec ere comprenitçenduçula / ene ahala Çenbatetaraiñocoaden Atorrac / hemen dauscat ezin hiriscatus baiñan halere ${ }^{20}$ banaqui etçintesquela haurten etcherat etorr / egor çinçasquet baiñan esparança horec gibelaxen / nau = hemen Guelditçen nais Çu helduden Vrtian / iqusteco ezparançan, Çure servitçary humilla ene / bihotz guciaz Çure ezpos fidela $={ }^{25}$ Francha $/$ Barere

/ milla goraintcy harismendic / eta Gure Familla Guçiac Amen

<49.4r> Memorio hau Egortçen dautçut çuri satifaçione / Emateco oray arteraiñoco gure eguitecoac nola duazen / edo nola guelditçendiren gana dargain Çor guelditçenda / Gatian eman Çausquitçun eta Guerostic egorri Çausquitçun $/^{5}$ en ) Alderat Çure ordenas $600^{\text {th }}$ emanic arastatçen da / hartçeco ... 113"t / harismendic Ecari Çausquitçun zoletaric ... 031 / saraco nuken harren zuri zerbeit laguntzen egitia, famillaren hazteko deus eskutan izan gabe ez da deusere irabazteko molderik. Eta othoizten zaitut egortziaz lehenbiziko komoitatian 100 ezkutuko letra de change bat, irabaz dezadan nik ere bi illabetetako ogia. Ezparantza dut, orai artian bezala, hemendik harat ere fagoratuko nauzula.

$<49.3 v>$ Egortzen dauzkitzut Masans handiarekin barril bat nafar, urdaiazpi, 2 galtzardi pare, belar piska bat eta biper piska bat. Toliqunekin urdaiazpi bat, eltze handi bat saheski horren kontra. Maistruarekin 30 laurdeneko barril bat agorient eta galtzardi pare bat. Martin Larumentekin urdaiazpi bat eta 30 laurdeneko barril bat agorient. $\mathrm{M}^{\mathrm{r}}$ Daguerreri eskribatzerat nua, ia plazer dautzun egin atsegin ekhartzia 40 laurdeneko barril bat arno, zuk hor pagatzeko edo nik hemen. Ez dakit azetatuko duen; azetatzen badarot emaren dautzu salbamendua duelarik ene letra batekin.

Horiek dire nik egor ahal dietzakedatzun guziak presentian. Desiratzen nuken harren haiñitz gihiagoren egortzia, ezin gihiago egor diezazuket, eta uste dut zeronek ere konprenitzen duzula ene ahala zenbatetaraiñokoa den. Atorrak hemen dauzkat, ezin hirriskatuz. Baiñan halere, banaki etzintezkela haurten etxerat etor, egor zintzazket, baiñan esparantza horrek gibelatzen nau. Hemen gelditzen naiz, zu heldu den urtian ikusteko esparantzan, zure zerbitzari humilla. Ene bihotz guziaz, zure espos fidela. Francha Barrere.

Milla goraintzi Harismendik eta gure familla guziak. Amen.

$<49.4$ r $>$ Memorio hau egortzen dautzut zuri satifazione emateko, orai arteraiñoko gure egitekoak nola duazen edo nola gelditzen diren. Gana Dargain zor gelditzen da, gatian eman zauzkitzun eta geroztik egorri zauzkitzunen alderat. Zure ordenaz 600 libera emanik arrastatzen da. Hartzeko: 113 libera. Harismendik ekarri zauzkitzun zoletarik: 031. Sarako Cristuali eman diozkat, zuk ordenatu 
Cristuali emandioscat çuc ordenatu beçala ) / $300^{\text {"t }}$ eta haren marçhandizec balio 334 "t arasta zor ... $34 /{ }^{10}$ ezdu onic eguin nahi batere haren añaiary eman / Çinioscan hemesorçy Liberaric $=$ Plaçhançhary eman / nioscan çuc haren semiari Fornitu çiñoiscanen / Gaiñeira 555 Liberaco letradeçhange hura / Contu harturic Çorda ... $100 / 15$ eta bertçe Alde Ganden Vrtian biçitçeco ) idequiac ) 200 / Presenteco hauc dire Çure eta ene obligaçioniac ... 478

Casanab Chumiary. / Emaniguen 1500 Liberaco Letrade çhange hura eguia / da çure ganic ordena nuen emateco $1400^{\text {tt }}$ baiñan $/{ }^{20}$ nola nerorec Eguin bainuen 100 Liberaren obligaçionia / Garniçione bat harturic eta dirubatçuec idequiric semper / tarraren hauçiaren seguitçeco hargatic emanioscan $1500^{\text {tt }}$

/ Digo Leheneco haren marçhandisetaric oraiño baduela / hor Çenbeit zaltçeco = haurten Egortçen dautçu toliquneq $/ 25$ uin ) barica bat Çare çenbeit tresnequin eta bertçe bat / Larumentequin. $<49.4 v>$ Marçhandiçac Çuri ene Gaiñian seguraturic egorçeco / Eguindut eguin ahala baiñan ezin progoitçhatu naiz / çergatic mr. Laraldec ez baitarot permetitu nahiçatu / digoelaric bere gaiñian nahituela hiriscatu seguratugabe I5 Cure Ezquetara, haguien Jaincoac permetitçendu gu / malur handiago batetaric beiraitceco Jaincoac hala / permeti ditçala $=$ bezala, 300 libera, eta haren marxandizek balio 334 libera. Arrasta zor: 34. Ez du onik egin nahi batere. Haren añaiari eman ziniozkan hemezortzi liberarik Plachanchari eman niozkan, zuk haren semiari fornitu ziñoizkanen gaiñeira. 555 liberako letra de change hura kontu harturik, zor da: 100. Eta bertze alde, gan den urtian bizitzeko idekiak: 200. Presenteko hauk dire zure eta ene obligazioniak: 478 libera.

Casanab Xumiari eman niguen 1.500 liberako letra de change hura. Egia da zureganik ordena nuen emateko 1.400 libera, baiñan nola nerorrek egin bainuen 100 liberaren obligazionia, garnizione bat harturik eta diru batzuek idekirik senpertarraren hauziaren segitzeko, hargatik eman niozkan 1.500 libera.

Digo leheneko haren marxandizetarik oraiño baduela hor zenbeit saltzeko. Haurten egortzen dautzu Toliqunekin barrika bat zare zenbeit tresnekin, eta bertze bat Larumentekin. <49.4v> Marxandizak zuri ene gaiñian seguraturik egortzeko egin dut eginahala, baiñan ezin progoitxatu naiz, zergatik $\mathrm{M}^{\mathrm{r}}$ Larraldek ez baitarot permetitu nahi izatu, digoelarik bere gaiñian nahi tuela hirriskatu, seguratu gabe, zure eskuetara. Hagien Jainkoak permetitzen du, gu malur handiago batetarik beiratzeko; Jainkoak hala permeti ditzala.

2r:6 Letretec : irakur bedi letrec. 2v:11 de : den behar luke. 3r:23 Comoitian : irakur comoditatian. 
